\title{
The use of assessment for institutional sensemaking by top administrative officials
}

Johnston Niven Hegeman

West Virginia University

Follow this and additional works at: https://researchrepository.wvu.edu/etd

\section{Recommended Citation}

Hegeman, Johnston Niven, "The use of assessment for institutional sensemaking by top administrative officials" (2010). Graduate Theses, Dissertations, and Problem Reports. 2970.

https://researchrepository.wvu.edu/etd/2970

This Dissertation is protected by copyright and/or related rights. It has been brought to you by the The Research Repository @ WVU with permission from the rights-holder(s). You are free to use this Dissertation in any way that is permitted by the copyright and related rights legislation that applies to your use. For other uses you must obtain permission from the rights-holder(s) directly, unless additional rights are indicated by a Creative Commons license in the record and/ or on the work itself. This Dissertation has been accepted for inclusion in WVU Graduate Theses, Dissertations, and Problem Reports collection by an authorized administrator of The Research Repository @ WVU.

For more information, please contact researchrepository@mail.wvu.edu. 
The Use of Assessment for Institutional Sensemaking by Top Administrative Officials

\author{
Johnston Niven Hegeman
}

Dissertation submitted to the College of Human Resources and Education at West Virginia University in partial fulfillment of the requirements for the degree of

\author{
Doctor of Education \\ In \\ Educational Leadership \\ Elizabeth Jones, Ph.D., Chair \\ Ernest Goeres, Ph.D. \\ Cindy Herzog, Psy.D. \\ Ann Richards, Ph.D. \\ Richard T. Walls, Ph.D. \\ Department of Educational Leadership Studies
}
Morgantown, West Virginia 2010

Keywords: Institutional assessment, Sensemaking, Organizational Change

Copyright 2010 Johnston Hegeman 


\begin{abstract}
The Use of Assessment for Institutional Sensemaking by Top Administrative Officials

Johnston Niven Hegeman

This study explored the relationship between the degree to which top administrators of four-year colleges and universities that have been effective in implementing and sustaining assessment view the use of assessment and seven components of institutional sensemaking at their institutions. The underlying premise is that outcomes assessment practices represent a transformational change in higher education, and institutional sensemaking has been identified as a central feature of institutional transformation efforts. Understanding how assessment results and institutional sensemaking are intertwined should be useful for professionals charged with designing or implementing assessment plans, because it may lead to new ways to connect assessment with institutional decision-making and planning.

Surveys were completed by 311 top academic and student affairs administrators at 66 four-year institutions of higher education in the United States that were identified as having mature cultures of institutional assessment. Strong relationships were found between perceived use of assessment at those institutions and six aspects of sensemaking: Identity type, identity commitment, strategic orientation, present image, information processing structure, and issue interpretation. These findings suggest the importance of intentionally linking assessment planning with sensemaking activities.
\end{abstract}




\section{Acknowledgments}

I would like to thank the following for their unwavering support. First and foremost, my wife and companion Rita Hegeman. The completion of this project would not have been possible without her proofing and questioning countless revisions, compiling mailing addresses for 1077 potential participants, helping prepare the three mailings, and keeping the kids at bay, mostly. She also supplied the moral support and encouragement all these years while I worked on this project. I am particularly thankful for the hot tea she supplied on those wintery nights spent working in front of our woodstove while the snow fell and the wind howled.

Next on the "thank you list" is Morris Willey for his spiritual inspiration and deep interest in the subject of this dissertation. We began discussing many of the underlying ideas of this paper in the early 1980's when we mutually discovered the works of Chris Argyris. I am grateful that I was able to close a chapter of our intellectual pursuit, though with much sadness, since he departed these shores several years ago.

I am grateful for all the contributions of my committee members. I cannot thank enough: Dr. Jones for her perseverance and ability to help me focus and think clearly; Dr. Herzog for always being in my corner; Dr. Goeres for introducing me to "Management Fads in Higher Education," now one of my foundational books; Dr. Walls for the help and pointed questions about the statistics used in the study; and Dr. Richards for hopping on board at the last minute. I would be remiss not to mention former committee member, now retired, Dr. Harnett for inspiring me to think broadly and deeply about higher education.

Several others provided me with crucial assistance. Selina Smith transformed my questionnaire into a scannable form and processed the returned surveys that produced my data file; Lois Bennett and Carol Davis helped me systematically manage the returned surveys; 
Phoebe Wiley and Harriet Douglas patiently led me through some finer points of grammar and copy edited the proposal; and Larry Orndorff provided invaluable technical assistance in preparing and mailing the thousands of survey packets.

Of course, other family members contributed to the cause. Daughters Quincy, Lucas, and Niven were a great team while assisting in the preparation of the three mailings (a real assembly line) and helping me maintain the focus on the rewards of being finished, in their case, rides in Dad's sports car. Jon, my son, busy living his own hectic life, provided constant encouragement. And finally, "thank you" to my mother for celebrating all of my accomplishments throughout my life, no matter how large or small, and, I am sure, she still is. 
Table of Contents

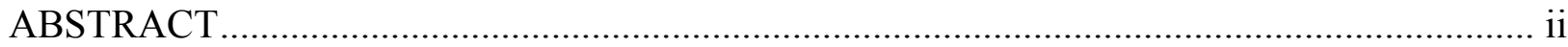

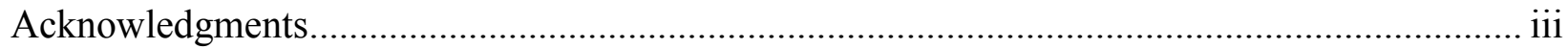

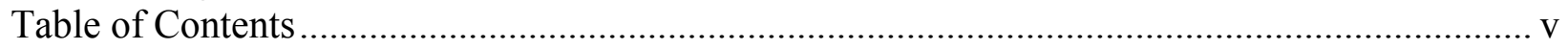

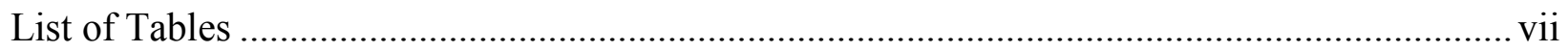

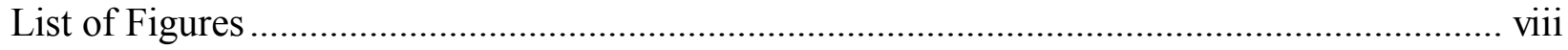

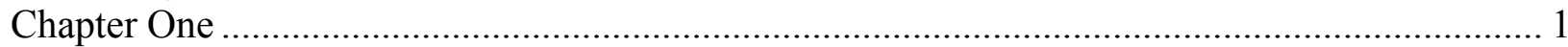

Introduction and Statement of the Problem ...................................................................... 1

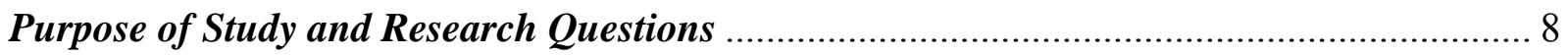

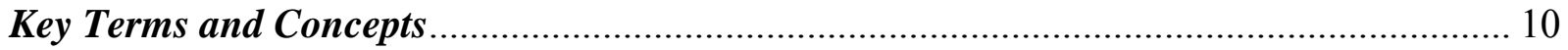

Chapter Two

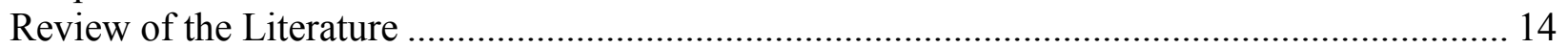

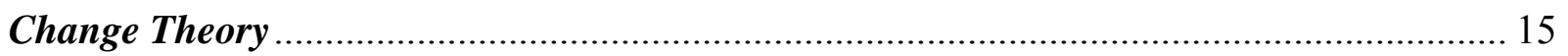

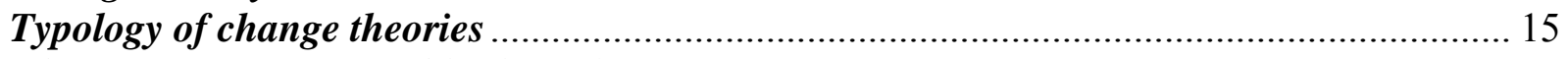

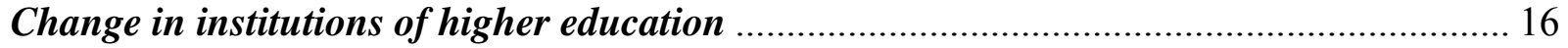

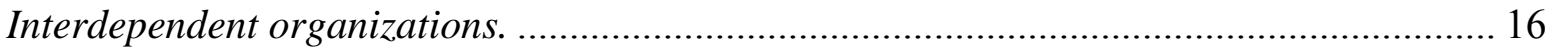

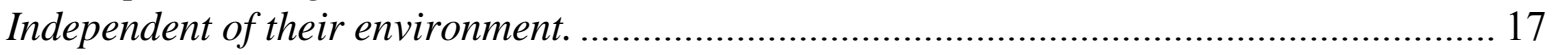

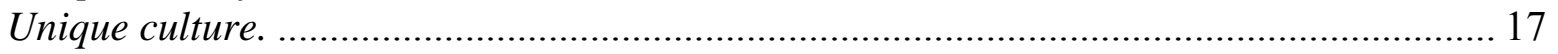

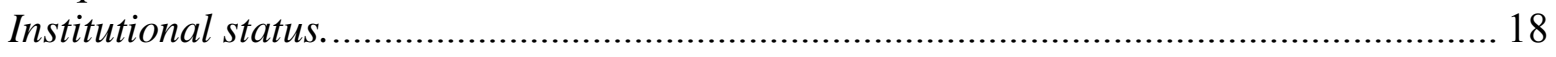

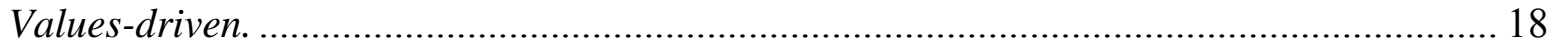

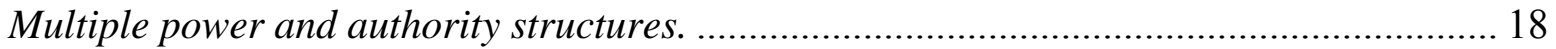

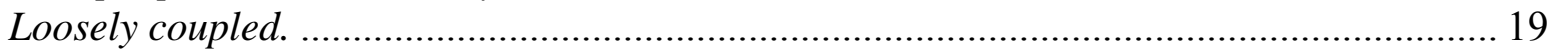

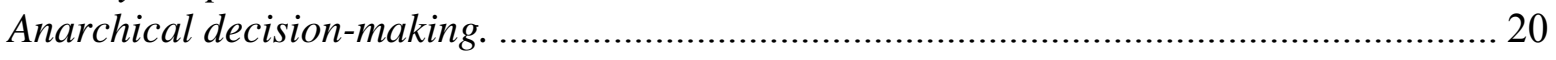

Professional and administrative values. .................................................................... 21

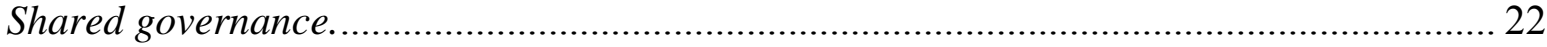

Employee commitment and tenure ............................................................................. 23

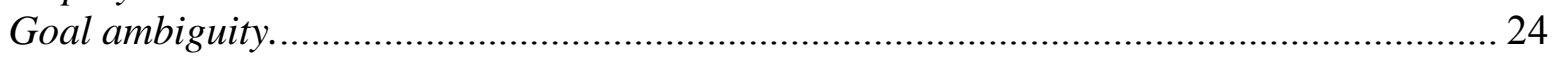

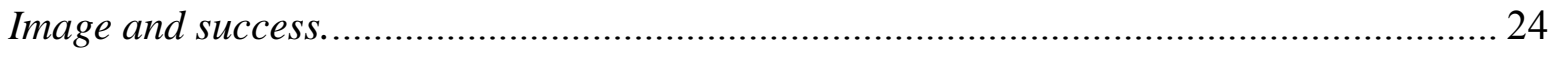

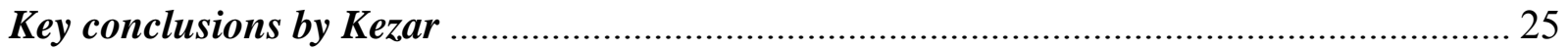

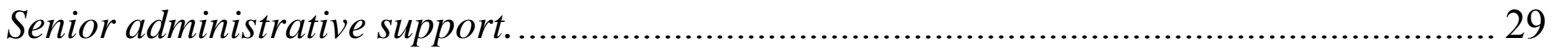

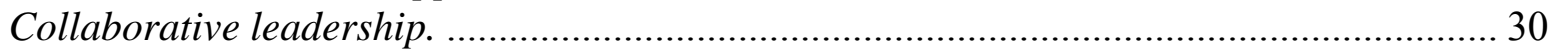

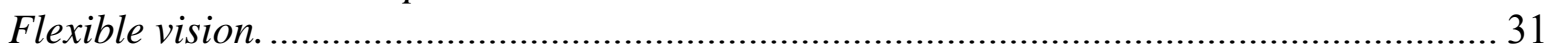

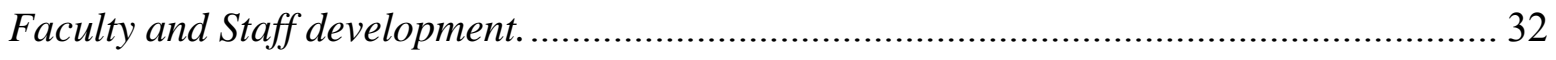

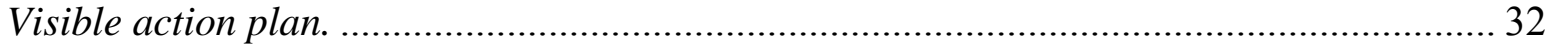

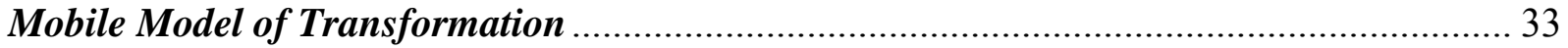

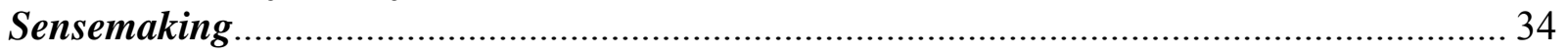

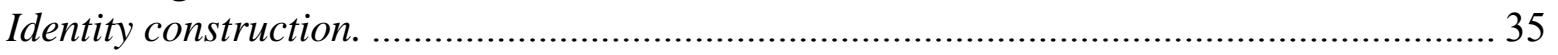

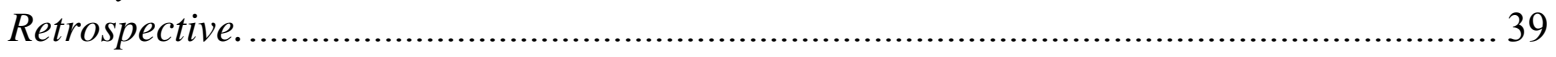

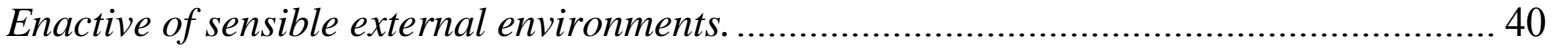

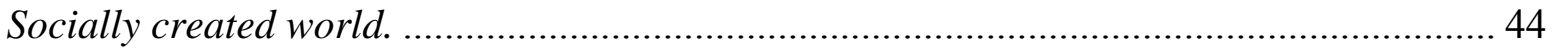

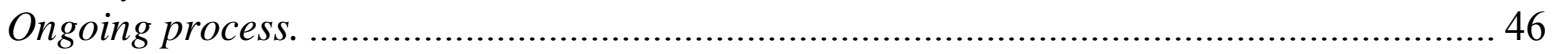

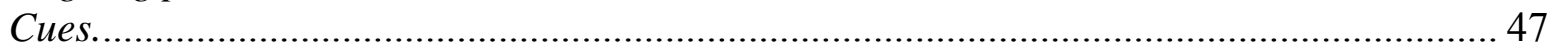

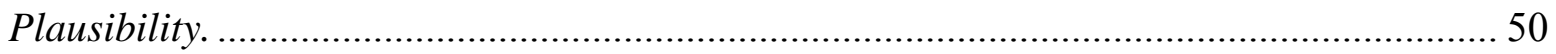

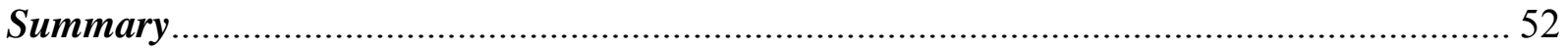

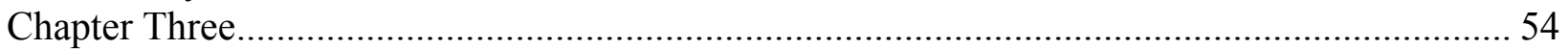




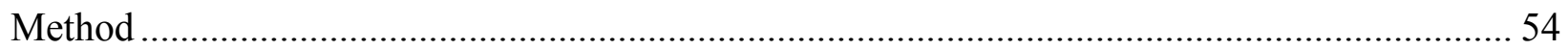

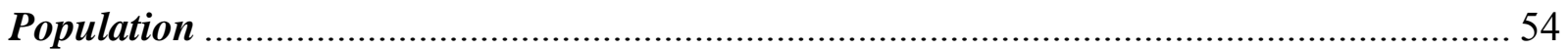

Survey

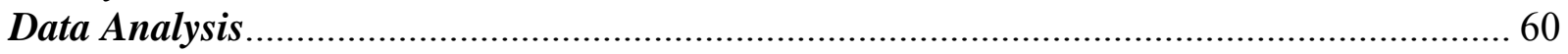

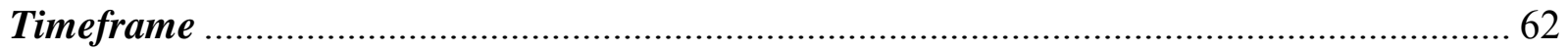

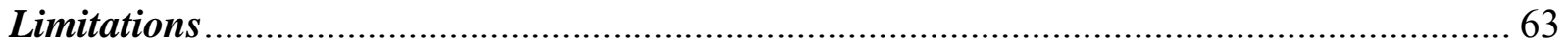

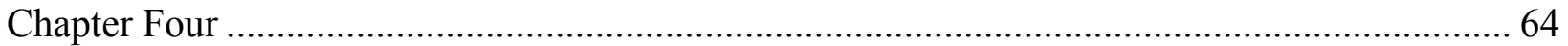

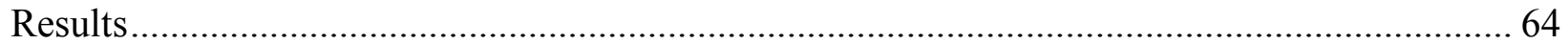

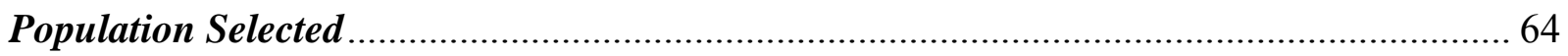

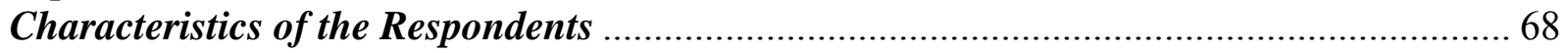

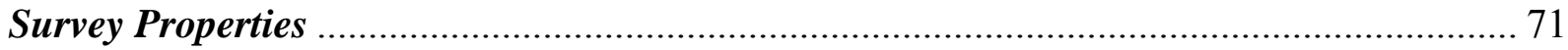

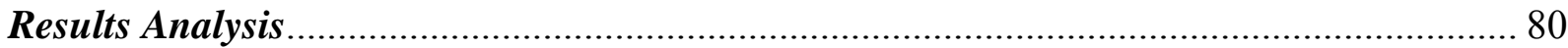

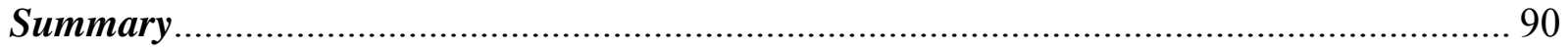

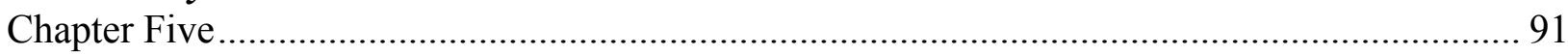

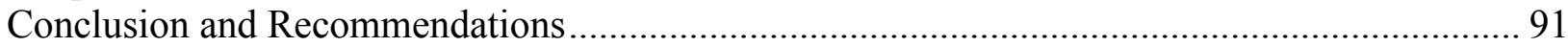

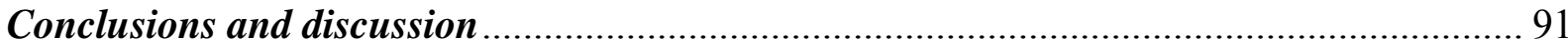

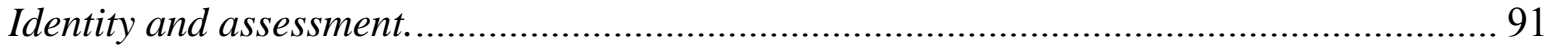

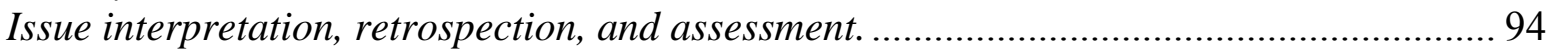

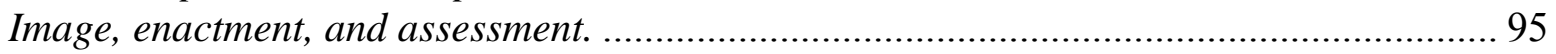

Information processing structure, socially created world, and assessment ........................ 96

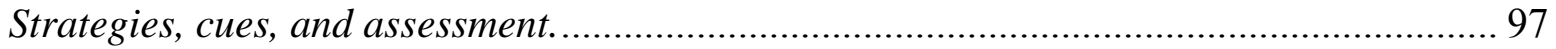

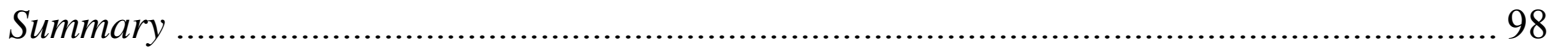

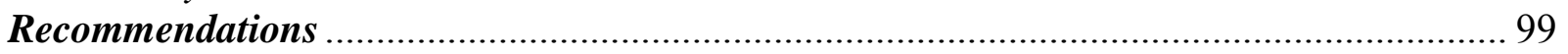

Recommendations for practice related to identity. .............................................................. 99

Recommendations for practice related to issue interpretation and retrospection. ............ 100

Recommendations for practice related to image and enactment........................................ 101

Recommendations for practice related to information processing structure and social

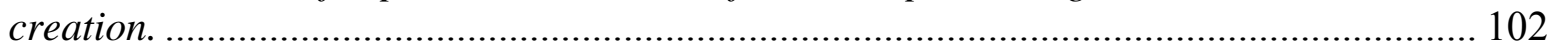

Recommendations for practice related to strategies and contextual cues.......................... 103

Recommendations for further research. ..................................................................... 103

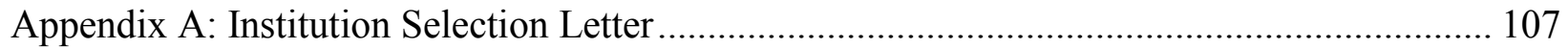

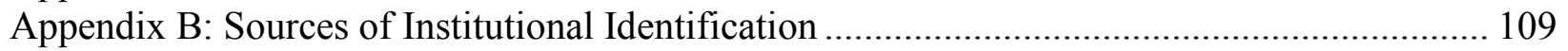

Appendix C: Cover Letter to Survey Participants ............................................................... 110

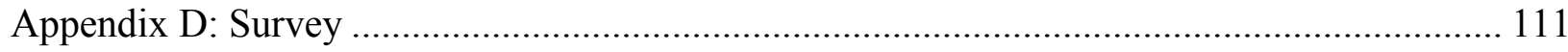

Appendix E: Strategic Orientation Interpretation Subscale Items .......................................... 116

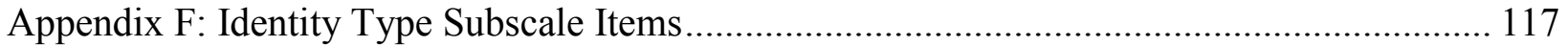

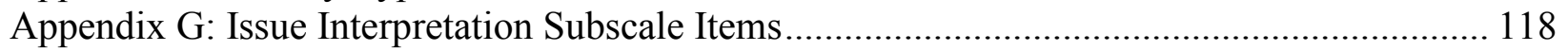

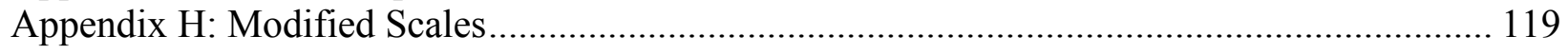

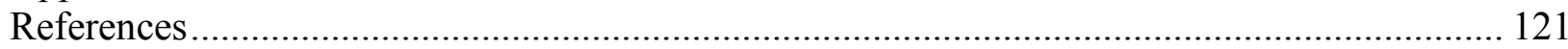




\section{List of Tables}

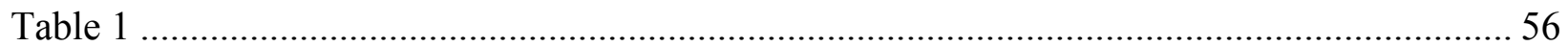

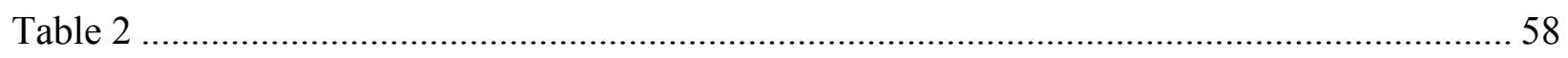

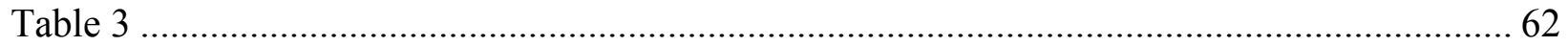

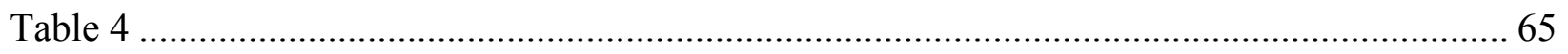

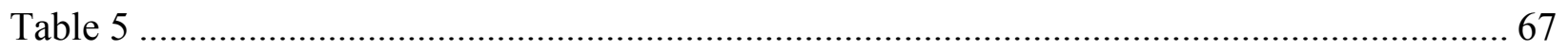

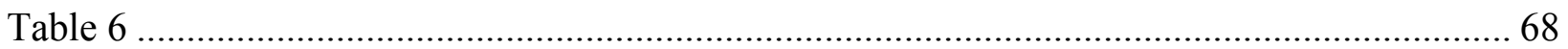

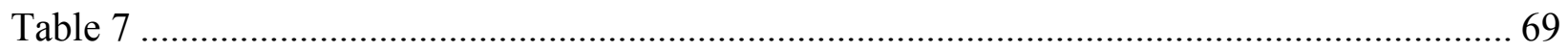

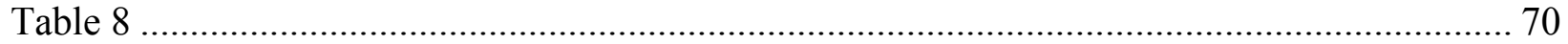

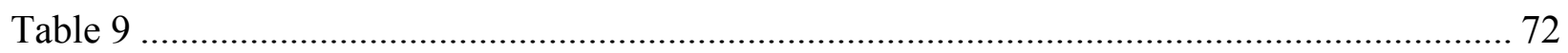

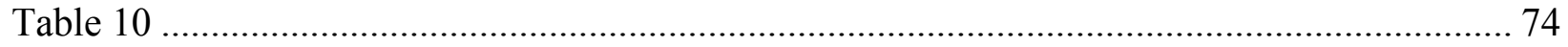

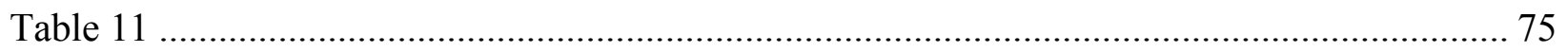

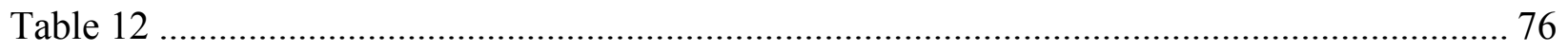

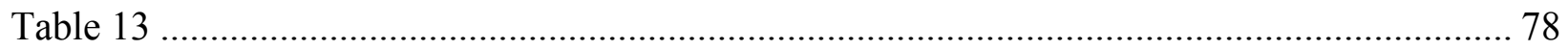

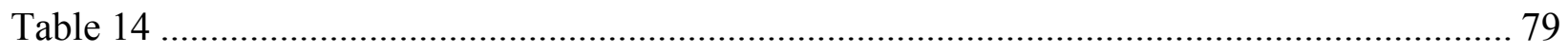

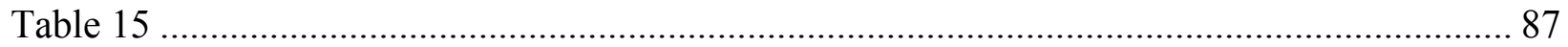

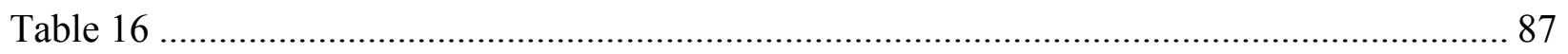

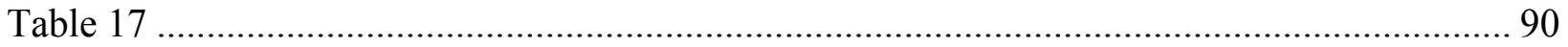


Institutional Sensemaking and Assessment viii

\section{List of Figures}

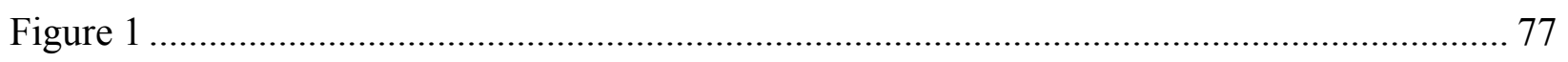

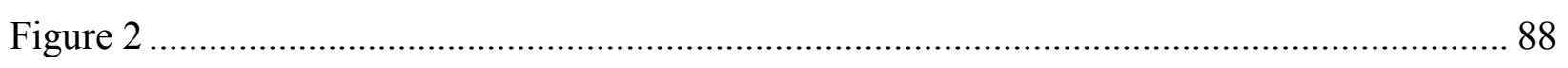

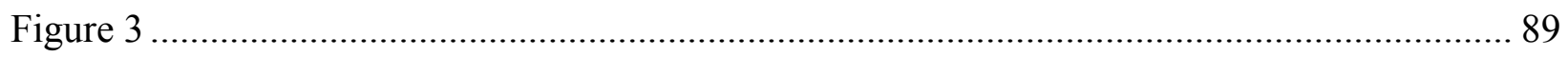




\section{Chapter One}

Introduction and Statement of the Problem

One of the perplexing problems facing faculty, staff, and accreditors who believe in the importance of assessment in higher education is that, though assessment processes have become widespread, assessment results are not used for decision-making, and the impact of assessment efforts on institutions is limited (Alstete, 2004; Cross, 1986; Ewell, 2002; López, 2004; Peterson \& Augustine, 2000; Peterson \& Einarson, 2001; , 2002; Soundarajan, 2004). This is not a new phenomenon; twenty years ago Cross reported that almost all (91\%) college and university administrators believed that assessment should be used to improve instruction, yet very little assessment was used in practice (Cross, 1986). More recently, Peterson and Vaughan (2002) found that almost all institutions collect some sort of student assessment data, most of which is relatively easily collected, such as student progress indicators. Most institutions (70\%) also have an institution-wide group to lead assessment efforts, indicating some degree of institutional support for assessment. However, Peterson and Vaughan also found that assessment data were not used or influential in making most educationally related decisions, and the impact of assessment data was extremely limited. As López (2004) concluded about the 989 institutions that comprise the North Central Association of Colleges and Schools (NCA), the number of institutions that are using assessment results to develop and test ways to improve student learning in each academic department is small, and the number of institutions yet to engage departments in assessment is “disappointingly large" (p. 31).

Given the pressure by regional accrediting agencies for institutions to show evidence of student learning and continual improvement, the implementation of assessment practices is not fading away (López, 2004; Middle States Commission on Higher Education, 2007; Schuh \& 
Upcraft, 2001), as some (Daniel, 2002) believe it will, like management fads in higher education including Zero-Based Budgeting, Management by Objectives and Business Process Reengineering (Birnbaum, 2000b). Calls for higher education to assess student outcomes have been made for at least a quarter of a century. In 1979, the Council of Postsecondary Accreditation (COPA), a national group preceding the Council for Higher Education Accreditation (CHEA), created in 1996, called for accreditation teams to make judgments about the quality of institutions based on the evidence of student achievement (Alstete, 2004). Ewell (2002) traces the formal assessment movement in higher education to the First National Conference on Assessment in Higher Education held in 1985, though the roots may reach further back (Edgerton, 1987). The conference was organized as a reaction to political pressures at the time and began the formation of a scholarship of assessment grounded in the research traditions found in the studies of student learning, retention, evaluation, and mastery learning. Two years later, in 1987, the president of the Educational Testing Service said, "With somewhat dramatic suddenness, the assessment of learning in college has emerged as an institutional, state, and national issue" (Anrig, 1987, p. v). Something similar could be said today as the ramifications of A Test of Leadership Charting the Future of U.S. Higher Education, (U.S. Department of Education, 2006) are considered. In that document, commonly referred to as the Spellings Report, "outcomes-focused" accountability is a prominent theme and suggests that measures of student learning be value-added, of high quality, evidence-based, and part of "a culture of continuous innovation and quality improvement" (p. 5), echoing similar appeals by assessment practitioners and others (Banta, 2002; Dugan \& Hernon, 2006; Hearn, 2006; Middle States Commission on Higher Education, 2005; Peterson \& Vaughan, 2002; Suskie, 2004). 


\section{Barriers to Assessment}

Numerous reasons are offered to explain why assessment results are not widely used to make decisions (Peterson \& Einarson, 2001; Peterson \& Vaughan, 2002). López (2004), for example, provides a straightforward framework to understand what challenges face those attempting to implement assessment. After examining the North Central Association evaluation team and self-study reports from 989 institutions, Lopez found a combination of three factors which inhibit institutions from having fully functional assessment plans: (1) basic misunderstandings about the purpose and nature of assessment, (2) emotionally-based resistance to assessment from those responsible for it, and (3) inadequate information and skills needed to conduct assessment. López found that faculty members misunderstand assessment because they believe that it is a fad or an outside imposition rather than a tool to improve the likelihood that intended student outcomes will be achieved. Faculty members also mistakenly view evaluations of instruction and faculty performance as measures of student learning. Teaching effectiveness is important but is not the same as student learning.

Emotionally-based resistance to assessment can come from a number of beliefs or concerns held by faculty and administrators including the following: assessment results may reveal that many students are not learning; assessment is an infringement on faculty academic

freedom; individuals cannot make any real difference in learning outcomes because of students' academic aptitude, motivation, and inadequate preparation for college-level work; assessing important aspects of what students are learning is too complex to yield meaningful results; and the magnitude of changing the culture of an entire department, college or institution is either impossible or undesirable. 
The final factor inhibiting implementation of assessment - lack of information or skills needed to conduct assessment - also has multiple dimensions, according to López (2004). Faculty members are unfamiliar with good practices that are necessary to develop and sustain assessment plans. As they try to create assessment plans, faculty members do not know how to address essentials such as providing adequate administrative leadership, developing clear lines of authority, generating faculty ownership and increasing student participation, implementing a structured process with realistic timetables, and providing adequate funding. Few faculty members have technical skills in test development, research design, and statistics, which are significant aspects of an assessment program. According to López, faculty have difficulty moving beyond the assessment of easily quantifiable skills, determining direct and indirect measures of student learning, creating tests or other measures aligned with the educational goals, and understanding the meaning or purpose of using multiple measures and valid and reliable instruments.

Suskie (2004) reinforced López's findings of the various reasons faculty may be slow to adopt outcomes assessment. In addition to understanding, emotional, and skill issues related to assessment, Suskie adds that many faculty members do not see outcomes assessment as relevant to their work. Some claim to be too busy to reflect upon their teaching while others believe their discipline-based research is more important. Even if the latter group of faculty members recognizes that the implementation of assessments or pedagogical research that follows good practices yields data or information that is equivalent to that collected by good applied or action research (Boyer, 1990; Pike, 2002; Weimer, 2006), this type of "research" is virtually absent from faculty evaluation and reward procedures (Braxton, Luckey, \& Helland, 2002; Peterson \& Vaughan, 2002; Weimer, 2006). 
Other researchers and theorists discuss the magnitude of change as the major impediment affecting the acceptance of assessment at institutions of higher education. If, as Banta (2002) says, the adoption of assessment practices is a transformational change for an organization, the task of making assessment a fundamental element of the organizational culture, which consists of the values and beliefs held by institutional members (Peterson \& Vaughan, 2002), is formidable. Transformational change implies intentionally going beyond the usual day-to-day decisionmaking machinery of organizations and reaching deeply into their values, missions, underlying assumptions, institutional behaviors, processes, and structures (Argyris \& Schön, 1996; Eckel, Hill, \& Green, 1998; Heifetz \& Linsky, 2002; Kuhn, 1970; Levy \& Merry, 1986). Transformational change is rare and complex (Duderstadt, 2000; Eckel \& Kezar, 2003b; Kezar \& Eckel, 2002b). As Kezar (2001) notes, "Because higher education institutions are loosely coupled, have normative embeddedness and high institutional commitment, and generally lack environmental vulnerability, change - especially radical change - is less likely" (p. 104).

Kezar (2001), Birnbaum (1988), and Cameron (2000) have synthesized the organizational change literature to create models specifically for colleges and universities. Eckel and Kezar (2003b) have gone a step further by coupling a synthesis of nearly 100 research-based strategies (Kezar, 2001) with empirically derived findings based on the six institutions of higher education - of the 23 institutions taking part in a five-year study sponsored by the American Council of Education (ACE) Project on Leadership and Institutional Transformation- that had made the most significant changes. Eckel and Kezar concluded that five core strategies were central to transformation: senior administrative support, collaborative leadership, flexible vision, staff development, and visible action strategy. Kezar and Eckel (2002b) found that one notion, "sensemaking," emerged as underlying the strategies in their model. Sensemaking is defined by 
Weick (1995) as "the making of sense" (p. 4), which belies the reality that sensemaking is a complex process of active structuring, interpreting, and reinterpreting the unknown. Weick uses the terms creating, inventing, constructing, filtering, and framing as sensemaking activities that lead people to "read into things the meaning they wish to see" (p. 14) and make their experience intelligible and consistent. The sensemaking process consists of seven characteristics: grounded in identity construction, retrospective, enactive of sensible environments, social, ongoing, focused on and by extracted cues, and driven by plausibility rather than accuracy. People make sense to "impose order, counteract deviations, simplify and connect" (p. 82).

Practitioner-oriented diagnosis of the hurdles to assessment adaptation such as those offered by Lopez (2004) fit within the sensemaking framework advocated by Weick (1995). For example, a number of sensemaking characteristics can be illustrated by Lopez's finding that faculty misunderstand assessment because they believe that it is a fad or an outside imposition. It could be that assessment does not fit faculty members' identities as largely independent actors who see their primary affiliations to academic disciplines. Many, if not most, of the cues faculty are receiving about assessment are probably coming from outside agencies rather than lead administrators, many of whom are also receiving their cues from sources external to the institutions and do not use assessment practices for decision-making. In addition, the justifications for assessment may not seem plausible to faculty, as well. Without widespread use of assessment results, there is a lack of demonstrated usefulness.

If the strategies designed to implement and sustain assessment do not contain components of sensemaking, the chances for second-order change will be limited. Assessment is intended to be itself a change process. Therefore, by extension, if assessment results are not used by 
organizational members to make sense of the organization (Keeling, Wall, Underhile, \& Dungy, 2008), then assessment as an on-going activity will be limited.

In one of the few studies of sensemaking in higher education, Gioia and Thomas (1996) suggest that institutions undergoing strategic change have a different sensemaking system than other institutions. Gioia and Thomas developed some useful constructs and a framework to understand sensemaking used by top administrative officials as they engaged in strategic change initiatives. In their view, borrowing from Albert and Whetten (1985), institutional identities can be classified as either utilitarian or normative. Lead administrators with the former view see their institution through an economic lens while those with the latter view focus on values and philosophy, especially those found in the institution's mission.

The retrospective aspect of sensemaking determines how issues are interpreted. Gioia and Thomas (1996) found that top administrators viewed issues as strategic or political, rather than threats or opportunities. Leaders view strategic issues as those that alter an institution's market, goals and mission, or the whole institution. Political issues involve conflict, negotiation, or influence and tend to be internally focused.

Several components of sensemaking appear to contribute to how issues are framed by the decision makers. Top administrators' views of the institutional identity, how sensemaking enacts the environment, and the social structure of sensemaking at the upper management level seem to influence administrators' interpretation of issues as either strategic or political (Gioia \& Thomas, 1996). Leaders with a utilitarian view of the institution's identity, and strong commitment toward the identity, tend to see issues as strategic while those with a lesser commitment see issues as political. In addition, image, what Weick (1995) would regard as an enacting the environment aspect of sensemaking, is how the administrators hope others will view their 
institutions and, in turn, a lens on how they interpret information about their institutions. Gioia and Thomas (1996) found that the lead officials tended to focus on either the institution's present image or desired future image. Those that were more attentive to the present image saw issues as political, while those with a desired future image orientation were inclined to view issues as strategic.

The interaction among top administrators also influenced how issues were interpreted by top administrators (Gioia \& Thomas, 1996). Gioia and Thomas labeled the manner in which the administrators communicate to make decisions as the information processing structure and established that a greater degree of interaction, participation, and process informality among the top managers involved in the decision process was related to a strategic interpretation of issues rather than a political interpretation.

Context influences how extracted cues are interpreted (Weick, 1995), and Gioia and Thomas (1996) found that institutions tend to be either domain offensive or domain defensive. Domain offensive institutions are characterized by new programs, curriculum, and marketing, while domain defensive organizations are concerned with maintaining market positions and efficiency.

\section{Purpose of Study and Research Questions}

The purpose of this study is to explore assessment as a sensemaking endeavor. The sensemaking apparatus may be different for those institutions that are actively engaged in the transformational process or in which assessment has become inculcated as an institutional value (Gioia \& Thomas, 1996; Kezar \& Eckel, 2002b), than sensemaking at institutions where assessment is not part of the institutional culture. This study is an exploration of the relationship 
between outcomes assessment and institutional sensemaking within institutions that have been effective in implementing and sustaining assessment.

The general question of this study is: How do faculty and administrators use assessment results to make sense of the organization? Specific research questions to be addressed by this investigation are as follows:

(1) Is the extent of use of assessment results by top administrators related to their view of an institution's identity as primarily utilitarian or normative?

(2) Is the extent of use of assessment results by top administrators related to the strength of their commitment to the institutional identity?

(3) Is the extent of use of assessment results by top administrators related to their view of issues as primarily strategic or political?

(4) Is the extent of use of assessment results by top administrators related to their attempt to enact the environment by primarily focusing on the present or future image of the institution?

(5) Is the extent of use of assessment results related to the social/information structure of top administrators?

(6) Is the extent of use of assessment results by top administrators related to the contextual cues being seen by them as either domain offensive or domain defensive?

The findings of this study will be useful to professionals charged to design or implement assessment plans and those attempting to use assessment results to encourage change within an institution. They will have another lens, sensemaking, to view aspects of organizational change necessary for the adoption of a functional and functioning assessment process. The study will expand the scholarship of assessment by placing it into the context of a more comprehensive 
model of organizational behavior. The study may also support the addition of outcomes assessment as an important feature to existing models of organization change and effectiveness.

Chapter two will provide a further review of literature related to transformational change, sensemaking, particularly in regards to organizational change in institutions of higher education, and assessment as it relates to sensemaking. Chapter three will describe the research model proposed to answer the research questions.

\section{Key Terms and Concepts}

1. "Assessment" is an ongoing process that involves identifying expected goals, ensuring that sufficient activities are in place to achieve those goals, systematically collecting and interpreting evidence about the achievement of the intended goals, and using the information to make improvements (Suskie, 2004, p. 155).

2. "Collaborative leadership" is a result of leaders across the campus working simultaneously, encouraging departmental and individual participation, and allowing other leadership to emerge for change initiatives to be successful (Kezar \& Eckel, 1999).

3. "Cues," as a component of sensemaking, refers to the process in which people extract clues from the ongoing flow of moments that people embellish to develop a larger sense of what is occurring (Weick, 1995).

4. "Domain defensive" describes strategies employed when organizations are concerned with maintaining market positions and efficiency (Cameron \& Tschirhart, 1992; Gioia \& Thomas, 1996).

5. "Domain offensive" describes strategies that organizations employ to expand core offerings (Cameron \& Tschirhart, 1992; Gioia \& Thomas, 1996). 
6. "Enactive of sensible external environments," as a component of sensemaking, denotes the importance of people creating the environments they face by sending cues to others (Weick, 1995).

7. "Flexible vision" is a clear, desirable, yet flexible picture of the future held by those involved with the change initiative (Eckel \& Kezar, 2003b).

8. "Identity," as a component of sensemaking, refers to an active process that institutional members attempt in order to maintain a consistent, distinctive, positive self-conception (Albert \& Whetten, 1985; Eckel \& Kezar, 2003a; Weick, 1995).

9. "Information processing structure" is the degree of interaction, participation, and process informality among the top managers used to make decisions (Gioia \& Thomas, 1996).

10. "Institutional image" is an enactment of the institutional identity.

11. "Normative organizational identity" is primarily cultural, educational, or expressive, exemplified by churches, political parties, hospitals, and schools, focused on the efficiency of processes rather than the effectiveness of outcomes, and largely managed by ideology. Members are generally highly committed to the work of the organization and have internalized the values of the organization, which they see as legitimate (Albert \& Whetten, 1985).

12. "Ongoing," as a component of sensemaking, captures the notion that there is no beginning or ending to sensemaking (Weick, 1995). This continuous sensemaking only becomes an event when boundaries are put "around some portion of the flow or when some interruption occurs" (Weick, 2001, p. 462). Disruptions cause emotions and introduce affect into sensemaking.

13. "Organizational culture" consists of the values and beliefs held by institutional members (Peterson \& Vaughan, 2002). 
14. "Plausibility," as a component of sensemaking, is about acceptability and credibility being important for sensemaking rather than accuracy or being right (Weick, 1995).

15. "Political issues" are those issues that involve conflict, negotiation, or influence and tend to be internally focused (Gioia \& Thomas, 1996).

16. "Retrospective," as a component of sensemaking, deals with past events since anything that can affect the remembering of an event will affect the sensemaking based on the memories (Weick, 1995). Viewing an emerging issue as a threat or opportunity is dependent upon the sense made from remembered past experiences of similar or related situations (Eckel \& Kezar, 2003a).

17. "Senior academic administrators or leaders" include the president or chancellor, provost or vice president for academic affairs, assistant or associate provosts, deans, assistant or associate deans, director of assessment, and department chairs.

18. "Senior administrative support" is responsible for making the macro structural and cultural changes necessary for change (Kezar \& Eckel, 1999).

19. "Senior or top administrators" include the president or chancellor, provost or vice president for academic affairs, vice president for student services, and the chief financial officer.

20. "Sensemaking" is a complex process of active structuring, interpreting, and reinterpreting the unknown done by individuals and organizations (Weick, 1995).

21. "Socially created," as a component of sensemaking, implies that sensemaking is predicated on a socially created world (Weick, 2001). It involves shared meaning emanating from talk, discourse, conversation, and, most importantly, shared collective action (Eckel \& Kezar, 2003a). 
22. "Staff development" involves the programmatic efforts of individuals to learn skills and knowledge related to the change agenda (Kezar \& Eckel, 1999).

23. "Strategic issues" are those issues that alter an institution's market, goals and mission, or the whole institution (Gioia \& Thomas, 1996).

24. "Transformational change" implies intentionally going beyond the usual day-to-day decision-making machinery of organizations and reaching deeply into their values, missions, underlying assumptions, institutional behaviors, processes, and structures (Argyris \& Schön, 1996; Eckel, Hill, \& Green, 1998; Heifetz \& Linsky, 2002; Kuhn, 1970; Levy \& Merry, 1986).

25. "Utilitarian organizational identity" is oriented toward economic production, governed by the values of economic rationality, maximization of profit, minimization of cost, and financial return as the central symbol of success, and largely managed by information. Members' relationships with the organization are guided by self-interest (Albert \& Whetten, 1985).

26. "Visible action plan" consists of the steps to make the change process noticeable and signal that it is progressing (Eckel \& Kezar, 2003b). 


\section{Chapter Two}

Review of the Literature

In a broad sense, assessment is an ongoing process that involves identifying expected goals, ensuring that sufficient activities are in place to achieve those goals, systematically collecting and interpreting evidence about the achievement of the intended goals and using the information to make improvements (Suskie, 2004, p. 155). This process model of assessment can be applied at any level in a college or university, from an individual course or program to the institutional level, the focus of this study. At almost any level, it appears as though a transformational change is required for colleges and universities to adopt this model of assessment and to inculcate it into their practices and decision-making processes (Banta, 2002). To sustain assessment efforts, it is particularly important that top administrative officials view institution-wide assessment as

- a way to produce credible evidence of learning and organizational effectiveness,

- a means to continuously improve programs and services,

- a vehicle for demonstrating accountability to stakeholders within and outside the institution,

- an ongoing, not episodic, practice, and

- the incorporation of ongoing evaluation and improvement of the process itself (Banta, 2002).

Practitioners working to develop sustainable institutional assessment programs can be guided by principles of organizational change. The following sections will examine the organizational change processes, with a concentration on institutions of higher education as a unique organizational type. A Mobile Model of Transformational Change (Kezar \& Eckel, 
1999) and an overarching principle of change, sensemaking, will also be discussed. As a means for institutions to make sense of themselves, institution-wide assessment can be both the object of change initiatives and an agent of that change.

\section{Change Theory}

Change is one of the paradoxes of organizational life and institutions of higher education in particular (Czanriawska, 1997). This is because there is a tension between order and stability on one hand and the need for change on the other, leading to a state of adaptive instability for organizations (Gioia, Schultz, \& Corley, 2000). The manner in which this state is managed will determine the success or failure of any change initiative.

Though it is essential for organizations to understand the notion of change, the definition of change depends upon the lens through which it is viewed (Kezar, 2001). These different lenses are formally represented by different models or theories of organizational change. Theories and models of change differ along certain dimensions: why change occurs (forces and sources affecting change), what will change (degree, timing, scale, and/or focus of change), how change will occur (responsiveness, intentionality, response time, and implementation of the change effort), and the target of change (the process and outcomes of change). Each model or theory is built upon certain assumptions about the nature of humans, organizations, and reality, and the choice of a model is an "ideological one" (Kezar, 2001, p. 25).

\section{Typology of change theories}

Kezar (2001) categorized 100 change models into six types: evolutionary, teleological, life cycle, dialectical, social cognition, and cultural, and compared each type. Evolutionary models of change presuppose that the environment external to the organization is the major factor pushing change, and change proceeds in a slow, adaptive, and non-intentional way that 
results in new structures and processes. The underlying assumption of teleological models is that organizations are purposeful and changes are initiated by leaders due to the internal environment; proceed in a rational, linear, and purposeful way; and result in new structures and organizing principles. The life cycle models view change as an inevitable function of an organization's growth, maturity, and subsequent decline and guided by leaders who encourage members' “natural growth" (Kezar, 2001, p. 57) through training and motivation that alters members' habits and identities and results in a new organizational identity. Change in dialectical (also referred to as political) models occurs because the tension that is created by members' differing values, norms, and patterns of interaction is kept in check by negotiation and power that yield new organizational ideologies. The change associated with social cognition models is prompted by organization members experiencing cognitive dissonance and a perceived need to change that results in altered paradigms or the perceptual lenses of the members due to learning or other mental processes, such as sensemaking. Cultural models propose that change is a response to alterations in the human environment and is a long-term, slow process that is nonlinear and unpredictable, resulting in a new organizational culture consisting of altered values, beliefs, and rituals.

\section{Change in institutions of higher education}

Change in institutions of higher education is seen as distinctive due to the nature of the organizations. Kezar (2001) described thirteen key features that account for this distinctiveness. The following section discusses each of these features.

\section{Interdependent organizations.}

Kezar (2001) noted that colleges and universities are highly interdependent with some of the major actors being disciplinary societies, professional organizations, the state and federal 
governments, unions, and accrediting agencies.. Kezar and others (Alstete, 2004; Driscoll, 2006; Kezar \& El-Khawas, 2003; Lubinescu, Ratcliff, \& Gaffney, 2001; Peterson \& Einarson, 2001) have commented upon the particular role that accreditation plays in standardizing and improving institutions, specifically mentioning outcomes assessment as an emphasis.

\section{Independent of their environment.}

Though highly constrained by their environment (Birnbaum, 1988), colleges and universities are relatively independent, particularly when compared to public schools, of market, social, economic, and political forces (Kezar, 2001). Institutions of higher education are viewed as essential to society in spite of no national office of higher education and limited involvement by the states (A. M. Cohen, 1998; Kezar, 2001).

\section{Unique culture.}

Bergquist (1992) and Birnbaum (1988) developed models of higher education cultures and Bolman and Deal (1997) created models (they call them frames) of organizations that can readily apply to higher education. Kezar (2001) examined these models and concluded that colleges and universities are more consensus-based and political and less rational, organized, and structured than businesses.

Kezar (2001) suggests that an understanding of two cultural types, collegial and political, may contribute to successful change strategies for higher education. The collegial culture, as either historically (Bergquist, 1992) or empirically (Birnbaum, 1988) derived, involves equal standing among faculty from the different disciplines, collaborative and interdependent work, and faculty autonomy. Kezar believes that the collegial culture requires a shared and inclusive change process. However, as Bolman and Deal (1997) note, participative decision making may 
lead to resistance from sectors not involved, and Kezar believes the political culture, or frame, is also important for understanding change.

Bergquist (1992), Birnbaum (1988), and Bolman and Deal (1997) all identify the importance of political tools such as negotiation, coalition building, and bargaining to distribute resources and balance clashing values within organizations. Kezar (2001) considers these tools of the political culture, combined with the participation suggested by the collegial culture, important for institutional change initiatives.

\section{Institutional status.}

Colleges and universities are a distinctive organizational type called institutions (Kezar, 2001). The attributes of institutions are that they have long-standing, resistant-to-change missions; serve many diverse societal needs; set their norms and socialization processes based on their missions and societal needs; and have individuals who have internalized the values of the organization. Because of this, Kezar believes that change must be long-term and sustained in order to be effective.

\section{Values-driven.}

Higher education is driven by values that are both complex and contrasting (Kezar, 2001). Institution members have shared values, such as academic freedom; distinct, disciplinarybased values; and competing values that are held by students, faculty and administrators. This lack of a widely held, unifying value, such as maximizing the return to investors in a business organization, indicates to Kezar that politics will be involved in any change efforts.

\section{Multiple power and authority structures.}

There are multiple power and authority structures, both horizontal and vertical, within institutions of higher education, and it is difficult to readily determine who has power at a 
college or university (Kezar, 2001). This is because referent and expert power, rather than coercive, reward, or legitimate power, are the predominant sources of power in normative institutions, like those in higher education (Birnbaum, 1988). Referent power derives from a willingness to be influenced by someone with whom an individual identifies, while expert power emanates from a willingness to be influenced by someone who is perceived to have special knowledge or competence.

Where power implies an ability to control, authority suggests a right to influence with an expectation that directions are followed (Kezar, 2001). Clark (2000) chronicled the decentralization of the faculty and the concomitant diffusion of academic authority along with a rise in bureaucratic authority, further complicating an already multi-tiered, complex, "balkanized" state of affairs (B. R. Clark, 1983) within institutions of higher education.

Kezar (2001) notes that other types of competing authority such as enterprise-based, system-based, and charisma are also at play in institutions of higher education. Enterprise-based authority is derived from a legal right to act on behalf of the organization, such as the board of trustees and president. System-based authority is the government or political authority invested in such entities as state governing boards. Charisma authority originates from a willingness to follow someone such as a president, trustee or faculty member because of his or her personality.

\section{Loosely coupled.}

Higher education institutions are composed of loosely coupled systems (Weick, 1976). Loosely coupled systems are characterized by highly differentiated components, specialization, low predictability of actions, and largely independent actions by each component (Kezar, 2001). The term "loosely coupled" is what Weick (1976) calls a sensitizing device, or a means to highlight features of an organization. A loosely coupled organization has systems that are 
responsive to one another yet preserve their own identity and physical or logical separateness. The attachment between systems is "circumscribed, infrequent, weak in its mutual affects, unimportant, and/or slow to respond" (Weick, 1976, p. 3). Another element of loosely coupled systems is that intentions and actions are not necessarily logically linear; sometimes intentions follow action, which puts extensive planning into question. Kezar (2001) notes that attempts by states to tighten the coupling of systems within higher education institutions by control, centralization, and coordination have not worked. Tennessee was the first state to base some funding on institutional performance, notably the enhancement of student learning outcomes. There was "scant" evidence that student achievement was promoted after more than ten years of the effort, though the problem may have been in instruments used, both commercial or locally developed, to measure achievement and student motivation (Banta, Rudolph, Van Dyke, \& Fisher, 1996).

\section{Anarchical decision-making.}

Colleges and universities are characterized by organized anarchical decision-making due to having problematic goals, unclear technology, and fluid participation (M. D. Cohen \& March, 1974). Institutional goals are problematic because they are ambiguous, difficult to measure, and are "typically a loose collection of changing ideas rather than a coherent educational philosophy" (Birnbaum, 1988, p. 155).

Broadly, the term technology refers to the conversion of inputs to outputs, thus in an educational setting, it is the process that transforms entering students into graduates (Birnbaum, 1988). Birnbaum observed that while colleges and universities are effective in turning new students into educated graduates, no one fully understands the learning process, which is the technology of higher education. However, the knowledge of the student learning process seems 
to have improved some since Boyer (1990) advocated that teaching, along with discovery, integration, and application, be considered one of the four types of scholarship that should be supported and encouraged (Braxton, Luckey, \& Helland, 2002). However, Weimer (2006) found that few faculty read pedagogical research and those who do tend to read the research only within their own discipline and focus on teaching, not learning, indicating that the technology of higher education may remain largely unclear.

The third characteristic of organized anarchical decision-making is fluid participation in the process (M. D. Cohen \& March, 1974). Birnbaum (1988) describes how decisions about issues that may relate to one another, particularly at the faculty level, are seldom made by the same people because of teaching schedules, elections, and individual interests.

Birnbaum (1988) notes that the concept of organized anarchy questions the underlying rationality of an organization: that institutions have goals; leaders play critical roles in institutional processes; individuals can freely exchange their preferences; chains of cause and effect are the basis of actions to achieve desired outcomes; problems are solved by decisions; and decision making is a primary activity of organization members. It may appear to an outsider that there is no intent behind the decisions, and they are not controlled by anyone (M. D. Cohen \& March, 1974), and, further, that higher education organizations are not rational, "tidy, efficient, and coordinated structures" (Weick, 1976, p. 3). Kezar (2001) adds that trustee, state legislative, and presidential efforts to the contrary have not created less ambiguity in decision-making. The anarchical processes in higher education make change difficult.

\section{Professional and administrative values.}

The professional and administrative values at colleges and universities differ (Kezar, 2001; Kezar \& Eckel, 2000; Swenk, 1999) because administrative and faculty cultures are built 
on incompatible decision-making models and epistemological structures. Administrative authority is based on hierarchical control and coordination of activities while faculty authority emanates from autonomy and expertise. Administrators value rationality, goals, cost/benefit calculations, accountability and effectiveness. Faculty, alternatively, value autonomy, professional preparation, academic freedom, knowledge and understanding, and intellectual honesty (Birnbaum, 1988). As a result, there is a cultural divide between faculty and administration. Faculty members view administrators as bureaucratic, unscholarly, business minded, impatient with faculty concerns, and insensitive to academic values. Administrators see faculty as conservative, suspicious of the administration, reluctant to change, unwilling to contribute to the daily operations of the institution and, in some cases, cynical about whether any change is either possible or desirable (Martin, Manning, \& Ramaley, 2001). Kezar (2001) believes that the conflict between administrators and faculty is growing, making change more complex.

\section{Shared governance.}

Trustees or boards have legal authority over institutions of higher education, yet the faculty and administration claim authority over the major functions and decisions (Birnbaum, 1988). These decisions frequently also incorporate input from student governance (Kezar, 2005a). Benjamin and Carroll (1998) see this relatively unique organizational arrangement as unable to help set institutional priorities, differentiate missions, or contribute to the implementation of decisions about priorities or missions once made.

Governance is under pressure from an increasingly complex terrain occupied by higher education. Traditional governance mechanisms are limited when faced with decisions regarding such things as accountability, market competition, and shrinking public financing (Benjamin \& 
Carroll, 1998; Kezar \& Eckel, 2004). The intellectual capital and institutional memory of governance participants will be reduced greatly by the large number of faculty and staff retirements in the next ten years and complicated by more diversity within the faculty and among students (Benjamin \& Carroll, 1998; Kezar \& Eckel, 2004), further restricting the effectiveness of governance. The relative reach of governance has also diminished as the traditional core activities of institutions shrink and peripheral activities expand (Tierney, 2004c). Not surprisingly, some scholars of higher education such as Balach (2004), Dudersbtadt (2004), Duderstadt and Womack (2003), Keller (2004), and Tierney (2004a) have called for changes in governance. (This is not a new phenomena, as Birnbaum (2000a) notes with an illustration from 1918.) Amid these calls for change, Kezar (2005a) found that radical change to governance structures will likely lead to more negative consequences than positive ones; he concluded from an examination of a number of studies that increasing decision-making efficiency may jeopardize effectiveness of the decisions (Kezar \& Eckel, 2004). Decentralized decision-making, which is a result of shared governance, tends to dampen the rate of organizational change (Kezar, 2001) and is likely to remain a predominant factor.

\section{Employee commitment and tenure.}

Postsecondary institutions, compared to other organizations, have a stable workforce at both the faculty and administrative levels. Faculty retention is largely due to tenure, a rare benefit outside of academe, though non-tenure track faculty members also tend to stay. It is unclear how this employee commitment affects the change process (Kezar, 2001). Institutions are at the cusp of a major shift, however, as a large portion of current faculty and administrative staff members are nearing retirement (R. L. Clark, 2005). These retirements may provide a unique opportunity for change (Kezar, 2001), which may be modulated by the need to phase the 
generational turnover in such a way as to maintain intellectual capital and cultural traditions (Berberet, Brown, Bland, Risbey, \& Trotman, 2005).

\section{Goal ambiguity.}

Birnbaum (1988) noted that institutional goals in higher education, such as "prepare students who are liberally educated" (p. 155), are ambiguous and difficult to measure, as is characteristic of anarchical organizational systems. Cohen and March (1974) commented that "universities tend to produce goals that are either meaningless or dubious" (p. 195). They noted three problems with goals themselves: clarity, achievability, and acceptance, as well as an inconsistency between goals and actions. This inconsistency has been thought of as a source of organizational ineffectiveness (Argyris \& Schön, 1996; Smart \& St. John, 1996). More recently Kezar and Eckel (2004) observed that "institutions operate with a multitude of unclear, competing, and inconsistent goals," (p. 378) with faculty (and staff) from different units supporting those goals tied to their own units. The embraced goals also change over time, further complicating their usefulness in uniquely defining an institution and facilitating change (Kezar, 2001). While Tierney notes (2004b) that higher education is becoming a more competitive marketplace amid increasing demands for accountability and effectiveness and that it will be important for institutions to determine if they are achieving their goals as one means of demonstrating their quality, Kezar (2001) believes that goal ambiguity makes change uncertain.

\section{Image and success.}

Because of ambiguous goals, institutions of higher education have limited metrics of success and instead have focused on "inputs" (Tierney, 2004b) and image (Gioia \& Thomas, 1996) as proxies for quality. Image is what organizational members believe is the way others view their organization (Kezar, 2001) and is closely linked to organizational and individual 
identity (Gioia \& Thomas, 1996). Change initiatives need to take into account identity modification (Eckel \& Kezar, 2003b; Kezar, 2001).

Institutions of higher education are unique among organizations along thirteen dimensions (Kezar, 2001). These institutions are interdependent yet relatively independent, possess a distinct organizational culture and institutional status, and are values-driven, though these values may conflict, particularly between administrators and faculty. Multiple power and authority structures, loose coupling, anarchical decision-making processes, shared governance, and ambiguous goals also characterize institutions of higher education. Employees have a strong commitment to the institution for which they work, and faculty members have tenure, making turnover relatively low. Lastly, institutions of higher education focus on their images as a measure of success. Each of these characteristics contributes to the complexity of change processes in colleges and universities.

\section{Key conclusions by Kezar}

After examining the main dimensions (the why, what, how, and target of change) of each of the six groups of change models, while taking into consideration the relevant characteristics of colleges and universities, Kezar (2001) proposes the following seventeen principles of change for institutions of higher education:

1. Promote organizational self-discovery. Change initiatives should promote organizational self-discovery and serve as "mechanisms that draw people together to talk, relate, and understand issues that facilitate self-discovery" (Kezar, 2001, p. 115).

2. Realize that the institutional culture affects change. Institutions engaged in change need to realize that the institutional culture affects change and should conduct an assessment of their culture so that change strategies may reflect the institution's history, traditions, and norms. 
3. Be aware of politics. Members interested in change need to understand the alliances, influence-makers, informal processes, conflicts, and motivations that exist within the institution.

4. Lay groundwork. In almost every change theory, the process begins with some sort of institutional self-assessment and learning about the change initiative. This collaborative process should answer questions about what kind of change is to take place (first or second order), how the change will occur (revolutionary or evolutionary), and why the change effort is being undertaken.

5. Focus on adaptability. Incremental, first order, adaptive change is more likely to occur than transformational or second order change. It is "wiser for institutions to invest in innovation throughout the campus and to let great ideas bubble up" (Kezar, 2001, p. 117).

6. Facilitate interaction to develop new mental models. Many change models suggest ways to bring institutional members together to facilitate understanding of the change, develop new mental models, integrate the new models with existing models, and develop a common language related to the change initiative.

7. Strive to create homeostasis and balance external forces with the internal environment. The response to change in loosely coupled systems is difficult to manage and gauge. Leaders should avoid direct responses to the external environment and intervene only when significant problems occur. Leaders should facilitate dialogue within the institution intended to develop a “cognitively complex decision" (Kezar, 2001, p. 118) to deal with the external conditions.

8. Combine traditional teleological tools such as establishing vision, planning, or strategy with social-cognition, cultural, and political strategies. Studies have demonstrated that teleological tools, when used with principles of other models, are useful for facilitating change and help people understand the change initiative. 
9. Realize that change is a disorderly process. Orderly change processes often fail to produce change in higher education while long-term dialogues not connected with a clear change strategy have led to fundamental changes. Leaders and change agents need to be open to ambiguity and disorder.

10. Promote shared governance or collective decision making. Almost every model emphasizes the need to collaborate, which is consistent with collective governance.

11. Articulate and maintain core characteristics. Continuity is an important component of most change models. The important core values of an institution need to be discussed and communicated.

12. Be aware of image. Many changes in higher education have occurred due to the normative influence of institutional image and the emulation and imitation of other institutions viewed as better in some way.

13. Connect the change process to individual and institutional identity. Higher education has deeply entrenched beliefs, habits and norms that form its identity. Combined with strong employee commitment and longevity, identity at the individual and institutional levels is an important influence that change initiatives must address.

14. Create a culture of risk and help people to change belief systems. Institutional members are generally socialized to contribute to a stable and efficient organization, an antithetical position to change. An institutional culture open to change must be fostered so that members feel comfortable attempting change and making different choices than in the past, without blame.

15. Realize that various levels or aspects of the organization will need different change models. No change model captures the complex nature of higher education institutions. Some 
models are appropriate for the broadest level of the organization while others are more applicable to each unit. For example, teleological models seem very appropriate for administrative change while political models may be better for changes in academic departments.

16. Know that strategies for change vary by change initiatives. Large scale, secondorder change initiatives may be better realized with strategies from social-cognition and cultural models. Teleological and evolutionary models are more aligned to first-order changes.

17. Consider combining models or approaches. Change initiatives are institutiondependent and situational. Kezar (2001), echoing other conceptions for understanding organizations and change (Bergquist, 1992; Birnbaum, 1988; Bolman \& Deal, 1997; Burns, 2004; Morgan, 2006; Senge, 1990), notes that the "advantage to multiple models is that they combine the insights of various change theories" (p. 53).

\section{Emergent Transformational Change Theory}

The adoption and implementation of assessment practices is considered a transformational change (Banta, 2002) or a paradigm shift toward a learning-centered institution. A learning-centered institution focuses on learning outcomes rather than other variables such as the characteristics of the entering students or number of volumes in the library as proxies for institutional quality (Barr \& John, 1995; Fear et al., 2003; Huba \& Freed, 2000; Jones, 2002; Tagg, 2003). The terms transformational change and paradigm shift describe the "what" of change and "degree of change," specifically. According to Kezar (2001), the degree of change is generally categorized as either first or second-order. First-order changes do not alter the core of the institution, whereas, the core is permanently changed if the organization has undergone second-order change. Second-order change, stemming from the work of Kuhn (1970) on paradigm shifts in science, involves going beyond the usual day-to-day decision-making 
machinery of organizations and reaching deeply into their values, beliefs, missions, underlying assumptions, theories-in-use, institutional behaviors, processes, and structures (Argyris \& Schön, 1996; Eckel, Hill, \& Green, 1998; Heifetz \& Linsky, 2002; Levy \& Merry, 1986). Second-order or transformational changes are deep and pervasive, affecting the entire organization (Kezar, 2001). However, transformational change is rare and complex (Burns, 2004), particularly in higher education (Kezar, 2001).

Kezar and Eckel (Eckel \& Kezar, 2003b; Kezar \& Eckel, 1999, 2002b) studied the six institutions of higher education among the 23 institutions taking part in a five-year study sponsored by the American Council of Education (ACE) Project on Leadership and Institutional Transformation that made the most significant changes. Coupled with a synthesis of nearly 100 research-based strategies (Kezar, 2001) with empirically derived findings, Kezar and Eckel concluded that five core strategies were central to transformation: senior administrative support, collaborative leadership, flexible vision, staff development, and visible action strategy.

\section{Senior administrative support.}

Senior administrators are responsible for making the macro structural and cultural modifications necessary for institutional change (Kezar \& Eckel, 1999). Adjustments to the organization's structure may include a reorganization or the addition of offices to support the change initiative, the provision of financial resources and incentives, and a change in the governance processes to improve decision making (Kezar \& Eckel, 2002a). Kezar and Eckel suggest that an important cultural revision may be the articulation of a philosophy that values what is currently being done well to make employees feel worthwhile and appreciated.

In addition, senior administrators focus attention and set priorities, invite collaboration, and facilitate collaborative leadership, as well as provide consistent messages about how the 
proposed change will improve the institution (Eckel \& Kezar, 2003b). This supports Bennis’ (1989) observation that effective higher education leadership consists of the management of attention, meaning, and trust that empower the workforce by making the institutional members feel that work is exciting and that they are significant, competent, and part of a community. Institutional leaders manage the complex new decisions, the fundamental aspects of an organization that result from change. Failure of leadership to embrace the change initiative will undermine full implementation (Kleiner, 2003).

The importance of senior academic leadership support from provosts, associate and assistant provosts, deans, and department heads is prevalent in the literature concerning the development of campus-wide assessment cultures (Jones, 2002; López, 2004; Peterson \& Vaughan, 2002; Shipman, Aloi, \& Jones, 2003; Suskie, 2004). Many of the leadership functions delineated by Kezar and Eckel (2002a) as important for promoting change also are important for creating a climate supportive of assessment. Some of these leadership functions include providing meaningful incentives (Jones, 2002; López, 2004; Shipman, Aloi, \& Jones, 2003; Suskie, 2004), recognizing the importance of appropriate budgeting to establish and sustain assessment (López, 2004; Shipman, Aloi, \& Jones, 2003; Suskie, 2004), and creating vital organizational structures such as an institutional assessment committee and support mechanisms (López, 2004; Suskie, 2004). The most important leadership function is that leaders' communication must indicate that assessment will improve the institution and be used for decision-making (Jones, 2002; López, 2004; Peterson \& Vaughan, 2002; Suskie, 2004).

\section{Collaborative leadership.}

Second-order change requires a leadership team, drawn from across the institution, to work in a collaborative environment that is created by senior management (Kezar \& Eckel, 
2002b). Both top-down and bottom-up change strategies can be successful, but the important decision about which strategy to use depends on the institutional culture (Eckel \& Kezar, 2003b). In either case, leaders across the campus must work simultaneously, encourage departmental and individual participation, and allow informal leadership to emerge (Kezar \& Eckel, 1999). In order to facilitate trust, the change process must be open to different ways of operation, public challenge, and criticism (Eckel \& Kezar, 2003b). It is important that shared goals and a common language be developed. As Curry (1992) notes, higher education leaders must "involve other members of their organization in designing, implementing, and institutionalizing change" (pp. 22-23).

Within the assessment community, Jones (2002) notes that trust is the primary condition for facilitating change that is promoted by a collaborative, open process. Collaboration also facilitates a feeling of ownership in the change. Lopez (2004) found that strong assessment programs, similar to successful change initiatives, are characterized by multifaceted administrator and faculty collaborations.

\section{Flexible vision.}

Flexible vision, previously labeled "robust design" (Kezar \& Eckel, 1999, 2002b), is a clear, desirable, yet flexible picture of the future held by those involved with the change initiative (Eckel \& Kezar, 2003b). The flexible vision allows for the emergence of details that reflect the institutional culture, language, and beliefs (Kezar \& Eckel, 2002b). Because of the uniquely complex nature of higher education organizations, plasticity in leadership is required. Cohen and March's (1974) notions of sensible foolishness and playfulness are useful concepts to manage complexity while fostering flexibility. 
While the mention of a "flexible vision" does not appear directly in the assessment literature, the notion is implicit in implementation strategies. Jones (2002) counsels change agents to be open to feedback and respond to criticism throughout the change process. Suskie (2004) instructs leaders to set clear expectations yet be flexible and encourage experimentation with assessment strategies and the modifications to courses and programs based on assessment results.

\section{Faculty and Staff development.}

Faculty and staff development that results from programmatic efforts of individuals to learn skills and knowledge related to the change agenda may be the most important strategy for change (Kezar \& Eckel, 1999). Transformational change requires individuals to change their behavior, learn new skills, and develop new capacities (Eckel \& Kezar, 2003b). Training can provide information and the language to facilitate change as well as provide the faculty and staff with the leadership skills, such as effective communication and decision making, to be able to convey information about the change initiative (Kezar \& Eckel, 2002b). The specifics of staff development — the who, what, and when — are tied to the change initiative.

Lopez (2004) believes faculty development is the primary means to increase faculty participation in assessment. Although on-going staff development, thoughtfully planned and developed, is a prominent feature of successful assessment implementations (Jones, 2002; López, 2004; Peterson \& Vaughan, 2002; Suskie, 2004), technical support is also deemed important (Peterson \& Vaughan, 2002; Suskie, 2004).

\section{Visible action plan.}

Visible actions are the steps taken to make the change process noticeable and signal that it is progressing. These actions are very context-dependent, and their content is not important; 
the timing is (Eckel \& Kezar, 2003b). It is important that accomplishments are demonstrated in the first year or two and that they are promoted and publicized by leaders. Providing visible products along the way is a key to maintaining momentum (Kezar \& Eckel, 1999).

Lopez (2004) advises regularly reporting on new developments in the assessment program, all assessment activities throughout the institution, upcoming deadlines, and the results of assessment efforts. The likelihood of successful implementation of an assessment program can be improved by starting small or incrementally (Jones, 2002), publicly celebrating and rewarding assessment efforts, and regularly publishing a campus-wide assessment newsletter (Suskie, 2004).

\section{Mobile Model of Transformation}

The five above mentioned strategies of senior administrative support, collaborative leadership, flexible vision, staff development, and visible action strategy were common among the six institutions undergoing transformative change. The intensity of each strategy varied among campuses depending on context, institutional type, and culture. These core strategies are linked to one another and to a set of 15 secondary strategies that must occur simultaneously to be effective (Eckel \& Kezar, 2003b; Kezar \& Eckel, 1999, 2002b). The fifteen secondary strategies include the following:

1. using persuasive and effective communication,

2. designing support structures,

3. providing incentives,

4. sustaining a long-term orientation,

5. making connections and synergy,

6. working within and challenging the culture, 
7. considering outside perspectives,

8. reviewing external factors,

9. developing opportunities to influence results,

10. inviting participation,

11. moderating momentum,

12. setting and holding people accountable to new expectations,

13. changing governance and administrative processes,

14. creating new ways old groups relate, and

15. putting local change into a broad context of change.

Eckel and Kezar call this network of core and secondary strategies the Mobile Model of Transformation. The model emphasizes that the transformation process requires balance among strategies, is situated in an ever-changing environment, and is bounded by the institutional culture.

As complex as the model appears, Kezar and Eckel (2002b) found that one notion, sensemaking, emerged as underlying the strategies. Sensemaking makes the strategies effective and necessary.

\section{Sensemaking}

Sensemaking is an active process that individuals (and organizations) use to structure, interpret, reinterpret and understand the vast amount of data they receive from their internal and external environments. Weick (1995) simply defines the term sensemaking as "the making of sense" (p. 4) of the unknown because people need to make sense in order to "impose order, counteract deviations, simplify and connect” (p. 82). According to Birnbaum (1988), sensemaking is the major purpose of organizations. The structure, goals, and processes of 
organizations are social constructions that exist to simplify the complexity of work for its members so that it stays within the limits of rationality and confines uncertainty. This concept of organizational purpose can be expanded to include people outside of the organization. A fuller definition is that the structure, goals, and processes of an organization exist to help constituents make sense of the work of the organization.

Weick (1995) believes that the sensemaking process consists of seven characteristics. Sensemaking must be grounded in identity construction, be retrospective, enactive of sensible environments, social, ongoing, focused on and by extracted cues, and driven by plausibility rather than accuracy. The following describes each of these characteristics.

\section{Identity construction.}

Organizational identity is typically defined "as the central and enduring attributes of an organization that distinguishes it from other organizations" (Whetten, 2006, p. 220). The three essential dimensions of the definition are central, enduring, and distinctive and are at the core of self-reflection questions posed by organizational members (Albert \& Whetten, 1985) such as "Who are we or who do we want to be as an organization?"

Each of the three dimensions of identity can be viewed through three domains: ideational, definitional, and phenomenological (Whetten, 2006). The ideational domain is the organizational members' beliefs of what they are as an organization and, Whetten believes, is the weakest of the three for model building, hypothesis testing, and empirical measurement. More useful for these purposes are the definitional and phenomenological domains.

Identity as understood by the definitional (or conceptual) domain consists of those attributes that are used by the organization to positively distinguish it from similar organizations, as long as the attributes encompass those associated with that type of organization, and those 
attributes manifest in the organization's core programs, policies, and procedures that reflect its highest values (Whetten, 2006). Generally, these programs, policies, and procedures have had a long organizational history, possibly as foundational features of the organization (Buenstorf \& Murmann, 2005; Whetten, 2006), though organizations may signal that a recent decision or resolution is going to be enduring (Whetten, 2006). The organizational attributes central for identity also operate as irreversible commitments that would be unthinkable to alter such as WalMart deciding to become a high-end, niche-oriented retail chain or, as Whetten offers, the University of Notre Dame abandoning its affiliation with the Catholic Church.

The phenomenological domain is the identity-referencing discourse most likely used by members of an organization when they have to make important choices that may alter the organization (Whetten, 2006). When the discourse takes the form of categorical imperatives to "avoid acting out of character" or to prevent the organization from acting out of character, the conversation references the distinctiveness of the organization. When the discourse serves as either a decision guide or justification in difficult situations or dominates the conversation when the organization is faced with an identity threat, the discourse references enduring and central aspects of organizational identity. Difficult or threatening situations elucidate identity-reference conversations since organizations" "claims to be when nothing is on the line is not how they act when everything is on the line" (Whetten, 2006, p. 227).

There is some disagreement about identity being distinctive and enduring. Gioia (1998) found that organizations may have multiple identities, each dependent on its own constituency. For example, the identity of a university may be different as presented to and perceived by the employees, a state governing board, potential students, or the alumni. In addition, Gioia and Thomas (1996) question the distinctiveness of organizations when emulation of another 
organization, many times deliberate, becomes the basis of an organization's identity. Gioia and Thomas believe that emulation is particularly pervasive in higher education. On the other hand, Elsbach and Kramer (1996) found that organizational members attempt to establish institutional distinctiveness, at least at the program level. Elsbach and Kramer studied the identity threat perceived by members, students, faculty, and administrators of MBA programs after they were ranked in a national publication. The members from programs at both lower ranked and higher ranked institutions reacted similarly by using two general tactics to assure they appeared distinctive. One method was to change comparison categories; for example, public schools compared themselves to other public schools, which allowed them to maintain or highlight a positive organizational self-identity characteristic. The other tactic was to focus on alternative attributes of the program's identity that the members felt were overlooked in the published ratings, resulting in the program appearing less distinctive than it actually was. This supports Dutton, Dukerich, and Harquail's (1994) conclusion that it is important for members to believe their organization is distinct even if the organization is not empirically or demonstrably so.

Organizations are also faced with the dilemma of appearing to be stable (enduring) over time while maintaining a necessary adaptability to rapid environmental changes, a condition that Gioia (1998) terms adaptive instability. This paradox is resolved, according to Gioia, Schultz, and Corley (2000), by organizational members using consistent, stable labels to describe their identity, but changing the meaning of the labels over time. The identity can be thought of as enduring, yet varying at the same time.

Albert and Whetten (1985), in their original attempt to define organizational identity, take the interesting position that identity is both enduring and shifting over time. They posit that 
there are two orientations of identity, normative and utilitarian, and that it may migrate between the two. Organizations may even exhibit signs of both, that is, have a dual identity.

Utilitarian organizations are those oriented toward economic production and are governed by the values of economic rationality, maximization of profit, minimization of cost, and financial return as the central symbol of success. Members' relationships with the organization are guided by self-interest. Utilitarian organizations are largely managed by information.

Normative organizations are primarily cultural, educational, or expressive, as exemplified by churches, political parties, hospitals, and schools (Albert \& Whetten, 1985). Members are generally highly committed to the work of the organization and have internalized the values of the organization, which they see as legitimate. Leadership rituals, manipulation of social and prestige symbols, and socialization are important as normative organizations are largely managed by ideology. Albert and Whetten note that "a common problem in all ideological organizations is assessing effectiveness" (p. 284), and, as a result, normative organizations tend to focus on the efficiency of processes rather than the effectiveness of outcomes.

Albert and Whetten (1985) believe that universities have characteristics of both normative and utilitarian organizations and thus have a dual identity, though hybrid identity may be a better descriptor. For example, like churches, universities have ceremonies, maintain traditions, and see as one of their primary purposes the transformation or socialization of people. Colleges and universities also articulate the utilitarian ethos of self-interest in preparing individuals for the workplace, meeting the needs of society, and researching for the national interest. Many institutions see their programs and services as commodities, for instance, research that can be transferred to commercial uses and certain academic programs that are considered profit centers. The proper emphasis makes for continued debate within and outside 
of higher education (Chickering, 2003; Kirp, 2003; Newman, Couturier, \& Scurry, 2004;

Ramsay, 1999) and may be particularly compelling at religion-affiliated institutions (Burrows, 1999).

After questioning two of the three tenets of organizational identity, distinctive and enduring, Gioia (1998) concluded that they are still useful organizing and analytical features along with the third tenet, centrality. As Dutton and Dukerich (1991) put it, knowledge of an organization's "identity is crucial for discerning the importance of an issue, its meanings, and its emotionality" (p. 547) as the identity guides and constrains organizational thinking and actions.

Effective assessment should contribute to or reinforce the members' and institution's sense of themselves. Many authorities ((Dugan, 2004; Keith, 2004; Suskie, 2004) suggest that assessment emanates from the mission and, by extension, the identity of the institution. In addition, almost every theory of organizational change notes the importance of identity in that process (Kezar, 2001).

\section{Retrospective.}

Sensemaking (and assessment) deals with the interpretation of past events. Anything that can affect the remembering of an event, including whatever is occurring currently, will affect the sensemaking based on the memories (Weick, 1995). Retrospection contributes to a feeling of order, clarity, and rationality, and stops when this feeling is achieved (Weick, 1995). Though retrospection is not an accurate representation of the past, it makes for a plausible history. When an outcome of a complex issue is known, events leading to it appear more determined than they were at the time. The recreated interpretation of events differs if the outcome is seen as good or bad (Eckel \& Kezar, 2003a; Weick, 1995). If the outcome is viewed as bad, the reconstructed antecedents "emphasize incorrect actions, flawed analyses, and inaccurate perceptions, even if 
such flaws were not influential or all that obvious at the time" (p. 28). On the other hand, Weick (2001) notes that the act of retrospection underestimates the false starts and glosses over the difficulties when an outcome is viewed as an accomplishment. In either case, the reasonable accounts of the unfolded events may be poor guides for prospective action (Weick, 2001). The development of faulty action maps may be amplified in higher education due to the complex, loosely coupled nature of the organizations (Birnbaum, 1988) that produces multiple, biased interpretations of the same event, incorrect assignments of causes to effects, and enhanced importance to seemingly trivial remarks or actions.

Within higher education, the academic leadership, faculty, and staff will view institutionwide initiatives, such as assessment, through the retrospective lens. They may focus on their previous experiences with large scale, probably costly, institutional improvement efforts that had similar aims as assessment (Suskie, 2004), such as management by objective and total quality management, that Birnbaum (2000b) showed had little impact on improving institutions and are now considered fads (Birnbaum, 2000b; Kezar, 2005b). Though these efforts may not have produced the intended results, the retrospective process will exaggerate the hurdles, produce conclusions about the programs that will be incomplete and faulty, assign causality where it does not exist, and make the failure of the implementation appear inevitable.

\section{Enactive of sensible external environments.}

Enactment is the "process in which we shape and structure our realities" (Morgan, 2006, p. 136). People help create the environment they face; that is, they enact a sensible environment (Weick, 1995). Akin to a self-fulfilling prophesy, actions taken by people (and organizations) serve as reinforcement of their current beliefs, brackets for what is extracted from the environment, and cues for others. Weick (2001) believes that self-fulfilling prophesies are 
commonplace in organizations due to their environment scanning activities that serve to validate their perceptions and actions and reinforce their existing identities or images.

Organizations enact policies, procedures, missions, declarations, job descriptions, pronouncements, testimonies, and images, based on the institutions' beliefs, which can be viewed as paradigms, metaphors, or shared meanings that influence how the world is seen or what is selectively attended to in the environment. These enactments reveal and influence how the organization is viewed by members and others. These actions create both opportunities and constraints on the environment in which the organization operates that did not exist before the actions.

Enactment can be conceptualized as a three-stage process (Weick, 2001). In the first stage people (or organizations) use preconceptions to bracket, or group, some elements from the field of experience. In the second stage, the bracketed raw data are transformed by categorizing and labeling them, a process known as punctuation, and a connection is made among elements. The connection imposes relationships, typically causal relationships, among punctuated elements, which results in causal maps. These causal maps consist of if-then assertions in which actions are related to outcomes and form a cognitive construction of the environment. These constructed maps may be more appropriately referred to as predictive models (Page, 2007) to suggest the indeterminate relationship between cause and effect.

The third stage is taking action on the bracketed or punctuated elements. These actions are shaped by the preconceptions and causal maps. Enactment makes it likely that the interpretations and actions will reinforce the preconceptions. Weick (2001) notes that people (and organizations) act in the way they think they should be acting. 
Enactment is a process of invention, rather than one of discovery (Weick, 2001), that imposes an order on the environment without assuming an underlying order. It brings events and structures into existence and sets them in motion. As Weick (1995) notes, "People create their environments as those environments create them" (p. 34). At the organizational level, Kakkuri (2004) terms this reciprocal environment creation as "boundary transactions" which involve both enactment and adaptation transactions. Enactment transactions are attempts by an organization to shape its environment while emphasizing favorable attributes of the organization. Adaptation transactions modify the organization in response to pressures from the environment. Kakkuri found that universities lose control of the effects of transactional enactments once made and that the enactments produce unanticipated consequences. For example, institutions of higher education in Finland began to "steal" doctoral students from one another after the number of doctorates awarded became a benchmark for resource allocations. In an effort to appear to be more prestigious to the funding sources, institutions found it more advantageous to package degrees to accommodate students already working on their doctorates rather than to educate students from the start.

Top administrators at higher education institutions attempt to influence the sensemaking and meaning construction of organizational constituents and stakeholders with a process termed sensegiving (Gioia \& Chittipeddi, 1991), which is largely a public display of enactment. (The signaling of this is provided by cues, another aspect of sensemaking discussed below.) Sensegiving emanates from the administrators' "preferred definition of organizational reality" ( $p$. 442), or preferred institutional image. Institutional image is an enactment of the institutional identity. 
When there is an interpreted incongruence between what institutional members anticipated will be seen as the environment as a result of the enacted preferred image and what is surmised as the actual environment (the construed external image), the institutional identity is threatened. The result is, one, a reinterpretation of the identity to highlight the alternate identity attributes or alternate comparison groups (Elsbach \& Kramer, 1996) or, two, an adaptation of the identity (Dutton \& Dukerich, 1991; Gioia, Schultz, \& Corley, 2000).

Gioia and Thomas (1996) found that the senior higher education administrators tend to focus on enacting either the institution's present image or desired future image. Those who were more attentive to the present image tended to view issues confronting the institution as political and believed their means of enactment required conflict resolution, negotiation or influence. Those administrators with a desired future image orientation were inclined to view issues as strategic and used planning, marketing, or expansion of programs as their instruments of enactment.

Assessment is used to interpret what has happened and can be used to shape the environment, decisions, and people's behavior. Effective assessment may help move an institution to where it wants to be, its desired future image, by providing useful and meaningful information that can be used to identify and make necessary changes. Resistance to assessment may reflect an attempt to enact the present image, perhaps also known as maintaining the status quo. Both positions may be understood by knowing the institutional constituents' causal maps of the teaching-learning process. For example, linking collected artifacts of student work primarily with instructor-controlled behaviors (classroom environment, curriculum sequencing, or expected outcomes, of the many possible) or primarily with student attributes (attitude, aptitude, preparation, or motivation, among others) will result in very different enacted environments. 
Without going into detail, the enacted environment of the former is likely characterized as learner or learning-centered, supporting assessment, while the latter is characterized as teachercentered and probably resistant to assessment efforts.

Another aspect of enactment that may have implications for change initiatives is that in highly ambiguous situations, like a crisis, many times people do not know what the appropriate action is until they take some action and see what happens, though not always to positive outcomes (Weick, 2001). The principle of making a decision or taking action to see what happens may be particularly appropriate in institutions of higher education, given the looselycoupled, anarchical decision-making, multiple centers of power and authority, and goal ambiguity that are the nature of the institutions (Kezar, 2001). Wrong decisions in these environments will probably not lead to such dire consequences as they would in a forest fire, for example.

\section{Socially created world.}

Sensemaking, as a theoretical construct, is predicated on a socially created world (Weick, 1995) or a co-constructed world (Hosking \& McNamee, 2006). When viewed from this perspective, the shared meanings within an organization that result from common interpretations of events, common symbols, and common stories or legends are more important than actual events for holding the institution together (Cameron, 2000). Organizational sensemaking is influenced by the actual, implied or imagined presence of others (Weick, 2001). It involves shared meaning emanating from talk, discourse, conversation, and most importantly, shared collective action (Eckel \& Kezar, 2003a), which Weick (1995) characterizes as an alignment of acts to form joint action, regardless of the motivation. 
The number and nature of the interactions among the actors influences how organizational events are interpreted. For example, the greater the number of interactions that employees had with managers, the greater the likelihood that employees perceived the organization to be treating them fairly (Lamertz, 2002). Argyris and Schön (1996) have shown extensively that the characteristics of the communication between members of an organization affect the interpretation of institutional narratives. They found that an espoused organizational value such as concern or caring could be interpreted as "acts diplomatically" or "says things people want to hear" if the communication within the organization consists of persuasion, abstractions, hidden feelings, and withheld information, what Argyris and Schön term Model I Theories-in-Use. The same organizational values could be seen as involving mutual support and understanding if the communication consists of requests for illustrations to help clarify issues, offers to jointly design and implement actions, and public attributions, communication consistent with Argyris and Schön's Model II Theories-in Use.

In higher education, the manner in which decisions are reached by top administrators, which Gioia and Thomas (1996) call the information processing structure, influence how the issues are characterized. The greater the degree of interaction, participation, and process informality among the top managers involved in the decision process, the more likely a strategic, rather than a political, interpretation of issues was made (Gioia \& Thomas, 1996).

It is important that within institutions of higher education, sensemaking produces sufficient shared meanings (though not necessarily the most accurate) for coordination. Effective assessment activities should become part of institutional conversations and shape these shared meanings and subsequent shared action. 
Institutional Sensemaking and Assessment 46

\section{Ongoing process.}

There is no beginning or ending to sensemaking. People (and organizations, as an extension) are always in the middle of something and constantly sensemaking (Weick, 1995). This continuous sensemaking only becomes an event when boundaries (brackets) are put "around some portion of the flow or when some interruption occurs" (Weick, 2001, p. 462).

People react to disruptions that, in turn, introduce affect into sensemaking. The emotions associated with the disruptions can be positive or negative. If the interruption is interpreted as harmful or detrimental, the emotion will be experienced as negative and become more intense the longer the disruption persists (Weick, 1995). Positive emotions occur when an interruption is removed or the interruption is a sudden, unexpected completion of the plan or action.

People can be associated with the disruptions and the concomitant emotion (Weick, 1995). Someone viewed as causing a negative disruption would be associated with the negative affect. On the other hand, someone could bring a new resource to a problem leading to an unforeseen conclusion of the plan, enacting a positive emotion. The intervention must be unanticipated for a positive affect to be experienced; when help is expected, the occasion for positive emotion is limited. Another factor limiting positive emotions in organizations is that working relationships mature and interpersonal transactions become routine, restraining possible disturbances. Loosely coupled organizations tend to limit disruptions, and when they do happen, it is more likely that organization members will experience negative rather than positive emotions. Institutions of higher education are characterized by relatively long term employment and loose coupling, and new sensemaking will likely be associated with negative emotion.

Retrospection compounds the effect of negative emotions associated with prior disruptions as current sensemaking is connected to experienced emotions that may influence the 
understanding of a current interruption (Weick, 1995). For example, a negative emotion will recall a similar negative experience, and that experience becomes the guide to deal with the existing situation.

\section{Cues.}

From the ongoing flow of events, people extract cues. Cues are simple, familiar aspects of the environment. Weick (1995) calls them seeds that people embellish to develop a larger sense of what is occurring. People notice what they expect to see as well as things that are novel, unexpected or disrupting. These noticed referents are cognitively linked to a more general form, category or idea that clarifies the meaning of that which was observed or bracketed. This, in turn, slightly alters the general form and so forth, iteratively (Bruner, 1973; Pinker, 1997; Weick, 1995). Extracted cues play a role in self-fulfilling prophesies by anticipating the nature of the referent from which it was extracted. Enactment occurs as if the nature that is inferred from the general category is true (Weick, 2001).

Context affects what cues are extracted and how they are interpreted. The context is both broad and narrow: broad in the sense of culture (Nisbett, 2003) and narrow in the sense of the immediate environment, including such things as place, time, physical spaces, and people (Strange \& Banning, 2001; Weick, 1995). Frames (Bolman \& Deal, 1997) and metaphors (Morgan, 2006) are two formal conceptualizations of organization context. Eddy (2003), for example, ascertained that community college presidents use different frames, visionary or operational, to interpret similar external environments, such as a decline in state funding. The frame presidents employ influences their views of the organization and change and, in turn, how the campus members interpret change. 
Gioia and Thomas (1996) found that the degree of interaction, participation, and process informality among top administrators in higher education institutions, along with the general institutional strategy_either domain offensive or domain defensive — formed the internal context for sensemaking by the administrators. Domain offensive strategies involve expanding the core offerings while domain defensive strategies aim to protect the core offerings and focus on efficiency. High collaboration among the top managers who use domain offensive strategies is related to a strategic interpretation, rather than a political interpretation, of issues.

In a study of an external context for sensemaking, Cameron and Tschirhart (1992) showed that college and university responses to postindustrial environments, characterized by turbulence, competitiveness, unpredictability, lean resources, and periods of declining resources or enrollments, depended upon the particular characteristics of the perceived environment they considered salient. For example, domain offensive strategies were directly related to a belief that there were fewer available resources, while domain defensive strategies were related to increased environmental turbulence and decreased competitiveness. A third set of strategies, domain creative strategies, intended to add new programs and services through innovation, diversification, or merger, were linked to organizational decline, decreased turbulence, and increased competitiveness. The more an institution emphasized one particular strategy, the less it employed either of the other two. Most importantly, domain offensive strategies were the most effective in mitigating the effects of postindustrial environments. Domain defensive and creative strategies are also important but had more restricted influences on institutional effectiveness than domain offensive strategies. It is probable that the dimensions of the postindustrial environment drawing attention and the strategies chosen to respond to the cues are consistent with each institution's identity (Levin, 1998). 
Cues tie elements together cognitively (Weick, 1995) by facilitating inferences between them (Pinker, 1997). People have faith in the cues and use them as reference points for sensemaking, thus making the control over the cues an important source of power (Weick, 1995). This is why assessment, to be effective, needs to be supported by key decision makers and influential faculty and staff who form the Core Group of the institution.

The Core Group is at the center of the organization's informal networks, and the Core Group members act as symbolic representatives of the organization's direction (Kleiner, 2003). Not all top administrators are necessarily included in the Core Group. Because Core Group members' remarks and actions are amplified, other organizational members can take an issue seriously when they see the Core Group paying attention to it, an important cue. If the Core Group fails to embrace something, the organization will also not embrace it. The central task of leaders, or the Core Group, is to create "appropriate systems of shared meanings that mobilize the efforts of people in pursuit of desired aims and objectives" (Morgan, 2006, p. 142). The cues emanating from enactments by the Core Group and/or administrators form the process of sensegiving which is an attempt to shape the sensemaking and shared meaning constructed by others, at least in institutions of higher education undergoing strategic change (Eddy, 2003; Gioia \& Chittipeddi, 1991; Gioia, Chittipeddi, Thomas, \& Clark, 1996).

Another important source of cues comes from outside of the organization. These cues are construed by organizational members as the external image (Dutton, Dukerich, \& Harquail, 1994; Elsbach \& Kramer, 1996). All aspects of organizational sensemaking, in particular identity, are influenced by the interpretation of these cues.

Sensemaking should produce sufficient cues to guide institutional conversations. Effective assessment activities should provide some of those cues. 
Institutional Sensemaking and Assessment 50

\section{Plausibility.}

Sensemaking is driven by plausibility rather than accuracy; it is not about being right but about being acceptable and credible (Weick, 1995). The process of sensemaking is a deeply individual matter. Organizational members' understanding and commitment to the organizational identity vary (Dutton, Dukerich, \& Harquail, 1994; Elsbach \& Kramer, 1996; Gioia, 1998). Members of the organization simplify prior events by retrospection, which may make the events a misleading guide to current situations (Weick, 2001), shape the environment by enactment, and follow existing causal maps (Morgan, 2006; Weick, 2001). Members dwell in a socially co-created entity that is their organization (Hosking \& McNamee, 2006) and respond emotionally to the fluid process of sensemaking (Weick, 1995). They also apply various frames of reference to extracted cues. Each person will interpret the same event differently, and, conversely, different interpretations of events can lead to similar actions (Weick, 1995).

Sensemaking is about making things coherent and reasonable, about embracing the past, and meeting an expectation. Sensemaking must resonate with other people, capture feeling and thought, be embellished to fit the current situation, and be constructed. "What is necessary in sensemaking is a good story" (Weick, 1995, p. 61).

This is not to say that accuracy is not important; it is, but only in a limited way, specifically when accuracy is needed to answer a very specific question. Something that facilitates the completion of a project is considered accurate. However, reasonableness, or what Birnbaum (1988) terms "satisficing," supersedes accuracy because sensemakers conclude that if a "superimposed order is reasonable and no less plausible than another imposed order, then the imposition is valid" (Weick, 2001, p. 194). 
Effective assessment is challenged by vastly different views of evidence across academic disciplines and between faculty and administrators. The core membership of institutions of higher education, the faculty, is discipline-centered, fragmented, and specialized (B. R. Clark, 1983; Weick, 1976). Faculty have a hard time understanding and identifying with one another because of their disciplinary subcultures, which are based on different research techniques and methodologies, vocabularies, membership in learned societies, membership requirements, and codes of ethics (Calhoun \& Starbuck, 2003; B. R. Clark, 1983, 2008; Kuhn, 1970). These distinct subcultures began to evolve in the nineteenth century (Collini, 1998), perhaps most famously noted by Snow (1998) as a "cultural divide." Important for plausibility and assessment is that within the faculty culture different disciplines have different rules and assumptions about what constitutes credible evidence needed to marshal belief and to justify actions (Huber \& Hutchings, 2005; Martin, Manning, \& Ramaley, 2001). Braxton, Luckey and Helland (2002), studying the institutionalization of the Boyer's four domains of scholarship, found that high consensus disciplines, such as biology and chemistry, are more oriented toward formal research than low consensus disciplines such as history and sociology.

Not only is there a difference in acceptable evidence across disciplines, there is a difference in the professional (faculty) and administrative values based on incompatible decision-making models and epistemological structures (Kezar, 2001; Swenk, 1999). For example, if action, such as a strategic plan, is reasonable or plausible to an administrator, the administrator will likely believe the action to be rational and goal-oriented and address such things as a cost/benefit analysis, accountability, and effectiveness. Some research has identified these administrative values to be primary inhibitors to organization learning (Argyris \& Schön, 1996), and faculty will be suspicious of actions that they believe threaten their autonomy, 
Institutional Sensemaking and Assessment 52

professional preparation, academic freedom, knowledge and understanding, and intellectual honesty (Birnbaum, 1988).

\section{Summary}

Transforming institutions of higher education into assessment-informed organizations requires second-order change in the institutional cultures (Banta, 2002). Any change initiatives of that magnitude must take into account the unique organizational characteristics of higher education institutions. Kezar (2001) noted thirteen aspects of higher education institutions that differentiate them from other organizations, most notably businesses, and make colleges and universities highly complex entities. Change strategies developed for higher education must be able to accommodate the complexity produced by such problems as multiple power and authority structures, loosely coupled components, anarchical decision-making processes, ill defined goals (particularly at the higher institutional levels), shared governance, and a focus on image rather than substance (or outcomes).

Eckel and Kezar (2003b) provide a grounded model of change in higher education that they call the mobile model of transformation. The model is an intricate web composed of five core strategies and 15 supporting strategies. Senior administrative support, collaborative leadership, flexible envisioning, faculty and staff development, and visible action form the five central strategies of the mobile model. These are supported by secondary components of the model such as persuasive communication, appropriate support structures, and incentives.

Organizational sensemaking is the concept captured by the web; that is, the model nurtures change by helping members make a new sense of their organization and their roles within it. Sensemaking, as proposed by Weick (1995), consists of seven interrelated factors that explain how individuals and organizations understand their internal and external environments 
and enable them to take action. Research on sensemaking in higher education shows that all seven factors contribute to advancing change initiatives (Kezar \& Eckel, 2002b). Perhaps the most important aspect of sensemaking for promoting change is how it influences issue interpretation by lead officials at colleges and universities. The actions taken as a result of the interpretation are sensegiving acts, influencing constituents inside and outside the institution (Gioia \& Thomas, 1996).

Top higher education administrators tend to categorize issues as strategic or political, rather than as threats or opportunities (Gioia \& Thomas, 1996). Strategic issues are seen as those that alter an institution's market, its goals and mission, or the whole institution, while political issues are those that involve conflict, negotiation, or influence and tend to be internally focused. Gioia and Thomas also found that leaders who viewed the institution as primarily utilitarian and focused on the desired future image of the organization tended to view issues as strategic.

How leaders interpret assessment will determine the role it plays in organizational sensemaking. For example, a political interpretation may focus administrators on minimizing internal conflict to best achieve the mandate, thereby negotiating or coercing an assessment system that maintains the status quo to the extent possible. A strategic interpretation may lead the integration of assessment into program or institutional development and be used to further an institution's story to internal and external audiences. In this case, assessment may play an expanded role in organizational sensemaking, thus making assessment possibly both the object and agent of transformational change.

The following chapter will present the proposed method for studying sensemaking as it relates to outcomes assessment in higher education. The research methodology will address the instrument, target population, data collection, and analysis to answer the five research questions. 


\section{Chapter Three}

\section{Method}

This study utilized quantitative methods to determine how faculty and administrators use assessment results to make sense of their colleges and universities. This chapter will detail the population surveyed, survey instrument, process of data collection, method of data analysis, time frame, and limitations of the study. Top academic and student affairs administrators of higher education institutions were surveyed in the Spring 2009 semester to determine if their use of assessment results corresponds to how they make sense of their organizations. Specifically, the study explored the relationship between the extent to which assessment findings are used in decision-making processes and a number of aspects of sensemaking employed by Gioia and Thomas (1996) in their model of strategic change.

\section{Population}

The population consisted of top academic and student affairs administrators from fouryear institutions that were identified, through a review of literature and the recommendations made by experts in assessment, as having a "mature" culture of assessment. An institution with a "mature" culture of assessment has assessment practices that Banta (2002) considers to be in the sustainment and improvement phase. Assessment programs in this phase

- produce credible evidence of learning and organizational effectiveness,

- ensure that assessment data are used continuously to improve programs and services,

- provide a vehicle for demonstrating accountability to stakeholders within and outside the institution,

- encompass the expectation that outcomes assessment will be ongoing, and

- incorporate ongoing evaluation and improvement of the assessment process itself. 
Nationally recognized assessment leaders and higher education officials with broad knowledge of assessment practices used by institutions were asked to submit recommendations to determine the institutions to be included in this study. Adopting the process used by McCullough (2007), these individuals were emailed requests (see Appendix A) to provide the names of four-year institutions that meet the Banta (2002) criteria for having assessment plans in the sustainment and improvement phase. There were 41 institutions recommended by assessment scholars and experienced higher education officials. The researcher also identified from the literature an additional 31 colleges and universities likely to be in the sustainment and improvement phase of assessment. The institutions identified from the literature were characterized by having relatively long experience developing their assessment practices or being described with terms such as having "a culture of data-informed decision-making." Top administrators from all 72 institutions were invited to participate in the study. (Appendix B contains a complete list of sources.)

Only a limited number of higher education institutions systemically use assessment results for course, program, service, and institutional improvement and decision-making (López, 2004; Peterson \& Vaughan, 2002). It is important to gain a view of how the members of these relatively few institutions make sense of assessment results that are among the myriad issues confronting them, and act upon their interpretations.

The top administrators at each institution acted as the informants for this study. These individuals were most likely members of the institution's Core Group (Kleiner, 2003) and were in a good position to comment on how assessment information is used to shape institutional sensemaking and decision-making. Table 1 shows the categories of administrators in academic and student affairs that were invited to participate in the study. 
The 1072 potential participants and their addresses were identified in several ways. An electronic database directory of higher education personnel was the primary source for this information (Higher Education Publications, 2008). Institutional websites were searched if institutional personnel were not available from the database. Websites were particularly useful to identify top assessment officials since many were faculty members and not titled administrators.

The number of officials invited to participate from each institution varied greatly, corresponding to the size of the institution. The minimum invited was four, from a small liberal arts college, and the maximum was 32, from two large research universities.

Table 1

Categories of Administrators Surveyed

Academic Affairs $\quad$ Student Affairs

Provosts/Vice Presidents

Assistant/Associate Provosts

Deans

Assistant/Associate Deans

IR Directors

Top Assessment Officials

Director Center for Teaching and Learning
Vice Presidents

Assistant/Associate Vice Presidents

Deans of Students

Assistant/Associate Deans

\section{Survey}

The survey (see Appendix D) was adapted from an instrument developed by Gioia and Thomas (1996) for their study of the contribution made by various aspects of sensemaking 
during periods of strategic change at institutions of higher education. The instrument was designed to measure institutional identity, image, and issue interpretation. The survey was composed of a demographic section and five parts: Assessment Extent of Use, Institutional Environment, Institutional Perceptions, Institutional Context for Decision Making, and Issue Interpretation, each containing one or more scales designed to ascertain a different aspect of sensemaking (see Table 2). The respondents were asked to rate all items on each scale on a 7point Likert scale ranging from 1, To a Small Extent, to 7, To a Great Extent. The mean response among items comprising each scale was computed to determine the score for that scale.

The extent to which institutions use assessment results was ascertained in Part I, Assessment Extent of Use according to the respondents' perceptions. Part I was composed of one eight-item scale derived from the fundamental elements of institutional and student learning assessment and optional evidence suggested by the Middle States Commission on Higher Education (2007). Parts II through V were from the original Gioia and Thomas (1996) survey, as outlined in their article.

Part II, Institutional Environment, contained an eight-item scale to measure the Strategic Orientation of the institution. Four of the eight items (see Appendix E) asked the respondents to rate domain offensive strategies and the other four to rate domain defensive strategies.

The Institutional Perceptions, Part III of the survey, contained scales for Institutional Identity Type, Present Image, Identity Commitment, and Desired Future Image. Identity Type consisted of ten items that seek to determine if respondents perceived the institution as primarily Utilitarian or Normative (see Appendix F). The Present Image was determined by a 10-item scale that asked the respondents how their institutions would be rated by individuals from their peer institutions. Identity Commitment was ascertained by a 6-item scale that asked the 
respondents their perception of how committed top administrators are to the institution's identity. The Desired Future Image was assessed by asking the respondents to identify three institutions they would like to emulate and rate why these institutions were selected, using the same ten items as the Present Image scale.

Part IV of the survey consisted of the Information Processing Structure scale. Nine items were designed to capture a composite of the degree of interaction, participation, and formality of the decision-making processes used by the top managers of the institution. A higher score on the scale indicated more interaction, participation, and process informality.

The last section of the questionnaire, Part V, sought to determine the extent to which participating respondents believe their institutions interpret issues as political and/or strategic. Informants were presented with five common issues facing institutions and, they for each issue, completed two 4-item scales, one for the Political Interpretation scale and one for the Strategic Interpretation scale (see Appendix G).

Table 2

Survey Scale Summary

Items Range

Part I - Assessment Extent of Use

Assessment Extent of Use

8

$1-7$

Part II - Institutional Environment

Strategic Orientation

Domain Offensive

Domain Defensive
$8 \quad 1-7$

$4 \quad 1-7$

$4 \quad 1-7$ 
Table 2 (Continued)

Survey Scale Summary

\begin{tabular}{lcc}
\hline & Items & Range \\
\hline Part III - Institutional Perceptions & 10 & $1-7$ \\
Identity Type & 5 & $1-7$ \\
$\quad$ Utilitarian & 5 & $1-7$ \\
$\quad$ Normative & 10 & $1-7$ \\
Present Image & 6 & $1-7$ \\
Identity Commitment & 10 & $1-7$ \\
Desired Future Image & & \\
Part IV - Context for Decision Making & 9 & $1-7$ \\
Information Processing Structure & & $1-7$ \\
Part V - Issue Interpretation & 40 & $1-7$ \\
Issue Interpretation & 20 & $1-7$ \\
$\quad$ Political Interpretation & 20 & \\
Strategic Interpretation & & \\
\hline
\end{tabular}

\section{Data Collection}

The researcher developed a cover letter (Appendix C) that explained the purpose of the study and requested the informants complete the 15 minute survey and return it in the selfaddressed envelope provided. A follow up letter and survey were sent four weeks later thanking those who had already completed the survey and asking the others to complete the survey by March 27, 2009. A second follow up mailing was conducted on April 17, 2009 with a May 8, 
2009 deadline. The goal was a 50\% response rate of the lead academic and student affairs administrators that were part of the original mailing, regardless of institutional affiliation.

\section{Data Analysis}

The returned surveys were machine scanned to produce an electronic data file. The file was imported into SPSS version 17.0. Following the practice of Gioia and Thomas (1996), the items comprising each scale were averaged to derive the score for that scale. Detailed below are the research questions proposed for this study and the way survey items from the questionnaire were used to answer each question.

(1) Is the extent of use of assessment results by top administrators related to their view of an institution's identity as primarily utilitarian or normative?

This question was answered by a Pearson product-moment correlation to gauge the relationship between the Extent of Use and the Identity Type scales. A higher score on the Identity Type scale indicated a more utilitarian view of the institution.

(2) Is the extent of use of assessment results by top administrators related to the strength of their commitment to the institutional identity?

This research question was answered by computing a Pearson product-moment correlation between the Extent of Use and the Identity Commitment scales.

\section{(3) Is the extent of use of assessment results by top administrators related to their view of} issues as primarily strategic or political?

This question was answered by computing three separate Pearson product-moment correlations: (1) the Extent of Use and the Strategic Interpretation scales, (2) the Extent of Use and Political Interpretation scales, and (3) the Extent of Use and combined Strategic and Political Interpretation scales, named Issue Interpretation scale. To merge the scales, the Political 
Interpretation items were reverse coded and averaged with the Strategic Interpretation items to form a composite Issue Interpretation score, with a higher score associated with a strategic interpretation.

(4) Is the extent of use of assessment results by top administrators related to their attempt to enact the environment by primarily focusing on the present or future image of the institution?

Pearson product-moment correlations were used to address this question, as well. Two Pearson product-moment correlations were used to examine the relationships: (1) between the Extent of Use and Present Image scales; and (2) between the Extent of Use and Future Image scales.

(5) Is the extent of use of assessment results related to the social/information structure of top administrators?

The items for the Information Processing Structure scale were coded so that the higher scores represent a social/information structure that is characterized by high interaction, high participation and low formality among top administrators. A Pearson product-moment correlation was used to show any relationship between Extent of Use and the social/information structure of top administrators.

(6) Is the extent of use of assessment results by top administrators related to the contextual cues being seen by them as either domain offensive or domain defensive?

This question was answered by computing three separate Pearson product-moment correlations: (1) the Extent of Use and the Domain Offensive scales, (2) the Extent of Use and Domain Defensive scales, and (3) the Extent of Use and combined Domain Offensive and Defensive scales, named the Strategic Orientation scale. To produce the Strategic Orientation 
scale, the Domain Defensive items were reverse coded and combined with the Domain Offensive items to produce one score so that a higher score means a more domain offensive strategy.

A multiple regression was employed to study the combined effects and the relative contribution that each component of sensemaking measured by the instrument has on the extent that institutions use assessment. The criterion variable, Extent of Use, was run against seven predictor variables (see Table 3). This allowed for an analysis of the possible contribution that each variable may contribute to how assessment results are used by top administrators.

Table 3

Multiple Regression Summary

Criterion Variable $\quad$ Predictor Variables

Extent of Use

Utilitarian/Normative Combined

Identity Commitment

Issues Interpretation

Present Image

Future Image

Information Processing Structure

Domain Offensive/Defensive Combined

\section{Timeframe}

May - June, 2008

September - November, 2008

January 20, 2009

February 18, 2009
Solicited names of institutions

Gathered addresses of participants

Sent survey

Sent reminder one 
April 17, 2009

Summer 2009
Sent reminder two

Data entry and analysis

\section{Limitations}

There are a number of limitations to this study. Participants may have exaggerated the extent to which current assessment practices inform decisions. The institutional informants were top administrators, and their time and attention may have precluded their participation. Sensemaking is generally studied with qualitative approaches since it deals with personal interpretation events, and the survey captured discrete aspects of sensemaking but eliminated any nuanced responses.

Another limitation may have been the use of non-profit bulk postage for the first two mailings, which probably affected the response rate. The main problem with the first mailing was the researcher underestimated the delivery time of this type of mail and had requested a return date that, in most cases, was before the questionnaires were delivered, confusing invited participants. This timing issue was rectified in the second mailing and first-class mail was used for the third mailing. 


\section{Chapter Four}

Results

This chapter addresses the findings concerning sensemaking related to the extent that assessment results are used by top administrators at selected four-year institutions of higher education. There are five sections of the chapter. The first and second sections describe the population selected to be surveyed and the characteristics of the respondents, respectively. The third section details the properties of the survey, and the fourth provides an analysis of the results, including answers to the research questions. A summary concludes the chapter.

\section{Population Selected}

Surveys were sent to 1072 top academic and student affairs administrators from 72 fouryear institutions that were identified as having a "mature" culture of assessment. An institution with a "mature" culture of assessment has assessment practices that Banta (2002) considers to be in the sustainment and improvement phase. The selected institutions represent nine of the 19 (47\%) basic Carnegie Foundation for the Advancement of Teaching (2008) types of four-year colleges and universities (see Table 4). The nine types, however, account for the majority (1601 of 2551 or $62.8 \%$ ) of four-year institutions. Research universities, as a group, and Baccalaureate Colleges--Arts \& Sciences appear to be well represented among those institutions identified as having a mature culture of assessment. The 22 research institutions selected represent $31 \%$ of the total institutions identified for this study, close to three times $(2.75)$ greater than the $11 \%$ representation among all institutions classified by Carnegie. The eighteen Baccalaureate Colleges--Arts \& Sciences identified were about double (2.2 times) their overall representation, that is, $25 \%$ of those selected versus $11.3 \%$ of all institutions classified. 
The special focus institutions were surprisingly underrepresented among the institutions chosen for this study, as only one of the 806 institutions representing a special focus Carnegie Classification was identified as having a "mature" culture of assessment. None of the institutions in the third largest Carnegie classification, Spec/Faith: Special Focus Institutions, were recognized as having a "mature" culture.

Table 4

Basic Carnegie Classification summary of institutions selected

\begin{tabular}{|c|c|c|c|c|}
\hline & \multicolumn{2}{|c|}{ Selected } & \multicolumn{2}{|c|}{ All Carnegie } \\
\hline & $\mathrm{N}$ & Percentage & $\mathrm{N}$ & Percentage \\
\hline RU/VH: Research Universities/Very High Activity & 9 & 12.5 & 96 & 3.8 \\
\hline RU/H: Research Universities/High Activity & 6 & 8.3 & 103 & 4.0 \\
\hline DRU: Doctoral/Research Universities & 7 & 9.7 & 84 & 3.3 \\
\hline Master's L: Master's Colleges and Universities/Large & 14 & 19.4 & 345 & 13.5 \\
\hline Master's M: Master's Colleges and Universities/Med & 7 & 9.7 & 190 & 7.4 \\
\hline Master's S: Master's Colleges and Universities/Small & 5 & 6.9 & 128 & 5.0 \\
\hline Bac/A\&S: Baccalaureate Colleges--Arts \& Sciences & 18 & 25.0 & 287 & 11.3 \\
\hline \multicolumn{5}{|l|}{ Bac/Diverse: Baccalaureate Colleges--Diverse } \\
\hline Fields & 5 & 6.9 & 360 & 14.1 \\
\hline Bac/Assoc: Baccalaureate/Associate's Colleges & & & 120 & 4.7 \\
\hline Spec/Engg: Special Focus Institutions--Engineering & 1 & 1.4 & 8 & 0.3 \\
\hline Spec/Faith: Special Focus Institutions & & & 314 & 12.3 \\
\hline Spec/Med: Special Focus Institutions & & & 57 & 2.2 \\
\hline
\end{tabular}


Table 4 (continued)

Basic Carnegie Classification summary of institutions selected

\begin{tabular}{|c|c|c|c|c|}
\hline & \multicolumn{2}{|c|}{ Selected } & \multicolumn{2}{|c|}{ All Carnegie } \\
\hline & $\mathrm{N}$ & Percentage & $\mathrm{N}$ & Percentage \\
\hline Spec/Health: Special Focus Institutions & & & 129 & 5.1 \\
\hline Spec/Tech: Special Focus Institutions & & & 57 & 2.2 \\
\hline Spec/Bus: Special Focus Institutions & & & 64 & 2.5 \\
\hline Spec/Arts: Special Focus Institutions & & & 106 & 4.2 \\
\hline Spec/Law: Special Focus Institutions & & & 32 & 1.3 \\
\hline Spec/Other: Special Focus Institutions & & & 39 & 1.5 \\
\hline Tribal: Tribal Colleges & & & 32 & 1.3 \\
\hline Total & 72 & 100 & 2551 & 100 \\
\hline
\end{tabular}

The institutional return rate was quite high with at least one respondent from 66 of the 72 (91.7\%) selected colleges and universities (see Table 5). Most of the categories (six of nine, $66.7 \%$ ) had a $100 \%$ institutional return rate, with at least one returned questionnaire from the college or university, while the lowest return rate $(77.8 \%)$ was from those institutions in the Carnegie category Bac/A\&S: Baccalaureate Colleges--Arts \& Sciences. 
Table 5

Institutional return rate by Basic Carnegie Classification

\begin{tabular}{lccc}
\hline & & & Response \\
& & & \\
& Invited & Responded & Rate (\%) \\
\hline RU/VH: Research Universities/Very High Activity & 9 & 9 & 100 \\
RU/H: Research Universities/High Activity & 6 & 6 & 100 \\
DRU: Doctoral/Research Universities & 7 & 6 & 85.7 \\
Master's L: Master's Colleges and Universities/Large & 14 & 13 & 92.9 \\
Master's M: Master's Colleges and Universities/Med & 7 & 7 & 100 \\
Master's S: Master's Colleges and Universities/Small & 5 & 5 & 100 \\
Bac/A\&S: Baccalaureate Colleges--Arts \& Sciences & 18 & 14 & 77.8 \\
Bac/Diverse: Baccalaureate Colleges--Diverse Fields & 5 & 5 & 100 \\
Spec/Engg: Special Focus Institutions--Engineering & 1 & 1 & 100 \\
Total & 72 & 66 & 91.7 \\
\hline
\end{tabular}

The distribution of institutional representation was very similar to the distribution of selected institutions (see Table 6). The responding institutions were from all nine of the basic Carnegie Classifications represented in the selection pool. 
Table 6

Institutional participation by Basic Carnegie Classification

\begin{tabular}{|c|c|c|c|c|}
\hline & \multicolumn{2}{|c|}{ Invited } & \multicolumn{2}{|c|}{ Responded } \\
\hline & $\mathrm{N}$ & Percentage & $\mathrm{N}$ & Percentage \\
\hline RU/VH: Research Universities/Very High Activity & 9 & 12.5 & 9 & 13.6 \\
\hline RU/H: Research Universities/High Activity & 6 & 8.3 & 6 & 9.1 \\
\hline DRU: Doctoral/Research Universities & 7 & 9.7 & 6 & 9.1 \\
\hline Master's L: Master's Colleges and Universities/Large & 14 & 19.4 & 13 & 19.7 \\
\hline Master's M: Master's Colleges and Universities/Med & 7 & 9.7 & 7 & 10.6 \\
\hline Master's S: Master's Colleges and Universities/Small & 5 & 6.9 & 5 & 7.6 \\
\hline Bac/A\&S: Baccalaureate Colleges--Arts \& Sciences & 18 & 25.0 & 14 & 21.2 \\
\hline Bac/Diverse: Baccalaureate Colleges--Diverse Fields & 5 & 6.9 & 5 & 7.6 \\
\hline Spec/Eng: Special Focus Institutions--Engineering & 1 & 1.4 & 1 & 1.5 \\
\hline Total & 72 & & 66 & \\
\hline
\end{tabular}

Characteristics of the Respondents

There were 1072 top academic and student affairs administrators invited to participate in the study and 311 (29\%) returned usable surveys. Table 7 displays the distribution of invited participants, respondents, and the response rate by title. The highest response rate was from Top Assessment Officials (officials with titles such as Director of Institutional Assessment, Assistant Director for Institutional Effectiveness, and Chair Assessment Advisory Committee) at 76.3\% followed by Assistant/Associate Vice Presidents of Student Affairs (36.8\%) and 
Assistant/Associate Provosts (33.6\%). Anecdotally, a number of the assistants and associates were responding on behalf of their superiors. It appears that the views of highest administrative levels of the respective divisions were well represented, even though the Academic Provosts/Vice Presidents had the lowest response rate at $11.9 \%$. There was roughly an equal proportion of surveys returned by academic and student affairs administrators, with $28.4 \%$ and $31.0 \%$ rates, respectively.

Table 7

Administrators Surveyed

Invited Responded Response Rate (\%)

Academic Affairs

Provosts/Vice Presidents

84

10

11.9

Assistant/Associate Provosts

125

42

33.6

Deans

302

69

22.9

Assistant/Associate Deans

218

68

31.2

IR Directors

63

17

27.0

Top Assessment Officials

38

29

76.3

Director Center of Teaching/Learning

42

13

31.0

Academic Affairs Subtotal

872

248

28.4

Student Affairs

Vice Presidents

54

18

33.3

Assistant/Associate Vice Presidents

57

21

36.8

Dean of Students

37

12

32.4 
Table 7 (continued)

Administrators Surveyed

Invited Responded Response Rate (\%)

Assistant/Associate Deans

Student Affairs Subtotal

Not identified

Total
52

200

1072
11

62

1

311

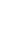

21.6

31.0
29.0

It appeared that the respondents knew their institutions fairly well. Table 8 displays the mean self-reported years of experience at the institution and mean years in their current position for each category of participation. They averaged close to $16(M=15.7)$ years of service at their institutions and $6(M=6.3)$ years in their current positions. The self-reported assistant/associate provosts and assistant/associate vice presidents had been employed by their institutions for almost 19 years $(M=18.8$ and 18.7 years, respectively). These two groups also had relatively high response rates.

Table 8

Mean Years of Respondent Experience

Academic Affairs

Provosts/Vice Presidents

Assistant/Associate Provosts

18.8

5.0

Deans

14.6

6.1 
Table 8 (continued)

Mean Years of Respondent Experience

\begin{tabular}{lcc}
\hline & At Institution & In Current Position \\
\hline Assistant/Associate Deans & 17.6 & 5.1 \\
IR Directors & 14.3 & 9.3 \\
Top Assessment Officials & 14.9 & 6.0 \\
Director Center of Teaching/Learning & 11.5 & 6.0 \\
Student Affairs & & \\
Vice Presidents & 13.9 & 8.2 \\
Assistant/Associate Vice Presidents & 18.7 & 10.4 \\
Dean of Students & 8.3 & 3.6 \\
Assistant/Associate Deans & 15.6 & 7.0 \\
Total & 15.7 & 6.3 \\
\hline
\end{tabular}

\section{Survey Properties}

The first step taken to analyze the survey responses was to determine the internal consistency or reliability among the items comprising each scale and sub-scale. Following the process outlined by Devellis (2003), a Cronbach alpha was computed for each scale. The Cronbach alpha results are shown in Table 9 along with those reported by Gioia and Thomas (1996), who developed the instrument. 
Table 9

Summary of Cronbach Alpha Scores

Gioia and Thomas

(1996)

Number of Items 2010 Alpha Published Alpha

Part I - Assessment Extent of Use

$\begin{array}{llll}\text { Assessment Extent of Use } & 8 & .92 & \text { NA }^{\mathrm{a}}\end{array}$

Part II - Institutional Environment

Strategic Orientation

$\begin{array}{lll}8 & .54 & .76\end{array}$

Domain Offensive

$4 \quad .74$

Domain Defensive

4

.84

Part III - Institutional Perceptions

Identity Type

10

.25

.71

Utilitarian

5

.59

Normative

5

.30

Present Image

10

.91

.88

Identity Commitment

6

.67

.82

Desired Future Image

10

.97

.86

Part IV - Context for Decision Making

Information Processing Structure

9

.56

.88 
Table 9 (continued)

Summary of Cronbach Alpha Scores

Gioia and Thomas

Number of Items 2010 Alpha Published Alpha

Part V - Issue Interpretation

Issue Interpretation

40

.85

Political Interpretation

20

.93

.92

Strategic Interpretation

20

.88

.88

${ }^{\mathrm{a}}$ The Assessment Extent of Use scale was constructed for this study.

DeVellis (2003, pp. 95 - 96) considers a Cronbach alpha below .60 to be unacceptable, between .60 and .65 to be undesirable, between .65 and .70 to be minimally acceptable, between .70 and .80 to be respectable, and above .80 to be very good. These Cronbach alpha score categories were employed to evaluate the survey scales.

There were six scales with an alpha less than .70 (minimally acceptable): Strategic Orientation, Identity Type, Utilitarian, Normative, Identity Commitment, and Information Processing Structure. For these scales, items were iteratively removed and a Cronbach alpha calculated until the highest alpha for that scale could be obtained (DeVellis, 2003; Pallant, 2007). The process yielded three scales that were at least "respectable" according to the DeVellis rubric: Strategic Orientation $($ alpha $=.72)$, Identity Commitment (alpha $=.87)$, and Information 
Processing $($ alpha $=.73)$. Acceptable Cronbach alphas could not be reached for Identity Type and its two sub-scales, Normative and Utilitarian.

A principal components analysis (PCA) was conducted on the Identity Type items to see if there were any constructs that may emerge and result in meaningful and useful scales. The items were determined to be suitable for a factor analysis (Pallant, 2007) as gauged by a MeyerOlkin Measure of Sampling Adequacy equal to .611, above the suggested minimum of .6, Bartlett's Test of Sphericity significant at $p<.001$, and a sufficient number of correlation coefficients above .3 in the correlation matrix (see Table 10).

Table 10

Identity Type Item Correlation Matrix $(N=310)$

\begin{tabular}{|c|c|c|c|c|c|c|c|c|c|c|}
\hline Item & 1 & 2 & 3 & 4 & 5 & 6 & 7 & 8 & 9 & 10 \\
\hline Question 1 & - & .014 & .248 & .164 & .053 & -.041 & -.016 & -.065 & -.023 & -.063 \\
\hline Question 2 & & - & .132 & .115 & .149 & -.014 & .553 & .045 & .223 & .303 \\
\hline Question 3 & & & - & .006 & .126 & .263 & .118 & .055 & .138 & .101 \\
\hline Question 4 & & & & - & .158 & -.068 & .061 & -.429 & .081 & .066 \\
\hline Question 5 & & & & & - & .041 & .210 & .084 & .336 & .305 \\
\hline Question 6 & & & & & & - & .152 & .044 & .050 & .052 \\
\hline Question 7 & & & & & & & - & .079 & .184 & .311 \\
\hline Question 8 & & & & & & & & - & .250 & .182 \\
\hline Question 9 & & & & & & & & & - & .419 \\
\hline Question 10 & & & & & & & & & & - \\
\hline
\end{tabular}


Four components emerge from the Identity Type items with eigenvalues of greater than 1.0 (see Table 11), a minimum value for consideration (DeVellis, 2003; Pallant, 2007).

Table 11

Identity Principal Component Analysis Eigenvalues

\begin{tabular}{cccc}
\hline Component & Eigenvalues & \% of Variance & Cumulative \% \\
\hline 1 & 2.364 & 23.64 & 23.64 \\
2 & 1.532 & 15.32 & 38.96 \\
3 & 1.279 & 12.79 & 51.75 \\
4 & 1.116 & 11.16 & 62.91 \\
5 & .976 & 9.76 & 72.67 \\
6 & .694 & 6.94 & 79.61 \\
7 & .615 & 6.15 & 85.76 \\
8 & .571 & 5.71 & 91.48 \\
9 & .450 & 4.50 & 95.98 \\
10 & .402 & 4.02 & 100 \\
\hline
\end{tabular}

An examination of the component matrix (see Table 12) and the scree plot (Figure 1) suggests one principal component, which accounts for $23.6 \%$ of the variance. 
Table 12

Identity Type Component Matrix

\begin{tabular}{|c|c|c|c|c|}
\hline \multirow[b]{2}{*}{ Identity Type Item } & \multirow[b]{2}{*}{1} & \multicolumn{2}{|c|}{ Component } & \multirow[b]{2}{*}{4} \\
\hline & & 2 & 3 & \\
\hline Economic performance important & .700 & -.088 & -.198 & .158 \\
\hline Marketing to attract students & .671 & .081 & -.089 & -.534 \\
\hline Cost-effectiveness guides change & .652 & -.128 & -.091 & .428 \\
\hline Students are customers or clients & .648 & .168 & -.188 & -.459 \\
\hline Financial returns measure success & .563 & .127 & -.040 & .438 \\
\hline Across-the-board budgeting & .128 & .816 & -.160 & .135 \\
\hline Selective budgeting & .286 & -.756 & .088 & .183 \\
\hline Symbols and ceremonies important & .348 & .103 & .748 & .011 \\
\hline Mission focused on academic quality & .204 & -.141 & .584 & -.313 \\
\hline Tradition guides change & .036 & .434 & .503 & .267 \\
\hline
\end{tabular}

Note. Values above .3 are bold 
Figure 1

Identity Type Principal Component Analysis Scree Plot

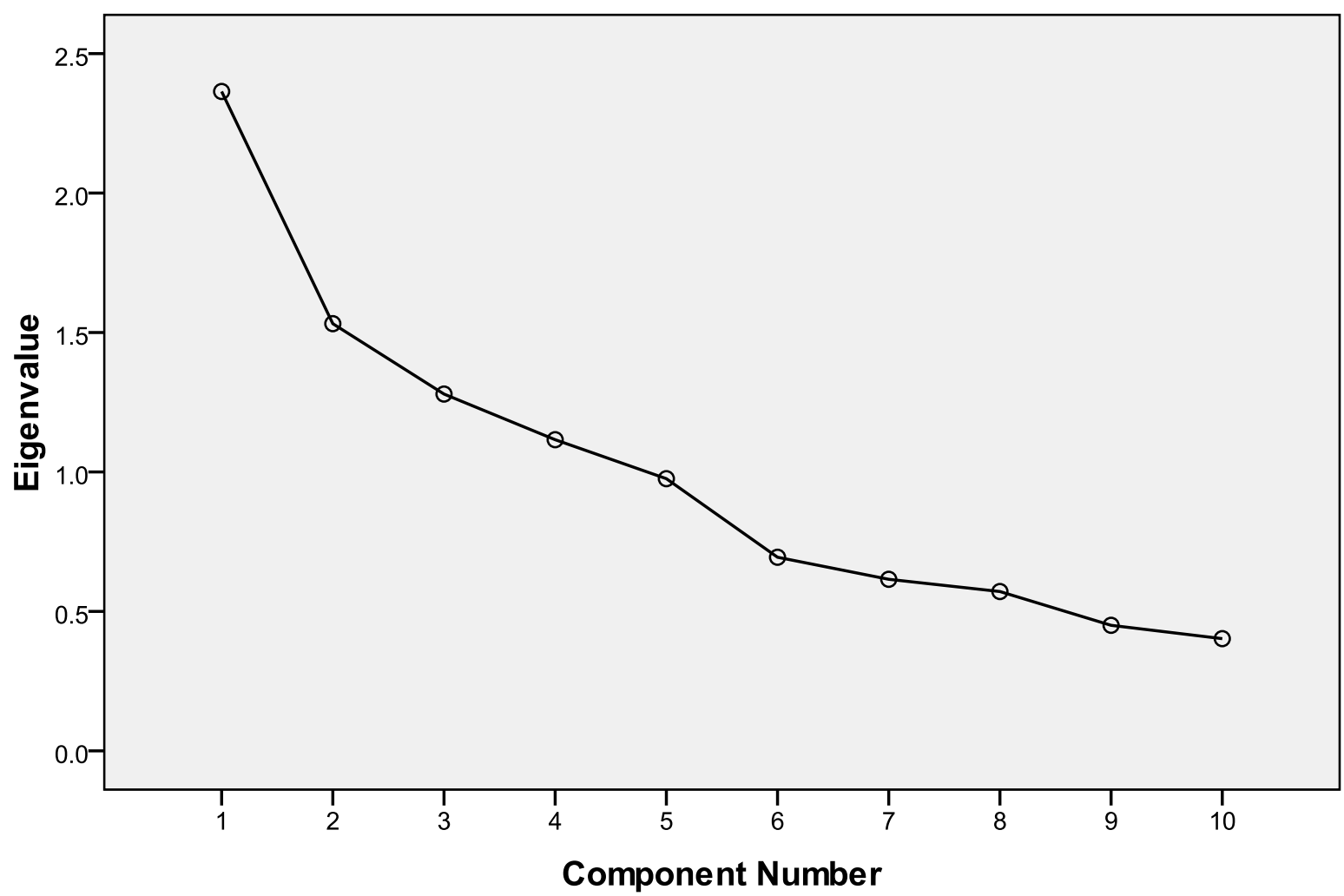

A Cronbach alpha was computed for the component. Items were then systematically removed until the highest alpha possible was reached for the factor. This process produced a scale with an alpha value of .67 , or acceptable, though undesirable, according to DeVellis (2003). This scale was derived from most of Gioia and Thomas' (1996) utilitarian items and one of their normative items. (The specific items used in all modified scales are found in Appendix H). The refined Identity Type scale appears to capture Gioia and Thomas' notion that the higher an institution is rated on the scale, the more oriented it is toward economic factors. Table 13 displays the final Cronbach alpha values for the survey scales and subscales. 
Table 13

Revised Survey Scale Cronbach Alphas

Items Alpha

Part I - Assessment Extent of Use

$\begin{array}{lll}\text { Assessment Extent of Use } & 8 & .92\end{array}$

Part II - Institutional Environment

Strategic Orientation

$5 \quad .72$

Domain Offensive

$\begin{array}{ll}4 & .74\end{array}$

Domain Defensive

$\begin{array}{ll}4 & .84\end{array}$

Part III - Institutional Perceptions

Identity Type

Present Image

Identity Commitment

Desired Future Image

Part IV - Context for Decision Making

Information Processing Structure

Part V - Issue Interpretation

Issue Interpretation

Political Interpretation

Strategic Interpretation
$40 \quad .85$

$20 \quad .93$

$20 \quad .88$ 
The mean of the items comprising each 7-point scale and subscale was computed for each respondent to derive the score for that scale. The mean responses for most (10 of 12) scales and subscales were higher than the midpoint, 4, for each scale (see Table 14). The highest mean scores were for Commitment to Identity (6.01) followed by Strategic Interpretation (5.50), Present Image (5.40), and Assessment Extent of Use (5.04). The mean responses for Strategic Orientation (3.83) and Political Interpretation (3.84) were the lowest.

The responses to most scales show near the maximum range demonstrating there was variability among responses. The scales Assessment Extent of Use, Identity Type, and Desired Future Image and subscale Domain Offensive had the most range and variability, as measured by their standard deviations, in their mean responses.

Table 14

Descriptive Statistics of Survey Responses

$\begin{array}{cc}\text { Mean } & \text { Standard Range } \\ \text { deviation } & \end{array}$

Part I - Assessment Extent of Use

$\begin{array}{llll}\text { Assessment Extent of Use }(N=311) & 5.04 & 1.16 & 1.13-7.00\end{array}$

Part II - Institutional Environment

Strategic Orientation $(N=309)$

.83

$1.17-5.83$

Domain Offensive

1.10

$1.00-7.00$

Domain Defensive

4.65

.81

$1.50-6.50$

Part III - Institutional Perceptions

$$
\text { Identity Type }(N=310)
$$

.96

$1.00-6.60$ 
Table 14 (continued)

Descriptive Statistics of Survey Responses

\begin{tabular}{lccc}
\hline & Mean & Standard & Range \\
& & deviation & \\
& & & \\
Present Image $(N=310)$ & 5.40 & .85 & $2.00-7.00$ \\
Identity Commitment $(N=310)$ & 6.01 & .90 & $3.20-7.00$ \\
Desired Future Image $(N=306)$ & 4.71 & 1.78 & $1.00-7.00$ \\
Part IV - Context for Decision Making & & & \\
Information Processing Structure $(N=306)$ & 4.74 & .82 & $2.00-6.75$ \\
Part V - Issue Interpretation & & & \\
Issue Interpretation $(N=310)$ & 4.83 & .59 & $3.40-6.73$ \\
$\quad$ Political Interpretation & 3.84 & 1.08 & $1.25-6.50$ \\
$\quad$ Strategic Interpretation & 5.50 & .78 & $2.85-7.00$ \\
\hline
\end{tabular}

\section{Results Analysis}

An examination of each of the six research questions follows. Each question concerns how a component of sensemaking relates to the perceived extent that assessment is used by colleges or universities. The section concludes with results of a multiple regression analysis conducted to explore the combined effects and the relative contribution that each component of sensemaking had on the extent that institutions use assessment. 
(1) Is the extent of use of assessment results by top administrators related to their view of an institution's identity as primarily utilitarian or normative?

The mean of the eight Assessment Extent of Use items and the mean of the five Identity Type items were determined for each respondent. A Pearson product-correlation was computed to examine the relationship between the two scales and used to answer this research question. (The analysis for this research question was condensed due to the scale modification described earlier. Originally, three Pearson product-moment correlations were to be used to gauge the relationship between the Extent of Use and each subscale, Utilitarian and Normative, and the Identity Type scale.)

There was a significant positive relationship between Assessment Extent of Use and Identity Type $(r=.28, p<.01, N=310)$. The greater the extent that assessment is reportedly used, the more the identity of the institution is viewed as utilitarian, or more like a business than a normative-based organization such as a church.

(2) Is the extent of use of assessment results by top administrators related to the strength of their commitment to the institutional identity?

The mean of the eight Assessment Extent of Use items and the mean of the five Identity Commitment items were determined for each respondent. A Pearson product-correlation was produced to examine the relationship between the two scales and used to answer this research question. There was a significant positive correlation $(r=.29, p<.01, N=310)$ between the Assessment Extent of Use and Identity Commitment scales. The more committed top administrators are to the identity of the institution, the greater assessment is perceived to be used by the institution. 
Institutional Sensemaking and Assessment 82

\section{(3) Is the extent of use of assessment results by top administrators related to their view of issues as primarily strategic or political?}

The mean of the eight Assessment Extent of Use items, the mean of the 20 Strategic Interpretation items and the mean of the 20 Political Interpretation items were determined for each respondent. The Political Interpretation scores were reverse coded, and the mean of all 40 of the Issue Interpretation items was also computed for each respondent, with a higher mean score associated with a strategic orientation. Three Pearson product-moment correlations were calculated for this research question and each was found to be significant. There was a positive relationship established between the Extent of Use and the Strategic Interpretation scales $(r=$ $.36, p<.01, N=309$ ), a negative relationship between the Extent of Use and Political Interpretation scales $(r=-.13, p<.05, N=309)$, and a positive correlation between Extent of Use and the composite, Issue Interpretation, score $(r=.35, p<.01, N=309)$; a higher score on this scale is associated with a strategic interpretation. The more that top administrators were believed to use assessment results, the more likely they viewed issues confronting them as strategic rather than political. Assessment results are associated with issues related to an institution's market, goals and mission, or the whole institution (strategic) rather than issues involving conflict, negotiation, or influence, and internally focused (political).

In an effort to further explore the participants' views of assessment as being either a strategic or political issue, participants were asked to rate "To what extent is the implementation and maintenance of an Institutional Assessment Program considered by your institution to be..." using the same response matrix as for other Issue Interpretation items. There were strong relationships between the Assessment Strategic Interpretation subscale (Cronbach alpha $=.89$ ) and Extent of Use $(r=.53, p<.01, N=309)$ and the Assessment Interpretation (combined 
Strategic and Political Assessment subscales, Cronbach alpha $=.63)$ and Extent of Use scales $(r$ $=.44, p<.01, N=309)$. However, no association was found between the Assessment Political Interpretation subscale (Cronbach alpha $=.83)$ and the Extent of Use scale $(r=-.03, p=.64, N=$ 308). In general, those who used assessment more, tended to view issues as strategic, as they did with other issues facing the college or university as measured by the instrument.

Looking at the two assessment interpretation subscales alone, respondents rated Strategic Interpretation $(M=5.31, S D=1.33)$ statistically greater than Political Interpretation $(M=3.52$, $S D=1.42)$, paired-samples $t(307)=18.12, p<.01$ (two-tailed), $d=1.03$, a large effect size (Gravetter \& Wallnau, 2004). This reinforces the finding that assessment is viewed as being more important to fulfilling the mission of the institution than it is a means to control.

(4) Is the extent of use of assessment results by top administrators related to their attempt to enact the environment by primarily focusing on the present or future image of the institution?

The mean of the eight Assessment Extent of Use items, the mean of the 10 Present Image items, and the mean of the 10 Desired Future Image items were determined for each respondent. Two Pearson product-moment correlations were used to address this question. There was a significant positive relationship found between the Extent of Use and Present Image scales ( $r=$ $.38, p<.01, N=310$ ). However, there was no relationship found between the Extent of Use and Future Image scales( $r=-.01, p=.88, N=306)$.

To explore the research question further, the mean responses to the Present Image and Desired Future Image scales were compared. The respondents rated their focus on present image $(M=5.40, S D=.85)$ significantly greater than their focus on future image $(M=4.71, S D=$ 1.78), paired-samples $t(305)=6.17, p<.01$ (two-tailed), $d=.35$, a medium effect size 
(Gravetter \& Wallnau, 2004). That is, the respondents believe their institutions concentrated on the quality of their program, students, and faculty, among other things, more than on emulating other institutions along the same dimensions of the program. The extent that assessment is used appears to be positively related to an institution's focus on current institutional elements rather than some projected, desired, distant image.

(5) Is the extent of use of assessment results related to the social/information structure of top administrators?

The mean of the eight Assessment Extent of Use items and the mean of the eight Information Processing Structure items were determined for each respondent. A Pearson product-correlation was then produced to examine the relationship between the two scales and used to answer this research question. There was a significant relationship revealed between the Extent of Use and the Information Processing Structure of top administrators $(r=.40, p<.01, N$ =306). The more assessment is used, the more the social/information structure among top administrators was characterized by high interaction, high participation, and low formality.

(6) Is the extent of use of assessment results by top administrators related to the contextual cues being seen by them as either domain offensive or domain defensive?

The mean of the eight Assessment Extent of Use items, the mean of the four Domain Offensive items, the mean of the four Domain Defensive items, and the mean of the five Strategic Orientation items were determined for each respondent. The Strategic Orientation scale was constructed by reverse coding the Domain Defensive scores and combining them with the Domain Offensive scores. A higher Strategic Orientation score indicated a more domain offensive strategy. 
Three significant positive Pearson product-moment correlations were discovered between the Extent of Use and the Domain Offensive $(r=.46 p<.01, N=309)$, the Domain Defensive ( $r$ $=.14, p<.05, N=309)$ and the Strategic Orientation scales $(r=.29, p<.01, N=309)$. In Gioia and Thomas'(1996) conception, domain offensive institutions are characterized by new programs, curriculum, and marketing, while domain defensive organizations are concerned with maintaining market positions and efficiency.

It appears that assessment use is related to both positions, though more strongly associated with domain offensive institutions. There was, however, no statistical difference between responses to the Domain Defensive $(M=4.65, S D=.81)$ and Domain Offensive $(M=$ $4.57, S D=1.10)$ scales, paired-samples $t(308)=.97, p=.34$ (two-tailed).

\section{Multiple regression}

The researcher went beyond the research questions to examine the combined effects and the relative contribution that each component of sensemaking measured by the instrument had on the extent that institutions use assessment. A standard multiple regression was employed to study the relative contribution of each of the seven variables of institutional sensemaking (Strategic Orientation, Identity Type, Present Image, Identity Commitment, Desired Future Image, Information Processing Structure, and Issue Interpretation) to a prediction of the degree to which institutions were reportedly using assessment results (Assessment Extent of Use scale). A summary of the variables used for the multiple regression analysis follows.

- Strategic Orientation was produced from the mean of five items, with Domain Defensive subscale items reverse coded. A high score indicated domain offensive orientation, and a low score indicated a domain defensive orientation. 
- Identity Type was produced from the mean of five items. A high score indicated a utilitarian identity type, and a low score indicated a normative identity type.

- Present Image was produced from the mean of ten items. A high score indicated a focus on the present image of the college or university.

- Identity Commitment was produced from the mean of five items. A high score indicated a high level of commitment.

- Desired Future Image was produced from the mean of five items. A high score indicated a focus on desired future image.

- Information Processing Structure was produced from the mean of eight items. A high score indicated that communication among top administrators can be characterized by high interaction, high participation, and low formality.

- Issue Interpretation was produced from the mean of 40 items with Political Interpretation items reverse coded. A high score indicated a strategic interpretation of issues.

- Assessment Extent of Use was produced from the mean of eight items. A high score indicated that assessment practices at the institution are well established. An analysis of multiple regression assumptions (Lomax, 2001; Pallant, 2007) was conducted and no violations detected. These assumptions included Multicollinearity (see Tables 15 and 16), normality, linearity, homoscedasticity, and independence of residuals. A Normal Probability Plot (P-P) of the Regression Standardized Residual and a Residual Scatterplot were used to validate the latter assumptions (see Figures 2 and 3). 
Table 15

Multicollinearity Statistics: Regression Correlation Matrix

\begin{tabular}{|c|c|c|c|c|c|c|c|c|}
\hline & 1 & 2 & 3 & 4 & 5 & 6 & 7 & 8 \\
\hline 1. Assessment extent & ---- & $.286 * *$ & $.283 * *$ & $.384 * *$ & $.289 * *$ & -.009 & $.404 * *$ & $.349 * *$ \\
\hline 2. Strategic orientation & & ---- & $.282 * *$ & $.192 * *$ & .048 & -.039 & $.150 * *$ & $.103^{*}$ \\
\hline 3. Identity type & & & ---- & .037 & .036 & .000 & .075 & -.074 \\
\hline 4. Present image & & & & ---- & $.569 * *$ & .007 & $.434 * *$ & $.408 * *$ \\
\hline 5. Identity commitment & & & & & ---- & .003 & $.390 * *$ & $.349 * *$ \\
\hline 6. Future image & & & & & & ---- & .008 & .007 \\
\hline 7. Information structure & & & & & & & ---- & $.383 * *$ \\
\hline 8. Interpretation & & & & & & & & ---- \\
\hline
\end{tabular}

$* p>.05 . * * p>.01$

Table 16

Multicollinearity Statistics: Collinearity Statistics

\section{Collinearity Statistics}

Model

Strategic orientation

Identity type

Present image
Tolerance

.871

1.148

.901

1.109

.580

1.724 
Table 16 (continued)

Multicollinearity Statistics: Collinearity Statistics

\begin{tabular}{lcc}
\hline & \multicolumn{2}{c}{ Collinearity Statistics } \\
\cline { 2 - 3 } Model & Tolerance & $\mathrm{VIF}^{\mathrm{a}}$ \\
\hline Identity commitment & .635 & 1.574 \\
Future image & .998 & 1.002 \\
Information structure & .732 & 1.366 \\
Interpretation & .758 & 1.320 \\
\hline
\end{tabular}

${ }^{a}$ Variance inflation factor

Figure 2

Normal P-P Plot of Regression Standardized Residual

\section{Dependent Variable: Extent_mean}

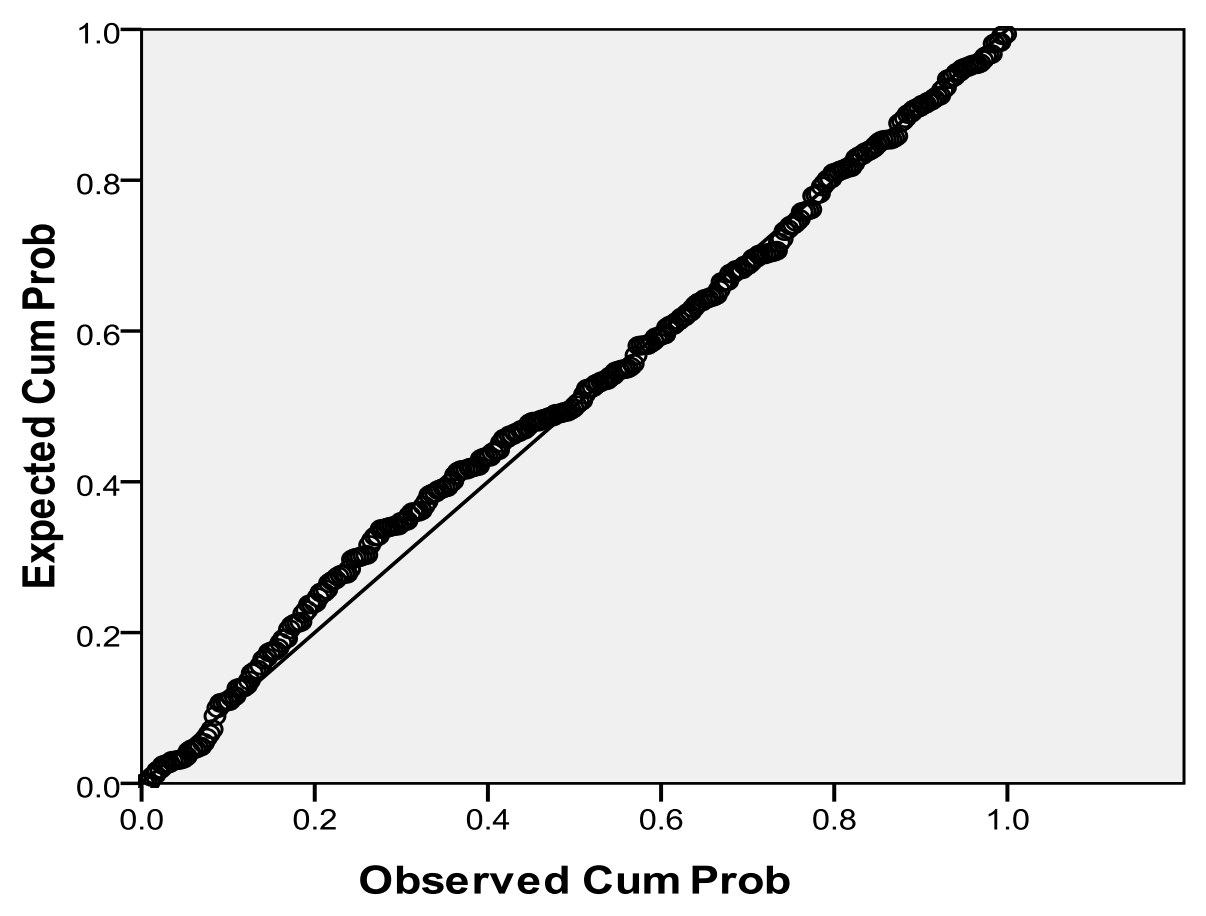


Figure 3

Residual Scatterplot

\section{Dependent Variable: Extent_mean}

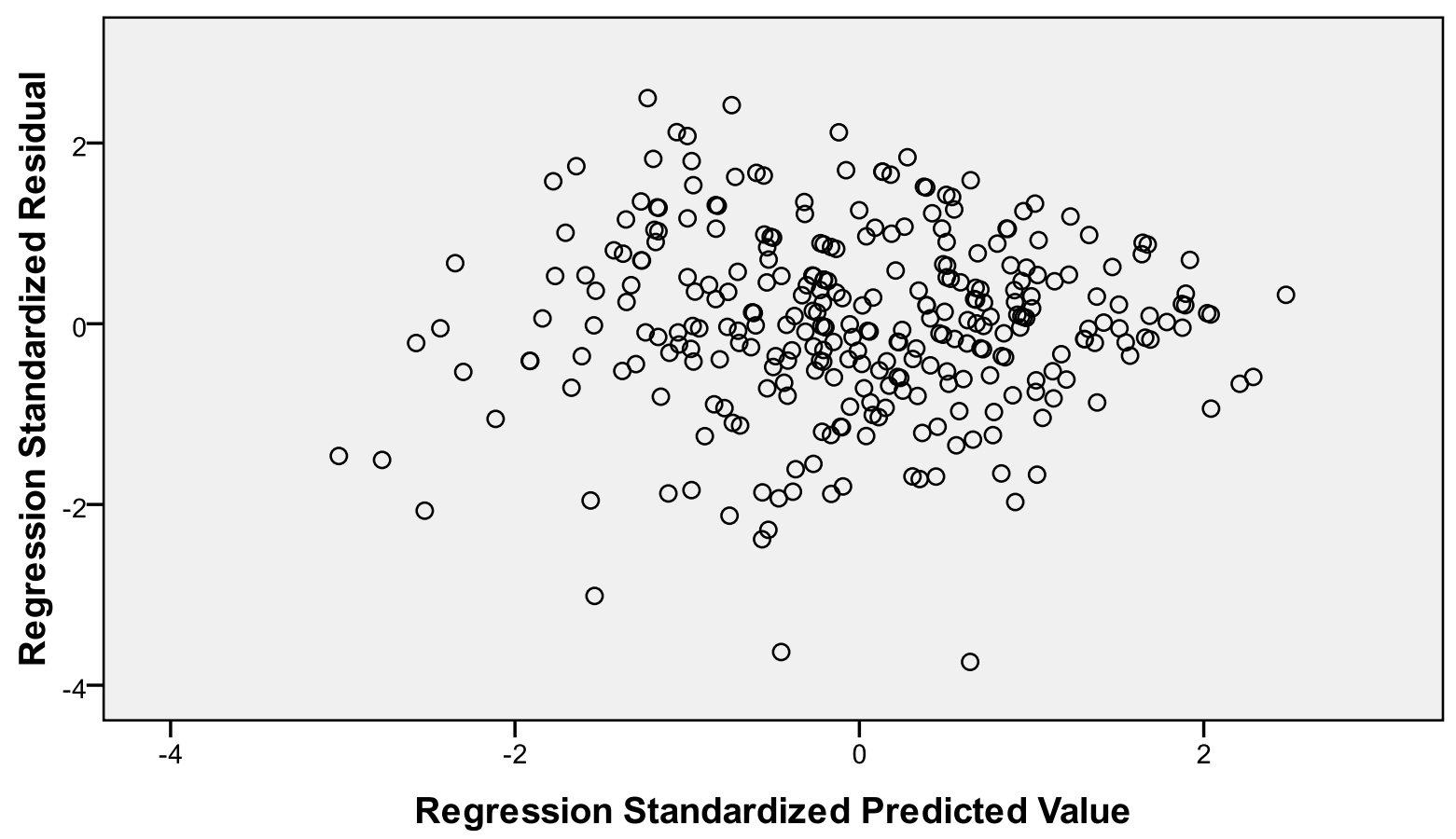

In addition, there were few cases (only three) with a standard residual greater than 3.0 , a Mahalanobis distance analysis yielded only one case above the critical value of 24.32 , and the maximum Cook's Distance value of .071 was less than 1, further supporting the conclusion that the assumptions for a multiple regression were met.

The regression model explains a significant amount of the total variance $32.9 \%, F(7$, $294)=20.730, p<.001$, of the predicted degree that assessment is perceived to be used by top administrators (Assessment Extent of Use scale). Table 17 demonstrates that five of the seven variables were found to be statistically significant contributors to the prediction, in descending order of their standardized beta values: Identity Type, Information Processing Structure, Issue Interpretation, Present Image, and Strategic Orientation. 


\section{Table 17}

Summary of Standard Regression Analysis for Variables Predicting Assessment Extent of Use ( $N$ = 302)

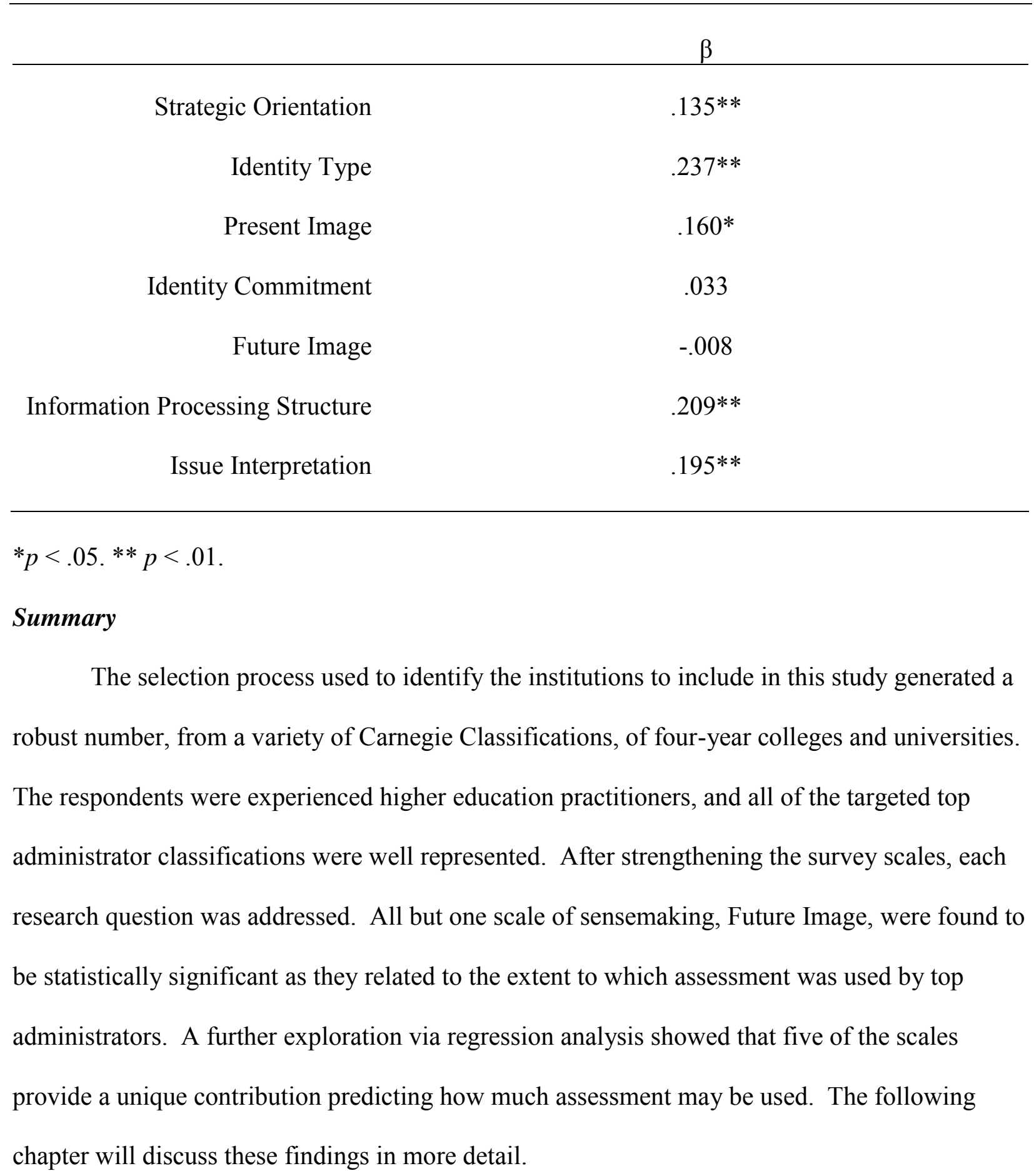




\section{Chapter Five}

\section{Conclusion and Recommendations}

The purpose of this dissertation research study was to explore the concept of organizational sensemaking as a means to understand how assessment results may be used by top administrators at institutions of higher education. Sensemaking may be particularly important to practitioners seeking to further institutional assessment, because sensemaking has been linked to the institutional transformation efforts believed necessary for assessment to become integral to an institution's culture (Kezar \& Eckel, 2002b). The general conclusion of this study is that sensemaking is significant, perhaps new, in considering how assessment processes can be implemented and sustained. The following section will discuss the conclusions drawn from the research questions.

\section{Conclusions and discussion}

\section{Identity and assessment.}

Institutional identity is composed of the central and enduring qualities that affirm an institution's distinction from other organizations and similar institutions (Whetten, 2006). These qualities are manifest in an institution's core programs, policies, and procedures, as well as institutional decisions when its identity is threatened in some way. This study examined two aspects of organizational identity: identity type and identity commitment. Both were found to be closely linked to the "maturity" of assessment practices at the selected institutions of higher education.

Identity type was measured on a continuum between normative and utilitarian types, with a higher score associated with utilitarian. A significant positive relationship was found between Identity Type and Assessment Extent of Use $(r=.28, p<.01)$ and Identity Type is the major 
contributor to Extent of Use in the multiple regression $(\mathrm{B}=.237, p<.01)$. This means that the more respondents believed their institution had characteristics similar to that of a utilitarian organizational identity, the more likely they reported that their institution had assessment programs that would be classified as in the "sustainment and improvement phase" (Banta, 2002). This major finding was not surprising as one of the hallmarks of utilitarian organizations is that they are largely managed by information (Albert \& Whetten, 1985). Utilitarian institutions are also characterized by a focus on economic principles such as profit, rationality, and self-interest.

The importance of identity type as it relates to the use of assessment by institutions of higher education is illustrated by looking at normative-oriented institutions, the pole opposite of utilitarian on the identity type continuum. The more a college or university was rated as normative, the less assessment data appeared to be used by top administrators. Normative institutions focus on the efficiency of processes rather than the effectiveness of outcomes and are largely managed by ideology (Albert \& Whetten, 1985), principles not congruent with good assessment practices (Banta, 2002; Banta, Jones, \& Black, 2009; Bresciani, 2006; Suskie, 2009). The first conclusion of the study is that identity type matters: institutional assessment practices will be promoted if top administrators operate from utilitarian values, which are congruent with those underlying assessment.

The Identity Type scale required substantial redevelopment from the original one created by Gioia and Thomas (1996). The redevelopment process produced a marginally acceptable scale with a Cronbach alpha value of .67 (DeVellis, 2003). The degradation of scale in the years since it was first employed was, perhaps, a result of several scenarios. One possibility was that it is a reflection of the changes in a higher education landscape littered with such challenges as reduced public funding and competition from proprietary institutions (Wilson, 2010). These 
issues may have forced institutions to become more clearly focused on utilitarian concerns. This finding is consistent with Albert and Whetten's (1985) notion that higher education institutions are hybrid organizations, having both normative and utilitarian features, and migrate between the two orientations over time. Another explanation of why the original Identity Type scale did not act as anticipated was the selectivity of the sample. As suggested by this study, it may be that in the universe of institutions the relationship between Identity Type and the use of assessment was so strong that this relationship, in effect, reduced the chance that the normative-focused institutions would end up in the studied population.

Top administrators' commitment to their institution's identity is also closely related to the use of assessment $(r=.29, p<.01)$. A second conclusion of the study is that mature assessment practices are associated with institutions that have administrators, faculty, and students who identify strongly with the institution and whose top administrators have a strong, knowledgeable sense of the institution's history and traditions, pride in the institution's mission and goals, and a belief that the institution has carved out a significant place in the higher education community.

The findings related to identity are consistent with the assessment and institutional effectiveness literature that recommends that assessment programs need to be grounded in an institution's mission (American Association of State Colleges and Universities, 2005; Banta, Jones, \& Black, 2009; Bresciani, 2006; Dugan, 2004; Keith, 2004; Kuh, Kinzie, Schuh, Whitt, \& Associates, 2005; Middle States Commission on Higher Education, 2005; Suskie, 2009) and by extension, the identity of the institution. The findings are also consistent with organizational change literature as almost every theory of organizational change notes the importance of identity in that process (Kezar, 2001). This suggests a third conclusion: effective assessment should contribute to or reinforce the members' and institutions' sense of themselves. This 
finding is supported by Dutton, Dukerich, and Harquail's (1994) conclusion that it is important for members to believe their organization is distinct, even if the organization is not empirically or demonstrably so.

Weick (2009) offers a major caveat to this analysis. Identity can blind organizations to problems that do not conform to their identity. An identity may restrict possible actions or contribute to misinterpretation of evidence which indicates there are problems. Consequently, care must be taken to develop institutional assessment plans that are not just monuments to the existing identity and that the plan is designed to find or address real problems.

\section{Issue interpretation, retrospection, and assessment.}

Retrospection is a component of sensemaking that posits current events are evaluated through the lens of the past (Weick, 1995). Viewing an emerging issue as a threat or opportunity depends on past experiences with similar or related situations (Eckel \& Kezar, 2003a). Within higher education, Gioia and Thomas (1996) found that top administrators tend to categorize issues as either strategic or political, rather than as threats or opportunities.

The interpretive lens that top administrators used to view issues was found to be strongly related to the extent assessment results were perceived to be used by the institution. A mature institution's culture of assessment was closely associated with a strategic interpretation of issues by top administrators $(r=.36, p<.01)$ and inversely related with a political interpretation $(r=$ $.13, p<.05)$. This finding was further supported by the composite score, with the items coded so that strategic interpretation received higher scores, being positively correlated with the extent of assessment scale $(r=.35, p<.01)$ and the finding that Interpretation is a significant contributor to Extent of Use in the multiple regression $(\mathrm{B}=.195, p<.01)$. 
Conceptually unpacked, organized and sustained assessment processes that are integrated into decision-making practices tend to emerge where top administrators view issues in the light of the institution's market, goals and mission, or when the issues impact on the whole institution (strategic). Less developed assessment practices are found where top administrators frame issues as involving conflict, negotiation, or influence, and are internally focused (political). A fourth conclusion of the study is that assessment should be viewed as a strategic issue in order to promote its development and integration into an institution's culture.

This is not to diminish multi-framed management approaches, as suggested by Bolman and Deal (1997) and others (Bess \& Dee, 2008a). These perspectives offer a way forward on issues; however, this study suggests the assessment must be evaluated, presented, and pursued as a strategic initiative to become part of an institution's culture of evidence.

\section{Image, enactment, and assessment.}

Enactment is a component of sensemaking that captures the importance of people creating the environments they face by signaling other individuals about how they want to be perceived (Weick, 1995). Institutional image is an enactment of an institution's identity and can focus on either the present or future image (Gioia \& Thomas, 1996). This study found a significant positive relationship between the Extent of Use and Present Image scales $(r=.38, \mathrm{p}<$ $.01)$, that Present Image was a significant contributor to the multiple regression equation $(\mathrm{B}=$ $.160, p<.05$ ), and there was no relationship between the Extent of Use and Future Image scales $(r=-.01, p=.88)$. Additionally, respondents rated their focus on present image significantly greater than their focus on future image (paired-samples $t(305)=6.17, p<.01)$. Not only did respondents attribute favorable ratings of their own institutions by other institutions (present image), this attribution was greater if they had "mature" cultures of assessment. The degree to 
which they desired to emulate other institutions (future image) had no relationship with assessment practices. The fifth conclusion of this study was that the enculturation of assessment practices and their contribution to the decision-making apparatus is connected to an institutional focus on the quality of their programs, students, and faculty, among other things, and not on some projected, desired aspirational image.

This finding appears to be at odds with the logic suggested by Gioia and Thomas (1996). Their model of how the components of sensemaking relate shows positive paths linking future image and strategic interpretation and linking present interpretation with political interpretation of issues. With the extent of assessment use strongly related to strategic interpretation, one would suspect a similar correspondence with assessment and future image in this study. Gioia and Thomas' analysis rests on the notion that an institution's future image is based on emulation. Perhaps institutions that have more mature assessment systems have internally articulated visions of how they will differentiate themselves rather than relying on a future image based on other institutions. There was some evidence of this trend in the current study where many respondents (50 of $306,16 \%$ ) reported they had no aspirational institutions to emulate.

\section{Information processing structure, socially created world, and assessment.}

Sensemaking is a social construction (Weick, 2001) that evolves from shared meaning emanating from talk, discourse, conversation, and, most importantly, shared collective action (Eckel \& Kezar, 2003a). This study found that "mature" institutional assessment programs were positively related to the Information Processing Structure of top administrators $(r=.40, p<.01)$ and the overall importance of the processing structure demonstrated as the second major contributor to Extent of Use in the multiple regression $(\mathrm{B}=.209, p<.01)$. The sixth conclusion of this study was that institutional assessment programs are likely to prosper at institutions where 
top higher education administrators employ relatively informal decision-making processes that include views from outside the top administration and are characterized by high levels of participation, interaction, and inclusiveness. These Information Processing Structure behaviors make it likely the top administrators are members of the Core Group (Kleiner, 2003). The Core Group is central for the creation of the sensegiving, "shared meanings that mobilize the efforts of people in pursuit of desired aims and objectives" (Morgan, 2006, p. 142), that is essential for the promotion of assessment activities. The "shared meanings" are cues (discussed further in the following section) that serve as reference points for sensemaking, and control over the cues is an important source of power (Weick, 1995). This study not only corroborates the importance of top administrative officials to support assessment initiative for them to become sustainable, but also suggests components of that leadership that facilitate the efforts.

\section{Strategies, cues, and assessment.}

Cues refer to the process in which people extract clues from the ongoing flow of events that people abstract or generalize to develop a larger sense of what is occurring (Weick, 1995). Cues tie elements together cognitively (Weick, 1995) by facilitating inferences between them (Pinker, 1997). These abstractions form the basis of actions related to the referent clues, playing a role in self-fulfilling prophesies. Domain offensive and domain defensive strategies are responses to the environment made by colleges and universities, depending upon which cues are considered salient by the decision-makers (Cameron \& Tschirhart, 1992). This study found both strategies positively related to the extent assessment practices pervaded institutions (Domain offensive $r=.46 p<.01$ and Domain Defensive $r=.14, p<.05$ ). The combined Strategic Orientation, with higher scores associated with a Domain Offensive strategy, was also positively related to assessment $(r=.29, p<.01)$ and a major contributor to Extent of Use in a multiple 
regression $(\mathrm{B}=.135, p<.01)$. These findings suggest a seventh conclusion from this study: "mature" assessment practices are promoted when institutions pay attention to the external environment and are prepared to react in a systematic manner, either with domain offensive strategies, such as new programs, curriculum, and marketing, or by domain defensive strategies, including concentrating on maintaining market position and improving efficiencies (Gioia \& Thomas, 1996). While both strategies appear relevant to assessment efforts, domain offensive strategies seem linked more closely to advancing those efforts.

This conclusion is consistent with Cameron and Tschirhart's (1992) finding that the more an institution emphasized one particular strategy, the less it employed the other. They also found that domain offensive strategies were the most effective in mitigating the effects of a turbulent, competitive, unpredictable environment characterized by declining resources or enrollments. Domain defensive (and creative strategies) are also important but had more restricted influences on institutional effectiveness than domain offensive strategies.

\section{Summary}

The findings of this study show that sensemaking can be a useful concept for understanding how assessment results may be used by top administrators in higher education. The study also suggests how aspects of sensemaking can be used by assessment practitioners to further their work.

Assessment seems to be more embedded in an institution's culture if the college or university's top administrators interpret issues as strategic; view the institution as utilitarian; are closely connected to the identity of the institution; and value participation, informal interaction, and inclusiveness when making decisions. In addition, it appears that assessment is perceived as 
more extensive if it focuses on the institution's present image and domain offensive strategies, such as new programs, curriculum, and marketing.

While this study expanded the framework for developing and improving sustainable assessment plans, the findings also placed assessment into the context of a more comprehensive model of organizational behavior and suggest the addition of outcomes assessment as an important feature to existing models of organization change and effectiveness. The following section details some of the recommendations and implications of this study for practitioners and assessment scholars.

\section{Recommendations}

Recommendations for practice related to identity.

This study reinforces the importance of mission statements as a manifestation of an institution's, program's, or unit's identity. Assessment, even at the course level, should address not only broadly defined institutional, program, or departmental missions, but also those parts of each mission that make it distinctive and contribute to making the institution, program, or department unique.

Assessment plans should be constructed in such a way as to verify, enhance, or reinforce a constituent's identity and commitment to the identity, as articulated by the mission, of their unit and the institution. There should be recognition within an assessment plan that the identities of faculty members are probably different than that of administrators. An academic department's assessment plan should show how the department contributes to the discipline, in addition to addressing other program and student learning outcomes.

By its nature, assessment incorporates the utilitarian values of rationality and management by information. This study also suggests that successful institutional assessment 
plans should address other aspects of utilitarian organizations such as revenues, expenses, and the educational marketplace. In addition, members of utilitarian institutions tend to be guided by self-interest. As a consequence, assessment plans must help address the question of "what's in it for me?"

The findings of the study should not be interpreted such that normative-oriented colleges and universities or academic departments should necessarily become more utilitarian, contrary to their values. Instead, the findings point to the difficulty that the implementation and sustainability of assessment practices may have at such institutions. It will be important for normative-oriented entities to incorporate the efficiency of processes and measures of principles and values in their assessment plans. The plans may emphasize qualitative methods, such as focus groups, interviews, and portfolios, to ascertain the less easily quantified nature of the intended outcomes.

\section{Recommendations for practice related to issue interpretation and retrospection.}

The results of this study show that assessment needs to be framed as a strategic issue. That is, assessment should help an institution understand and gauge its success in the higher education "marketplace," assure the institution meets its goals and mission (and be able to demonstrate this to accreditors), and impact the whole institution. It would be a mistake to primarily frame the justification of assessment efforts as a means to meet an outside requirement and as an effort to demonstrate that assessment is not a management control tool, both of which suggest a political interpretation of the issue of assessment.

This is not, however, to diminish the role of political interpretations. As others have argued, (Bergquist, 1992; Birnbaum, 1988; Bolman \& Deal, 1997), recognizing and managing issues requiring negotiation and conflict resolution are important organizational leadership skills. 
This study suggests the problem for implementing assessment if political interpretations are the predominant manner in which issues are framed and managed.

Because retrospective sensemaking is based on prior experiences of similar events, a top administration view of issues as political may be a challenge to overcome, suggesting the administrators have been able to maintain their position or the institution's position as a result of such a perspective of issues. In such a situation, assessment practitioners may want to utilize a paradoxical strategy (Haley, 1973) that presents assessment planning as an external mandate while connecting the plan to the aspects of strategic interpretation as mentioned above.

\section{Recommendations for practice related to image and enactment.}

This study points to the importance of focusing on the present image of the institution how others are thought to view the college or university - rather than a future image, at least if the future image is based on seeking to emulate other institutions. This buttresses the significance of an institution's mission and the relationship of assessment to what makes the college or university unique and addresses quality indicators of students, faculty, programs, and the institution. While it would be a mistake to ignore statements that articulate the institution's vision of itself in the future, assessment planning should be directed at those claims that extend or improve the college or university and not at emulating others. The findings of this study put into question a common practice that measures institutional effectiveness against a set of aspirational peers.

Assessment planners need to remember that assessment is an enactment exercise that seeks to shape how others see the unit, whatever the unit's size. This puts the notion of audience in another perspective. Suskie (2009, p. 280) speaks about assessment results telling "an important, coherent, interesting story." Sensemaking suggests that components of the story 
should be considered at the planning stage of any assessment efforts. Elements that planners can consider are story line, themes, symbols, characters, and plot.

In addition, assessment plans should state their purpose as promoting directional "improvement," rather than the generic "improvement." In other words, assessment should help drive the institution, program, or department toward a strategic vision.

\section{Recommendations for practice related to information processing structure and social}

creation.

Two important factors necessary for institutional change in colleges and universities are supportive senior leadership and collaboration (Kezar, 2001; Kezar \& Eckel, 1999). The sensemaking role of the two factors involves the significance of the cues sent by top administrative officials for guiding organizational interpretations and behavior and the development and use of a shared vocabulary that facilitates cooperative effort. The administrative signaling and vocabulary development constitute vital social constructions that enable institutional members to function.

The current study highlights the importance of top administrators having conversations, particularly in informal settings, with various constituencies about assessment and how assessment results are being acted upon in order for assessment practices to become embedded in the institutional culture. It is vital that the officials show that they are "closing the assessment loop" by using the findings of assessments to inform decision making. As Bess and Dee (2008b) conclude, leaders need to frame assessment positively and show-case the opportunities the process offers.

Sensemaking as a social construction points to the importance of a common assessment vocabulary and widely agreed upon constructs and processes related to assessment practices. 
This suggests that colleges and universities establish a set of definitions so that all members know what a "goal" and "closing the loop" may mean and that assessment is a cyclical process.

\section{Recommendations for practice related to strategies and contextual cues.}

The findings of this study imply that those interested in promoting a "culture of assessment" need to pay heed to events outside of their college or university, which act as cues to how assessment results may be interpreted. Assessment programs should be developed that direct an institution to employ domain offensive strategies, such as developing new programs, curriculum, and marketing or suggest domain defensive strategies, including maintaining current market positions and improving internal efficiencies. It is vital that strategic planning entities on campus use assessment results in their planning activities. Assessment or self studies based on assessment must focus on the future rather than the status quo. Significant assessment results also act as cues that signal and set expectations for members and outside stakeholders.

\section{Recommendations for further research.}

In this section, ten major recommendations for further research are discussed concerning how assessment efforts inform institutional sensemaking. Specific topics are explicated for eight of the recommendations, and two broader research agendas are proposed.

1. Research should be conducted to explore the relationships among the sensemaking variables and how they may interact to influence the perceived maturity level of assessment practices in colleges and universities. It is likely that there are interaction effects between the sensemaking components, and it is important to discover how the components influence one another. For example, does the institutional identity directly influence the degree to which assessment data is perceived to be used or is it mediated through one or several other 
sensemaking variables? A path analysis, similar to that done by Gioia and Thomas (1996), could be conducted to explore these interactions between the sensemaking variables.

2. Further research could determine if there are any differences in sensemaking and the perceived use of assessment among various groups of respondents. For example, do administrators at the level of vice president view institutional assessment and use sensemaking differently than those administrators at slightly lower levels at the college or university? Or, do student affairs professionals report a different experience with assessment and sensemaking than those in academic affairs?

3. Research is required to extend the findings of the current study to a broader spectrum of colleges and universities, including those who have little or no experience with assessment, those who have moderate experiences with assessment, and those who have more mature experiences with assessment. Any significant differences in sensemaking related to experiences with assessment by those three groups of institutions would be examined. For example, are issues interpreted differently by top higher education administrators if their institution is at the beginning stages of assessment planning, has some assessment practices in place, or is at the sustainment phase of assessment?

4. Research to explore differences related to assessment and sensemaking between colleges and universities of different Carnegie types is another avenue to extend the findings of the current research study. For example, are sensemaking components related to assessment manifested differently at Baccalaureate Colleges than at Research Universities?

5. Another way to further research findings of the present study is to investigate assessment and sensemaking between colleges and universities in different accrediting regions. This research may show the affects of differing regional accrediting agencies' expectations on 
assessment and sensemaking practices. For example, while assessment standards are very similar across regional accrediting agencies (Middaugh, 2010), are there regional differences about how these standards are interpreted? Or, are there regional differences about how issues, including assessment, are interpreted?

6. Future research could specifically focus on institutional identity, because understanding potential different beliefs about institutional identity held by units within an institution is vital for the promoting the collaboration among constituents needed to foster assessment practices (Kezar \& Lester, 2009). How does perceived institutional identity vary among academic departments? How does institutional identity vary between faculty and academic administration? How does institutional identity vary between academic and student affairs administrators? And, do any differences that may emerge affect the inculcation of assessment practices?

7. Another focus of potential research should be on assessment and issue interpretation, as issue interpretation appears to be a main sensemaking factor contributing to the extent that assessment is used. For example, is the issue of assessment interpreted as political or strategic? How does the interpretation of assessment as political or strategic translate into the degree to which assessment is woven into the institutional fabric? Or, is the issue of assessment interpreted consistent with how other issues are understood?

8. Research is needed to discern the behaviors and cues created by top administrators that enhance formation of assessment practices. For example, why does frequent and informal communication among top administrators seem to be related to the degree that assessment practices are employed by a college or university? 
9. The current study established a link between the use of assessment and sensemaking. Sensemaking is concept integral to a body of work related to organizational studies, including organizational learning. Kezar (2005b) recommends that leaders of colleges and universities "mine the organizational learning and learning organization concepts sooner rather than later" (p. 20). Sensemaking may be a gateway to understanding the relationship between assessment practices and the organizational learning concepts. Easterby-Smith and Lyles (2005) cite Weick, a major proponent of organizational sensemaking (Weick, 2001, 2009), as a co-author of a foundational work about organizational learning and Corley and Gioia (2005) have described how organizational identity contributes to organizational learning. It may be fruitful for assessment scholars to establish how assessment can contribute to organizational learning and organizational learning scholarship.

10. Weick described how sensemaking can be used by organizations to detect emergent change and to be mindful (Weick, 2009; Weick \& Putnam, 2009; Weick \& Sutcliffe, 2007). These concepts are unified by the notion that it is extremely difficult for established, formal organizational structures and processes to recognize and be prepared to react to unexpected events. An important research question for assessment scholars is how can institutional assessment programs be developed to be sensitive enough to recognize unanticipated events as they unfold. This could provide essential information for college and university planners and decision-makers to chart paths through turbulent environments. 


\section{Appendix A: Institution Selection Letter}

Dear «Prefix»»LastName»:

I am a doctoral student studying higher education administration at West Virginia University and seek your assistance in selecting institutions for a study on how assessment results are interpreted and used by top academic and student affairs administrators. I am interested in surveying administrators at institutions that have implemented and sustained their assessment plans.

Dr. Trudy Banta (2002) has identified characteristics of effective practice for colleges and universities that are in the sustainment and improvement phase of their assessment plans. I am requesting your assistance in identifying a sample of institutions of higher education, excluding community colleges, whose assessment plans demonstrate Banta's characteristics, to the best of your knowledge:

- produces credible evidence of learning,

- ensures that assessment data are used continuously to improve programs and services,

- provides a vehicle for demonstrating accountability to stakeholders within and outside the institution,

- encompasses the expectation that outcomes assessment will be ongoing, not episodic, and

- incorporates ongoing evaluation and improvement of the assessment process itself

(Banta, 2002, p. 263, Building a Scholarship of Assessment. San Francisco: Jossey Bass).

I would appreciate it if you would identify ten four-year institutions that you believe exhibit the characteristics of effective assessment practices within the sustainment and improvement. I plan to survey the top academic and student affairs administrators of the institutions selected base on your input.

This research is for the fulfillment of my dissertation requirement and your responses will be kept confidential. Let me know if you would like an executive summary of the research findings.

Thank you for your time.

Sincerely,

Jay Hegeman

Doctoral Student

West Virginia University 
Feel free to copy and paste to reply.

Nominations of Colleges and Universities in the Sustainment and Improvement Phase (excluding community colleges)

1.

2.

3.

4.

5.

6.

7.

8.

9.

10.

Yes, I would like an executive summary of the research findings.

No, I would not like an executive summary of the research findings.

Please return to Jay Hegeman by August 13, 2008. If you have questions, please contact me at jhegeman@frostburg.edu.

Thank you for your participation! 
Appendix B: Sources of Institutional Identification

Dr. Trudy Banta, Professor of Higher Education and Senior Advisor to the Chancellor for Academic Planning and Evaluation, Indiana University-Purdue University Indianapolis (T. Banta, personal communication, July 28, 2008)

Dr. Thomas Bowling, Vice President Student and Educational Services, Frostburg State University and experienced evaluator for the Middle States Commission on Higher Education (T. Bowling, personal communication, July 10, 2008)

Dr. James Limbaugh, Vice-President for Strategy, Planning, and Policy, Angelo State University (J. Limbaugh, personal communication, July 20, 2008)

Dr. Christopher McCullough, Assistant Dean of Assessment, School of Education, DePaul University (C. McCullough, personal communication, July 7, 2008)

“Assessment Update: Progress, trends and practices in higher education" (Bennion \& Harris, 2005; Kuh, 2005; Wehlburg, 2007; Weiner \& McMillan, 2005)

"Putting Assessment to Work" (Connor, 2008)

"Student success in college: Creating conditions that matter" (Kuh, Kinzie, Schuh, Whitt, \& Associates, 2005)

"Student Success in State Colleges and Universities: A Matter of Culture and Leadership" (American Association of State Colleges and Universities, 2005) 


\section{Appendix C: Cover Letter to Survey Participants}

Date

Dear «Prefix» «LastName»:

We are requesting your participation in a study we are conducting to investigate the relationship between higher education administrators' use of assessment information and factors that influence how they interpret important issues. The goal of the research is to advance the understanding about how assessment results influence positive change within higher education. The study will also be the foundation of the Co-Investigator's doctoral dissertation in Educational Leadership Studies at West Virginia University (WVU). We would really appreciate your time and perspectives on the survey questions. Your responses will help us better understand important assessment issues.

Gaining additional information about some institutional characteristics that may affect the implementation and use of assessment practices is vital. Your response is of particular interest because assessment experts have identified that your institution is likely to have a robust assessment program in the sustainment and improvement phase, as articulated by the nationally recognized assessment authority Dr. Trudy Banta. By completing this survey, you will help foster a better understanding regarding how administrators in higher education interpret issues, such as assessment, to guide their decision-making.

Your responses to the enclosed survey will be confidential since no individual answers will be shared at any time and your participation in this study is completely voluntary. This survey should take approximately 15 to 20 minutes to complete. Please use the self-addressed, stamped envelope to return your survey by

WVU's Institutional Review Board for the Protection of Human Subjects has acknowledged this study.

Thank you in advance for taking your valuable time to participate in the study. If you have any questions, please contact Jay Hegeman at 301-687-4738 or jhegeman@frostburg.edu.

Sincerely,

Elizabeth A. Jones, Ph.D.

Professor

Principal Investigator

304-293-1886

Elizabeth.Jones@mail.wvu.edu
Jay Hegeman

WVU Doctoral Candidate

Co-Investigator

301-687-4738

jhegeman@frostburg.edu 


\section{Appendix D: Survey}

\section{General Instructions}

This survey is divided into five parts. The survey will take approximately 15 minutes to complete. For most of the questions, please fill in the bubble, using pencil or blue or black ink, that corresponds with the number that best describes your response on the scale provided. Please feel free to comment on any of the items on the blank sheet at the end of the survey.

There are no right or wrong answers. We only ask that you respond as a representative of your institution/campus. All responses will remain strictly confidential and anonymous. If you have any questions, please don't hesitate to call.

Attached is a stamped addressed envelope with which to return the finished questionnaire.

Thank you for your help.

1. Your title/position

\section{General Information}

2. Years in this position at this institution

3. Years at this institution

4. Academic major or specialization

5. Your position is primarily in (please choose only one): $\square$ Academic Affairs $\square$ Student Affairs

\section{Part I: Assessment Extent of Use}

Using the scale provided, please fill in the bubble which corresponds to the number that best describes YOUR INSTITUTION'S use of assessment information.

To what extent is assessment information at your institution...
a. a result of documented, organized and sustained processes?
b. integrated into program reviews/evaluations?
c. integrated into institutional strategic planning?
d. shared and discussed with appropriate constituents?
e. used to make improvements to courses/programs/services?
f. used to make funding decisions?
g. used to judge students' achievement of institutional and program learning outcomes?
h. used to gauge institutional effectiveness?

Part II: Institutional Environment

Using the scale provided, please fill in the bubble which corresponds to the number that best describes YOUR INSTITUTION'S external environment and its responses to that environment.

To what extent does your institution...

a. tend to ignore external changes that have little immediate, direct impact on current operations?

b. try to be in the forefront of new programs or market developments in higher education?

c. offer a limited range of programs, but emphasize higher program quality, superior student services, etc.?

d. respond rapidly to early signals concerning areas of opportunity?

e. maintain relatively stable curricula and programs?

f. try to maintain superior strength in most areas it enters?

g. operate within a broad program/curriculum domain that undergoes gradual reshaping?

h. value being "first in" with new programs or market activities?

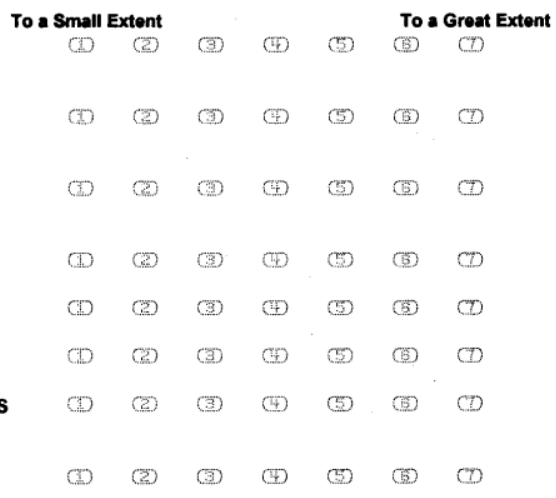


Part III: Institutional Perceptions

This part of the survey is designed to assess perceptions held by top administrators at your institution. Using the scales provided, please fill in the bubble that corresponds to the number that best describes YOUR INSTITUTION.

1. To what extent...
a. does tradition guide programmatic or administrative changes at your institution?

b. do top administrators feel that your institution should be "competing"

To a Small Extent

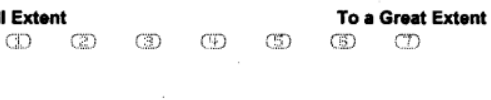
for students as if they were clients or customers?

c. are symbols and ceremonies important to the functioning of your institution?

d. have budget cuts or increases usually been made across-the-board?

e. are financial returns (e.g., from athletics, economic development, etc.) a measure of success for your institution?

$f$. is the institution's mission focused on issues of academic quality?

g. is there a feeling that the university should be (or continue to be) actively engaged in marketing campaigns to attract students?

h. are budget cuts or increases made selectively across departments or colleges at your institution?

i. is cost-effectiveness the major criterion that guides programmatic or administrative change?

j. is economic performance considered to be important to fulfilling your institution's mission or goals?

2. In general, how do you think your colleagues at peer institutions would rate your institution in terms of:

a. The quality of program offerings?

b. The quality of faculty?

c. The quality of students?

d. The quality of administrative leadership?

e. Overall academic climate?

f. Academic innovativeness?

g. Overall reputation and prestige?

h. Financial/Economic status?

i. Your goals?

j. Your administrative structure?

3. To what extent...

a. do the top management team members of your institution have a strong sense of the institution's history?

b. do your institution's administrators have a sense of pride in the institution's mission and goals?

c. do top administrators feel that your institution has carved out a significant place in the higher education community?

d. do the top management team members not have a well-defined set of goals or objectives for the institution?

e. does your institution have administrators who are knowledgeable about the institution's history and traditions?

f. does your institution have administrators, faculty, and students who identify strongly with the institution? very Low

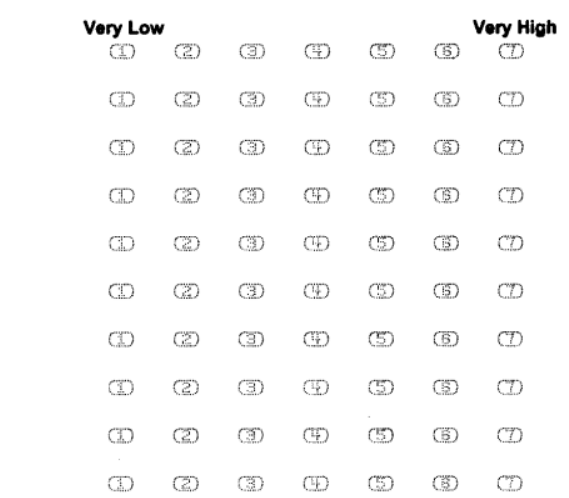

To a Small Extent To a Great Extent

(1) $C$ (b) $(5)$ To a Groat Ex

(1) (b) (B) क) (B)

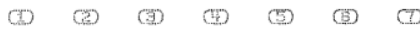

(ए) (2) (ए) क (ब) व

(1) (2) का का (5) क
(ए) क क का क क 
4. Identify up to 3 higher educaton institutions that you would like to emulate.

1.

2.

3.

To what extent is the reason for wanting to emulate the above institutions based on:
a. The institutions' goals?
b. The quality of their program offerings?
c. The quality of the administrative leadership of the institutions?
To a Small Extent
(1) (2) (3) (5) (5) a Groat Extont
d. The quality of their students?
e. The quality of their faculty?
f. Academic innovativeness?
g. The organizational structure of the institutions?
h. Economic/financial status?
i. The institutions' reputation and prestige?
j. Overall academic climate?
k. Other?

\begin{tabular}{|c|c|c|c|c|c|c|}
\hline & & & & & \multirow{2}{*}{26} \\
\hline CD & (द) & (8) & (Ф) & (5) & (5) & \\
\hline (D) & (2) & () & (Đ) & (5) & (5) & $\infty$ \\
\hline$\infty$ & (2) & (3) & (घ) & (5) & (6) & $\infty$ \\
\hline c) & (2) & (3) & (घ) & (5) & (5) & (7) \\
\hline (D) & (a) & (3) & (Đ) & (5) & (E) & $\infty$ \\
\hline (D) & (2) & (3) & (D) & (5) & (5) & (b) \\
\hline$C D$ & (3) & (3) & (4) & 5 & (B) & (D) \\
\hline$\infty$ & (2) & (3) & (D) & (5) & (6) & $(7)$ \\
\hline$\infty$ & (2) & (3) & (ㅁ) & (5) & (B) & (D) \\
\hline$\Phi$ & C) & (B) & (b) & (5) & (5) & $\infty$ \\
\hline (i) & (2) & (3) & (b) & 5 & (5) & $\Phi$ \\
\hline
\end{tabular}

Part IV: Institutional Context for Decision Making

This section is designed to assess the internal environment in which issue interpretation and decision making takes place. Using the scale provided, please fill in the bubble that corresponds with the number that best describes YOUR INSTITUTION.

\section{To what extent...}

a. are views other than those of top administrators included in executive decision processes?

b. can planning concerning important issues be characterized as participative?

c. are rules and procedures followed during executive decision processes?

d. are committees such as ad hoc task groups formed to deal with important issues?

e. can decision processes around important issues be characterized as interactive?

f. do one or two people dominate the handling of important issues?
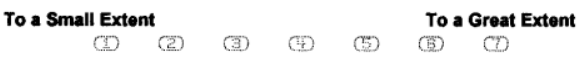

(ख) ए ए ए (ए) $\varnothing$

(1) का ए क (ए) $\varnothing$

(1) क क का का क

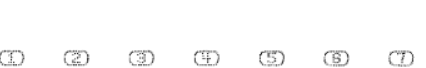

dhe handling of important issues?

(1) (2) (1) (5) (5) 7

$\mathrm{g}$. is there a free and open exchange of ideas among those affected by a given issue?

h. do people affected by an issue typically feel that the definition of the issue and the manner in which it was resolved were imposed upon them?

i. can decision making be characterized as a process dominated by formal rules and procedures? 
Part V: Issue Interpretation

This part is intended to assess how your institution interprets various issues that it confronts. Please respond in terms of how YOUR INSTITUTION would percieve the issue presented.

1. To what extent is Faculty Satisfaction considered by your institution to be...

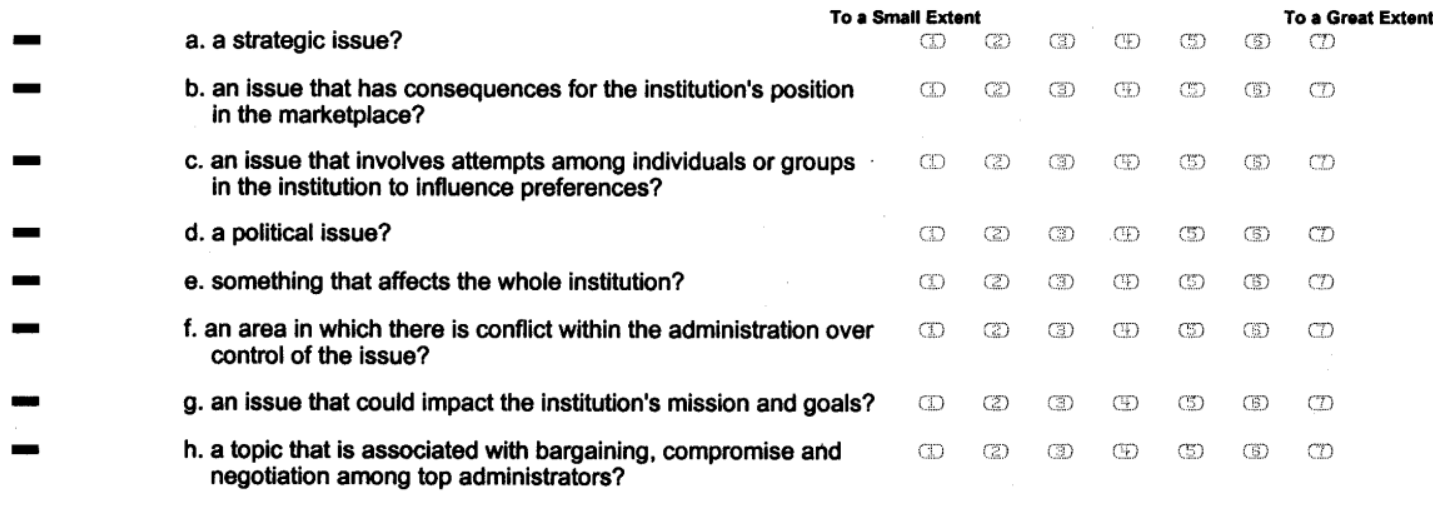

2. To what extent are Minority Issues considered by your institution to be...

a. strategic issues?

b. issues that impact the institution's position in the marketplace?

c. issues that involve a struggle among groups or individuals in the institution to influence preferences?

d. political issues?

e. issues that affect the whole institution?

f. an area in which there is conflict within the administration over control?

g. issues that could have consequences for the institution's mission and goals?

h. a topic that is associated with bargaining, compromise and negotiation among top administrators?
To a Small Extont To a Groat Extent

(1) (2) (3) (1) (5) (5) C

(1) (अ) (क) (5) 1

(2) (3) 1 (5) (5) $\infty$

क ए क क (क) $\infty$

(5) (2) (3) (क) (5) 0

(1) क क क (1) क

(1) (द) क क (1) क

(2) (B) (B) (B) (B) $C$

3. To what extent is External Funding (e.g., government, corporate, alumni) considered by your institution to be...

a. a strategic issue?

b. an issue that has consequences for the institution's position in the marketplace?

c. an issue that involves attempts among individuals or groups in the institution to influence preferences?

d. a political issue?

e. something that affects the whole institution?

$f$. an area in which there is conflict within the administration over control of the issue?

g. an issue that could impact the institution's mission and goals?

h. a topic that is associated with bargaining, compromise and negotiation among top administrators?

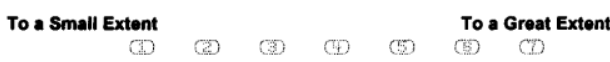

(ए) क क क क क

$\infty$ क क क (b) $\infty$

(1) (2) (3) (ए) (ए) (1) CD

(D) (द) $क$ (ए) $(7)$

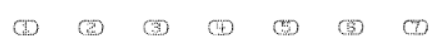

क ए ए $ए$ (ए) $\varnothing$

$(1)$ (द) क का ए) $C$ 
4. To what extent is Student Educational Satisfaction considered by your institution to be...

a. a strategic issue?

b. an issue that has consequences for the institution's position in the marketplace?

c. an issue that involves attempts among individuals or groups in the institution to influence preferences?

d. a political issue?

e. something that affects the whole institution?

f. an area in which there is conflict within the administration over control of the issue?

g. an issue that could impact the institution's mission and goals?

h. a topic that is associated with bargaining, compromise and negotiation among top administrators?

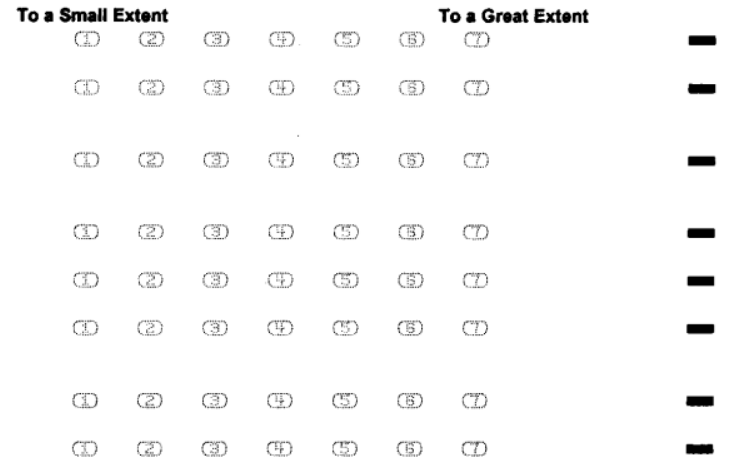

5. To what extent are Program Changes considered by your institution to be...

a. a strategic issue?

b. an issue that has consequences for the institution's position in the marketplace?

c. an issue that involves attempts among individuals or groups in the institution to influence preferences?

d. a political issue?

e. something that affects the whole institution?

f. an area in which there is conflict within the administration over control of the issue?

g. an issue that could impact the institution's mission and goals?

h. a topic that is associated with bargaining, compromise and negotiation among top administrators?

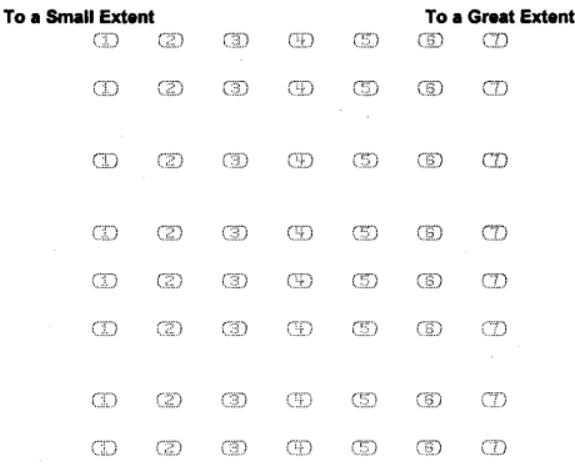

6. To what extent is the implementation and maintenance of an Institutional Assessment Program considered by your institution to be..
a. a strategic issue?
b. an issue that has consequences for the institution's position in the marketplace?
c. an issue that involves attempts among individuals or groups in the institution to influence preferences?
d. a political issue?
e. something that affects the whole institution?

f. an area in which there is conflict within the administration over control of the issue?

g. an issue that could impact the institution's mission and goals?

h. a topic that is associated with bargaining, compromise and negotiation among top administrators?

Thank you for your help. Please use the attached stamped envelope to mail your responses. 
Appendix E: Strategic Orientation Interpretation Subscale Items

\section{Survey Part II}

$(0=$ Offense, $\mathrm{D}=$ Defense $)$

a. tend to ignore external changes that have little immediate, direct impact on current operations? (D)

b. try to be in the forefront of new programs or market developments in higher education? (O)

c. offer a more limited range of programs, but emphasize higher program quality, superior student services, etc.? (D)

d. respond rapidly to early signals concerning areas of opportunity? (O)

e. maintain relatively stable curricula and programs? (D)

f. try to maintain superior strength in all of the areas it enters? (D)

g. operate within a broad program/curriculum domain that undergoes periodic reshaping? (O)

h. value being "first in" with new programs or market activities? (O) 


\section{Appendix F: Identity Type Subscale Items}

Survey Part III, question 1

$$
\text { ( } \mathrm{U}=\text { Utilitarian, } \mathrm{N}=\text { Normative) }
$$

a. does tradition guide programmatic or administrative changes at your institution? $(\mathrm{N})$

b. do top administrators feel that your institution should not be "competing" for students as if they were clients or customers? $(\mathrm{N})$

c. are symbols and ceremonies important to the functioning of your institution? $(\mathrm{N})$

d. have budget cuts or increases usually been made across-the-board? (N)

e. are financial returns (e.g., from athletics, economic development, etc.) a measure of success for your institution? (U)

f. is your institution's mission focused on academic quality? $(\mathrm{N})$

g. is there a feeling that the university should be (or continue to be) actively engaged in marketing campaigns to attract students? (U)

h. are budget cuts or increases made selectively across departments or colleges at your institution? (U)

i. is cost-effectiveness the major criterion that guides programmatic or administrative change? (U)

j. is economic performance considered to be important to fulfilling your institution's missions or goals? (U) 
Appendix G: Issue Interpretation Subscale Items

Survey Part V, all questions

$(\mathrm{S}=$ Strategic, $\mathrm{P}=$ Political $)$

a. a strategic issue? (S)

b. an issue that has consequences for the institution's position in the marketplace? (S)

c. an issue that involves attempts among individuals or groups in the institution to influence preferences? $(\mathrm{P})$

d. a political issue? (P)

e. something that affects the whole institution? (S)

f. an area in which there is conflict within the institution over control of the issue? (P)

g. an issue that could impact the institution's mission and goals? (S)

h. a topic that is associated with bargaining, compromise, and negotiation among top administrators? (P) 


\section{Appendix H: Modified Scales}

Survey Part II - Strategic Orientation

$(\mathrm{R}=$ Reverse Coded $)$

a. tend to ignore external changes that have little immediate, direct impact on current operations? (R)

b. try to be in the forefront of new programs or market developments in higher education?

d. respond rapidly to early signals concerning areas of opportunity?

e. maintain relatively stable curricula and programs? (R)

h. value being "first in" with new programs or market activities?

Survey Part III, question 1 - Identity Type

b. do top administrators feel that your institution should not be "competing" for students as if they were clients or customers?

e. are financial returns (e.g., from athletics, economic development, etc.) a measure of success for your institution?

g. is there a feeling that the university should be (or continue to be) actively engaged in marketing campaigns to attract students?

i. is cost-effectiveness the major criterion that guides programmatic or administrative change?

j. is economic performance considered to be important to fulfilling your institution's missions or goals?

Survey Part III, question 3 - Identity Commitment
a. Do the top management team members of your institution have a strong sense of the institution's history?
b. do your institution's administrators have a sense of pride in the institution's mission and goals?
c. do top administrators feel that your institution has carved out a significant place in the higher education community?
e. does your institution have administrators who are knowledgeable abou the insitution's history and traditions?
f. does your institution have administrators, faculty, and students who identity strongly with the institution?

Survey Part IV - Information Processing

a. are views other than those of top administrators included in executive decisions processes? 
b. can planning concerning important issues be characterized as participative?

c. are rules and procedures followed during executive decisions processes?

d. are committees such as ad hoc task groups formed to deal with important issues?

e. can decision processes around important issues be characterized as interactive?

g. is there a free and open exchange of ideas among those affected by a given issue?

h. do people affected by an issue typically feel that the definition of the issue and the manner in which it was resolved were imposed upon them?

i. can decision making be characterized as a process dominated by formal rules and procedures? 


\section{References}

Albert, S., \& Whetten, D. A. (1985). Organizational identity. Research in Organizational Behavior, 7, 263-295.

Alstete, J. W. (2004). Accreditation matters: Achieving academic recognition and renewal. San Francisco: Jossey-Bass.

American Association of State Colleges and Universities. (2005). Student success in state colleges and universities: A matter of culture and leadership. Washington, D.C.: American Association of State Colleges and Universities.

Anrig, G. R. (1987). Introduction. In Assessing the outcomes of higher education: Proceedings of the 1986 ETS invitational conference (pp. v-vi). Princeton, NJ: Educational Testing Service.

Argyris, C., \& Schön, D. A. (1996). Organizational learning II. New York: Addison-Wesley.

Balch, S. H. (2004). Toward a reconstitution of academic governance. Academic Questions, $17(1), 67-72$.

Banta, T. W. (2002). A call for transformation. In T. W. Banta \& Associates (Eds.), Building a scholarship of assessment (pp. 284-292). San Francisco: Jossey-Bass.

Banta, T. W., Jones, E. A., \& Black, K. E. (2009). Designing effective assessment: Principles and profiles of good practice. San Francisco: Jossey-Bass.

Banta, T. W., Rudolph, L. B., Van Dyke, J., \& Fisher, H. S. (1996). Performance funding comes of age in Tennessee. The Journal of Higher Education, 67(1), 23-45.

Barr, R. B., \& John, T. (1995). From teaching to learning: A new paradigm for undergraduate education. Change Retrieved May 17, 2007, from 
Institutional Sensemaking and Assessment 122

http://web.ebscohost.com/ehost/detail?vid=2\&hid=108\&sid=115de0e5-24a0-4d57-bf2ff320fa942770\%40sessionmgr109

Benjamin, R., \& Carroll, S. (1998). The implications of the changed environment for governance in higher education. In W. G. Tierney (Ed.), The responsive university: Restructuring for high performance (pp. 92-119). Baltimore, MD: The Johns Hopkins University Press.

Bennion, D. H., \& Harris, M. (2005). Creating an assessment culture at Eastern Michigan University: A decade of progress. Assessment update: Progress, trends and practices in higher education, 17(2), 7 - 9.

Bennis, W. (1989). Why leaders can't lead: The unconscious conspiracy continues. San Francisco: Joessy - Bass.

Berberet, J., Brown, B. E., Bland, C. J., Risbey, K. R., \& Trotman, C.-A. (2005). Planning for the generational turnover of the faculty: Faculty perceptions and institutional practices. In R. L. Clark \& J. Ma (Eds.), Recruitment, retention and retirement in higher education: Building and managing the faculty of the future (pp. 80-100). Northamption, MA: Edward Elgar Publishing, Inc.

Bergquist, W. H. (1992). The four cultures of the academy: Insights and strategies for improving leadership in collegiate organizations. San Francisco: Jossey-Bass.

Bess, J. L., \& Dee, J. R. (2008a). Understanding college and university organization: Theories for effect policy and practice (Vol. 1). Sterling, VA: Stylus.

Bess, J. L., \& Dee, J. R. (2008b). Understanding college and university organization: Theories for effect policy and practice (Vol. 2). Sterling, VA: Stylus.

Birnbaum, R. (1988). How colleges work: The cybernetics of academic organization and leadership. San Francisco: Jossey-Bass. 
Birnbaum, R. (2000a). The latent organizational functions of the academic senate. In M. C. Brown (Ed.), Organization and governance in higher education (5 ed., pp. 232-243). Boston, MA: Person Custom Publishing.

Birnbaum, R. (2000b). Mangement fads in higher education: Where they come from, what they do, why they fail. San Francisco: Jossey-Bass.

Bolman, L. G., \& Deal, T. E. (1997). Reframing organizations: Artistry, choice, and leadership (Second ed.). San Francisco: Jossey-Bass.

Boyer, E. L. (1990). Scholarship reconsidered: Priorities of the professoriate. Princeton, NJ: The Carnegie Foundation For The Advancement Of Teaching.

Braxton, J. M., Luckey, W., \& Helland, P. (2002). Institutionalizing a broader view of scholarship through Boyer's four domains. San Francisco: Jossey-Bass.

Bresciani, M. J. (2006). Outcomes-based academic and co-curricular program review: A compliation of institutional best practices. Sterling, VA: Stylus.

Bruner, J. S. (1973). On perceptual readiness. In J. M. Anglin (Ed.), Beyond the information given: Studies in the psychology of knowing (pp. 7-42). New York: W.W. Norton and Company.

Buenstorf, G., \& Murmann, J. P. (2005). Ernst Abbe's scientific management: theoretical instights from a nineteenth-century dynamic capabilities approach. Industrial and corporate change, 14(4), 543-578.

Burns, B. (2004). Managing change: A strategic approach to organisational dynamics (Fourth ed.). New York: Pearson Educational Limited. 
Burrows, J. M. (1999). Negotiating organizational identity: faculty members' academic and religious interpretations of a church-related college. Paper presented at the Conference Name|. Retrieved Access Date|. from URL|.

Calhoun, M. A., \& Starbuck, W. H. (2003). Barriers to creating knowledge. In M. Easteby-Smith \& M. A. Lyles (Eds.), The Blackwell handbook of organizational learning and knowledge management (pp. 473-492). Malden, MA: Blackwell Publishing.

Cameron, K. S. (2000). Organizational adaptation and higher education. In M. Christopher Brown II \& J. L. Ratcliffe (Eds.), Organization and governance in higher education (5th ed., pp. 273-286). Boston: Pearson Custom Publishing.

Cameron, K. S., \& Tschirhart, M. (1992). Postindustrial environments and organizational effectiveness in colleges and universities. The Journal of Higher Education, 63(1), 87108.

Carnegie Foundation for the Advancement of Teaching. (2008). Carnegie classifications data file, December 18, 2008. Retrieved January 21, 2009

Chickering, A. (2003). Reclaiming our soul: Democracy and higher education. Change, 35.

Clark, B. R. (1983). The higher education system. Berkeley, CA: University of California Press.

Clark, B. R. (2000). Faculty organization and authority. In M. C. Brown (Ed.), Organization and goverance in higher education (Fifth ed., pp. 119-127). Boston: Person Custom Publishing.

Clark, B. R. (2008). Small worlds, different worlds. In W. Smith \& T. Bender (Eds.), American higher education transformed 1940-2005: Documenting the national discourse (pp. 338342). Baltimore: The Johns Hopkins Press. 
Clark, R. L. (2005). Changing faculty demographics and the need for new policies. In R. L. Clark \& J. Ma (Eds.), Recruitment, retention and retirement in higher education: Building and managing the faculty of the future (pp. 1-22). Northamption, MA: Edward Elgar Publishing, Inc.

Cohen, A. M. (1998). The shaping of American higher education. San Francisco: Jossey-Bass.

Cohen, M. D., \& March, J. G. (1974). Leadership and ambiguity. New York: Mcgraw-Hill Book Company.

Collini, S. (1998). Introduction. In The two cultures (pp. vii-lxxiii). New York: Cambridge University Press.

Connor, W. R. (2008). Putting Assessment to Work. Retrieved 7/29, 2008, from http://www.teaglefoundation.org/liblog/entry.aspx?bid=1\&id=174\&return=\% 2 fliblog $\% 2 \mathrm{f}$ archive.aspx $\% 3 \mathrm{fbid} \% 3 \mathrm{~d} 1 \% 26 \mathrm{id} \% 3 \mathrm{~d} 2008 \% 26$ year $\% 3 \mathrm{~d} 1$

Corley, K. G., \& Gioia, D. A. (2005). Semantic learning as change enabler: Relating organizational identity and organizational learning. In M. Easteby-Smith \& M. A. Lyles (Eds.), Handbook of organizational learning and knowledge management (pp. 623-638). Malden, MA: Blackwell.

Cross, K. P. (1986). Using assessment to improve instruction. In Proceedings of the 1986 ETS invitational conference (pp. 63-70). Princeton: Educational Testing Service.

Curry, B. K. (1992). Instituting Enduring Innovation: Achieving continuity of change in higher education. Washington, DC: The George Washington University.

Czanriawska, B. (1997). Narrating the organization: Dramas of institutional identity. Chicago, IL: The University of Chicago Press. 
Daniel, J. (2002). Incentives and accountability: Instruments of change in higher education. Higher Education Management And Policy, 16(1), 9-18.

DeVellis, R. F. (2003). Scale development: Theory and applications (2nd ed. Vol. 26). Thousand Oaks, CA: Sage Publications.

Driscoll, A. (2006). Assessment and accreditation: Productive partnerships. In A. Driscoll \& D. Cordero de Noriega (Eds.), Taking ownership of accreditation (pp. 1-18). Sterling, VA: Stylus Publishing, LLC.

Duderstadt, J. J. (2000). A university for the 21st century. Ann Arbor: The University of Michigan Press.

Duderstadt, J. J. (2004). Governing the twenty-first century university. In W. G. Tierney (Ed.), Competing conceptions of academic governance (pp. 137-157). Baltimore, MD: The Johns Hopkins University Press.

Duderstadt, J. J., \& Womack, F. W. (2003). The future of the public university in America. Baltimore: The Johns Hopkins University Press.

Dugan, R. E. (2004). Institutional assessment planning. In P. Hernon \& R. E. Dugan (Eds.), Outcomes assessment in higher education: Views and perspectives (pp. 73 -88). Westport, CT: Libraries Unlimited.

Dugan, R. E., \& Hernon, P. (2006). Institutional mission-centered student learning. In P. Hernon, R. E. Dugan \& C. Schwartz (Eds.), Revisiting outocmes assessment in higher education (pp. 1-12). Westport, CN: Libraries Unlimited.

Dutton, J. E., \& Dukerich, J. M. (1991). Keeping an eye on the mirror: Image and identity in organizational adaptation. Academy of Management Journal, 34(3), 517-554. 
Dutton, J. E., Dukerich, J. M., \& Harquail, C. V. (1994). Organizational images and member identification. Administrative Science Quarterly, 39, 239-263.

Easterby-Smith, M., \& Lyles, M. A. (2005). Introduction: Watersheds of organizational learning and knowledge management. In M. Easteby-Smith \& M. A. Lyles (Eds.), Handbook of organizational learning and knowledge management (pp. 1-16). Malden, MA: Blackwell.

Eckel, P., Hill, B., \& Green, M. (1998). En route to transformation. Washington, DC: American Council on Education.

Eckel, P., \& Kezar, A. (2003a). Key strategies for making new institutional sense: Ingredients to higher education transformation. Higher Education Policy, 16, 39-53.

Eckel, P., \& Kezar, A. (2003b). Taking the reins: Institutional transformation in higher education. Westport, CT: Praeger Publishers.

Eddy, P. L. (2003). Sensemaking on campus: How community college presidents frame change. Community College Journal of Research and Practice, 27, 453-471.

Edgerton, R. (1987). An assessment of assessment. In Assessing the outcomes of higher education: Proceedings of the 1986 ETS invitational conference (pp. 93-110). Princeton, NJ: Educational Testing Service.

Elsbach, K. D., \& Kramer, R. M. (1996). Members' responses to organizational identity threats: Encountering and countering the Business Week rankings. Administrative Science Quarterly, 41, 442-476.

Ewell, P. T. (2002). An emerging scholarship: A brief history of assessment. In T. W. Banta \& Associates (Eds.), Building a scholarship of assessment (pp. 3-25). San Francisco: Jossey-Bass. 
Fear, F. A., Doberneck, D. M., Robinson, C. F., Fear, K. L., Barr, R. B., Berg, H. V. D., et al. (2003). Meaning making and "the learning paradigm": A provocative idea in practice. Innovative Higher Education 27(3), 151-168.

Gioia, D. A. (1998). From individual to organizational identity. In D. A. Whetten \& P. C. Godfrey (Eds.), Identity in organizations: Building theory through conversation (pp. 1732). Thousand Oaks, CA: Sage Publications.

Gioia, D. A., \& Chittipeddi, K. (1991). Sensemaking and sensgiving in strategic change initiation. Strategic Management Journal, 12, 433-448.

Gioia, D. A., Chittipeddi, K., Thomas, J. B., \& Clark, S. M. (1996). Symbolism and strategic change in academia. In J. R. Meindl, C. Stubbart \& J. F. Porac (Eds.), Cognition within and between organizations (pp. 207-244). Thousand Oaks, CA: Sage Publications.

Gioia, D. A., Schultz, M., \& Corley, K. G. (2000). Organizational identity, image and adaptive instability. Academy of Management Review, 25(1), 63-81.

Gioia, D. A., \& Thomas, J. B. (1996). Identity, image, and issue interpretation: Sensemaking during strategic change. Administrative Science Quarterly, 41(3), 370 - 403.

Gravetter, F. J., \& Wallnau, L. B. (2004). Statistics for the behavioral sciences (6th ed.). Belmont, CA: Wadsworth/Thomson Learning.

Haley, J. (1973). Uncommon therapy: The psychiatric techniques of Milton H. Erickson M.D. New York: W. W. Norton.

Hearn, J. C. (2006). Student success: What research suggests for policy and practice. Retrieved November 7, 2006, from http://nces.ed.gov/npec/pdf/synth_Hearn.pdf

Heifetz, R. A., \& Linsky, M. (2002). Leadership on the line: Staying alive through the dangers of leading. Boston: Harvard Business School Press. 
Higher Education Publications. (2008). Higher education directory, version 11. Retrieved September 13, 2008

Hosking, D. M., \& McNamee, S. (2006). Making your way: Please start here. In D. M. Hosking \& S. McNamee (Eds.), The Social Construction of Organization (pp. 23-31). Herndon, VA: Copenhagen Business School Press.

Huba, M. E., \& Freed, J. E. (2000). Learner-Centered assessment on college campuses: Shifting the focus from teaching to learning. Boston: Allyn and Bacon.

Huber, M. T., \& Hutchings, P. (2005). The advancement of learning: Building the teaching commons. San Francisco: Jossey-Bass.

Jones, E. A. (2002). Transforming the curriculum: Preparing students for a changing world. San Francisco: Jossey-Bass.

Kakkuri, J. (2004). Institutional change of universities as a problem of evolving boundaries. Higher Education Policy, 17, 287-309.

Keeling, R. P., Wall, A. F., Underhile, R., \& Dungy, G. J. (2008). Assessment reconsidered: Institutional effectiveness for student success: International Center for Student Success and Institutional Accountability.

Keith, B. (Ed.). (2004). Contexts for learning: Institutional strategies for managing curricular change through assessment. Stillwater, OK: New Forums Press.

Keller, G. (2004). A growing quaintness: Traditional governance in the markedly new realm of U.S. higher education. In W. G. Tierney (Ed.), Competing conceptions of academic governance (pp. 158-176). Baltimore, MD: The Johns Hopkins University Press.

Kezar, A. (2001). Understanding and facilitating change in higher education in the 21 st century: Recent research and conceptualizations. ASHE-ERIC Higher Education Report, from 
Institutional Sensemaking and Assessment 130

http://www.eric.ed.gov/ERICDocs/data/ericdocs2/content_storage_01/0000000b/80/0d/8

4/14.pdf

Kezar, A. (2005a). Consequences of radical change in governance: A grounded theory approach. The Journal of Higher Education, 76(6), 634-668.

Kezar, A. (2005b). What campuses need to know about organizational learning and the learning organization. New Directions for Higher Education, 131(Fall 2005), 7-22.

Kezar, A., \& Eckel, P. (1999, April 19-23, 1999). Balancing the core strategies of institutional transformation: Toward a "mobile" model of change. Paper presented at the Annual Meeting of the American Educational Research Association, Montreal, Canada.

Kezar, A., \& Eckel, P. (2000). Editor's Notes. In A. Kezar \& P. Eckel (Eds.), Moving beyond the gap between research and practice in higher education (pp. 1-7). San Francisco: JosseyBass.

Kezar, A., \& Eckel, P. (2002a). The effect of institutional culture on change strategies in higher education. The Journal of Higher Education, 73(4), 435-460.

Kezar, A., \& Eckel, P. (2002b). Examining the institutional transformation process: The importance of sensemaking, interrelated strategies, and balance. Research in Higher Education, 43(3), 295-328.

Kezar, A., \& Eckel, P. D. (2004). Meeting today's governance challenges: A synthesis of the literature and examination of a future agenda for scholarship. The Journal of Higher Education, 75(4), 371-399.

Kezar, A., \& El-Khawas, E. (2003). Using the performance dimension: Converging paths for external accountability? In H. Eggins (Ed.), Globalization and reform in higher education (pp. 85-98). Maidenhead, Berkshire, England: Open University Press. 
Kezar, A., \& Lester, J. (2009). Organizing higher education for collaboration: A guide for campus leaders. San Francisco: Jossey-Bass.

Kirp, D. L. (2003). Shakespeare, Einstein, and the bottom line: The marketing of higher education. Cambridge, MA: Harvard University Press.

Kleiner, A. (2003). Who really matters: The core group theory of power, privilege, and success. New York: Doubleday.

Kuh, G. D. (2005). Putting student engagement results to use: Lesson from the field. Assessment Update: Progress, trends and practices in higher education, 17(1), 12 -13.

Kuh, G. D., Kinzie, J., Schuh, J. H., Whitt, E. J., \& Associates. (2005). Student success in college: Creating conditions that matter. San Francisco: Jossey-Bass.

Kuhn, T. (1970). The structure of scientific revolutions. Chicago: University of Chicago Press.

Lamertz, K. (2002). Social construction of fairness: Social influence and sense making in organizations. Journal of Organizational Behavior, 23(1), 19-30.

Levin, J. S. (1998). Sense-making in the community college: The meanings of organizational change [Electronic Version]. Retrieved February 12, 2005 from http://www.eric.ed.gov/ERICDocs/data/ericdocs2sq1/content_storage_01/0000019b/80/1 5/54/5e.pdf.

Levy, A., \& Merry, U. (1986). Organizational transformation :Approaches, strategies, theories. New York: Praeger.

Lomax, R. G. (2001). Statistical concepts: A second course for education and the behavioral sciences (2nd ed.). Mahwah, NJ: Lawrence Erlbaum Associates. 
López, C. L. (2004). A decade of assessing student learning: What we have learned, and what is next. In P. Hernon \& R. E. Dungan (Eds.), Outcomes assessment in higher education: Views and perspectives (pp. 29-71). Westport, CT: Libraries Unlimited.

Lubinescu, E. S., Ratcliff, J. L., \& Gaffney, M. A. (2001). Two continuums collide: Accreditation and assessment. In E. S. Lubinescu, J. L. Ratcliff \& M. A. Gaffney (Eds.), How accreditation influences assessment (pp. 5-22). San Francisco: Jossey-Bass.

Martin, R. R., Manning, K., \& Ramaley, J. A. (2001). The self-study as a chariot for strategic change. In J. L. Ratcliff, E. S. Lubinescu \& M. A. Gaffney (Eds.), How accreditation influences assessment (pp. 95-115). San Francisco: Jossey-Bass.

McCullough, C. A. (2007). Factors that influence the effectiveness of assessment plans in the improvement and sustainment phase in colleges and universities Retrieved April 29, 2008, from https://eidr.wvu.edu/etd/documentdata.eTD?documentid=5304

Middaugh, M. F. (2010). Planning and assessment in higher education: Demonstrating institutional effectiveness. San Francisco: Jossey-Bass.

Middle States Commission on Higher Education. (2005). Assessing student learning and institutional effectiveness. Philadelphia, PA: Middle States Commission on Higher Education.

Middle States Commission on Higher Education. (2007). Student learning assessment: Options and resources (Second ed.). Philadelphia, PA: Middle States Commission on Higher Education.

Morgan, G. (2006). Images of organization (Updated ed.). Thousand Oaks, CA: Sage Publications, Inc. 
Newman, F., Couturier, L., \& Scurry, J. (2004). The future of higher education: Rhetoric, reality, and the risks of the market. San Francisco: Jossey-Bass.

Nisbett, R., E. (2003). The geography of thought. New York: The Free Press.

Page, S. E. (2007). The difference: How the power of diversity creates better groups, firms, schools and societies. Princeton, NJ: Princeton University Press.

Pallant, J. (2007). SPSS survival manual (3rd ed.). Glasgow, Great Britain: Open University Press.

Peterson, M. W., \& Augustine, C. H. (2000). Organizational practices enhancing the influence of student assessment information in academic decisions. Research in Higher Education, 41(1), 21-52.

Peterson, M. W., \& Einarson, M. K. (2001). What are colleges doing about student assessment? The Journal of Higher Education, 72(6), 629-669.

Peterson, M. W., \& Vaughan, D. S. (2002). Promoting academic improvement: Organizational and administrative dynamics that support student assessment. In T. W. Banta \& Associates (Eds.), Building a scholarship of assessment (pp. 26-46). San Francisco: Jossey-Bass.

Pike, G. R. (2002). Measurement issues in outcomes assessment. In T. W. Banta \& Associates (Eds.), Building a scholarship of assessment (pp. 131-147). San Francisco: Jossey-Bass.

Pinker, S. (1997). How the mind works. New York: W.W. Norton and Company

Ramsay, J. (1999). Talk of college: has it grown quiet? Liberal Education, 85(1), 54-58.

Schuh, J. H., \& Upcraft, M. L. (2001). Assessment practice in student affairs: An applications manual. San Francisco: Jossey-Bass. 
Senge, P. (1990). The fifth discipline: The art and practice of the learning organzation. New York: Doubleday.

Shipman, D., Aloi, S. L., \& Jones, E. A. (2003). Addressing Key Challenges in Higher Education Assessment. The Journal of General Education, 52(4), 335-346.

Smart, J. C., \& St. John, E. P. (1996). Organizational culture and effectivensess in higher education: A test of the "culture type" and "strong culture" hypothesis. Educational Evaluation and Policy Analysis, 18(3), 219-241.

Snow, C. P. (1998). The two cultures. New York: Cambridge University Press.

Soundarajan, N. (2004). Program assessment and program improvement: Closing the loop. Assessment \& Evaluation In Higher Education, 29(5), 597-610.

Strange, C. C., \& Banning, J. H. (2001). Educating by design: Creating campus learning environments that work. San Francisco: Jossey-Bass.

Suskie, L. (2004). Assessing student learning: A common sense guide. Bolton, MA: Anker.

Suskie, L. (2009). Assessing student learning: A common sense guide (2nd ed.). San Francisco: Jossey-Bass.

Swenk, J. (1999). Planning failures: Decision cultural clashes. The Review of Higher Education, $23(1), 1-21$

Tagg, J. (2003). The learning paradigm college. Bolton, MA: Anker Publishing Company. Tierney, W. G. (2004a). Improving academic governance. In W. G. Tierney (Ed.), Competing conceptions of academic governance (pp. 202-215). Baltimore, MD: The Johns Hopkins University Press. 
Tierney, W. G. (2004b). A perfect storm: Turbulence in higher education. In W. G. Tierney (Ed.), Competing conceptions of academic governance (pp. xv-xxxi). Baltimore, MD: The Johns Hopkins University Press.

Tierney, W. G. (Ed.). (2004c). Competing conceptions of academic governance: Negotiating the perfect storm. Baltimore, MD: The Johns Hopkins University Press.

U.S. Department of Education. (2006). A test of leadership: Charting the future of U.S. higher education

Retrieved 11/20/2006. from http://www.ed.gov/about/bdscomm/list/hiedfuture/index.html.

Wehlburg, C. M. (2007). Closing the feedback look is not enough: The assessment spiral. Assessment Update: Progress, trends and practices in higher education, 19(2), 2 and 15.

Weick, K. E. (1976). Educational Organizations as Loosely Coupled Systems. Administrative Science Quarterly, 21(1), 1.

Weick, K. E. (1995). Sensemaking in organizations. Thousand Oaks, CA: Sage Publications.

Weick, K. E. (2001). Making sense of the organization. Malden, MA: Blackwell Publishing.

Weick, K. E. (2009). Making sense of the organization: The impermanent organization (Vol. 2). West Sussex, UK: John Wiley and Sons.

Weick, K. E., \& Putnam, T. (2009). Organizing for mindfulness: Eastern wisdom and western knowledge. In K. E. Weick (Ed.), Making sense of the organization: The impermanent organization (Vol. 2, pp. 85-106). West Sussex, UK: John Wiley and Sons.

Weick, K. E., \& Sutcliffe, K. M. (2007). Managing the unexpected: Resilient performance in an age of uncertainty (2nd ed.). San Francisco: John Wiley and Sons.

Weimer, M. (2006). Enhancing scholarly work on teaching and learning: Professional literature that makes a difference. San Francisco: John Wiley \& Sons. 
Weiner, C. S., \& McMillan, D. N. (2005). Transforming the assessment culture through the use of assessment specialists at a regional university. Assessment Update: Progress, trends and practices in higher education, 17(6), 6 - 8 .

Whetten, D. A. (2006). Albert and Whetten revisited: Strengthening the concept of organizational identity. Journal of Management Inquiry, 15(3), 219-234.

Wilson, R. (2010). For-profit colleges change higher education's landscape [Electronic Version]. The Chronicle of Higher Education. Retrieved March 2, 2010 from http://chronicle.com/article/For-Profit-Colleges-Change-/64012/. 